\title{
MECHANICAL PROPERTIES OF LASER WELDED DUAL-PHASE STEEL JOINTS
}

\author{
By \\ NAHEEN FARABI \\ Bachelor of Science in Mechanical Engineering \\ Islamic University of Technology (IUT) \\ Dhaka, Bangladesh, 2007
}

\begin{abstract}
A thesis presented to Ryerson University
In partial fulfillment of the requirements for the degree of

Master of Applied Science in the program of Mechanical Engineering
\end{abstract}

Toronto, Ontario, Canada, 2010

(C) Naheen Farabi 2010 


\section{AUTHOR'S DECLARATION}

I hereby declare that I am the sole author of this thesis.

I authorize Ryerson University to lend this thesis to other institution or other individuals for the purpose of scholarly research.

Naheen Farabi

I further authorize Ryerson University to reproduce this thesis by photocopying or by other means, in total or in part, at the request of other institutions or individuals for the purpose of scholarly research.

Naheen Farabi 


\section{BORROWER'S PAGE}

Ryerson University requires the signature of all persons using or photocopying this thesis. Please sign below provide address and date.

\begin{tabular}{|c|c|c|c|}
\hline Name & Signature & Address & Date \\
\hline & & & \\
\hline & & & \\
\hline & & & \\
\hline & & & \\
\hline & & & \\
\hline & & & \\
\hline & & & \\
\hline & & & \\
\hline & & & \\
\hline & & & \\
\hline & & & \\
\hline & & & \\
\hline & & & \\
\hline & & & \\
\hline & & & \\
\hline
\end{tabular}




\title{
MECHANICAL PROPERTIES OF LASER WELDED DUAL-PHASE STEEL JOINTS
}

\author{
Naheen Farabi \\ MASc., Mechanical Engineering \\ Ryerson University, Toronto, 2010
}

\begin{abstract}
The application of dual phase (DP) steels in the automobile industry unavoidably involves welding operation. The objective of this thesis was to study the microstructure and mechanical properties of laser welded DP steel joints. The laser welding resulted in a significant hardness increase in the FZ but the formation of a soft zone in the heat affected zone (HAZ). While the soft zone influenced the tensile properties of the joints considerably, the fatigue properties of the welds showed dependence on both the softening and the applied stress amplitudes. Fatigue crack was observed to initiate from the specimen surface and crack propagation was basically characterized by striation-like features. Post-weld heat treatment was found to eradicate the negative effect of the soft zone and improve the mechanical properties of welds. However, the heat treatment resulted in a brittle fracture mode from the dominating ductile mode of fracture of the welded joints.
\end{abstract}




\section{ACKNOWLEDGEMENTS}

I would like to thank my supervisors Dr. Daolun Chen \& Dr. Norman Zhou for their invaluable guidance, support and motivation during my studies at Ryerson University. I express my deep gratitude for their detailed review, constructive remarks and excellent advice during my research period. I believe their encouragement from different perspectives will be highly beneficial to not only in my academic life but also in my future professional life.

I am grateful to Natural Sciences and Engineering Research Council of Canada (NSERC), Initiative for Automotive Innovation (Ontario Research Fund-Research Excellence) \& Ryerson Graduate Scholarship (RGS) program for providing financial support.

I would also like to acknowledge Jennifer Li from Center of Advanced Material Joining (CAMJ) of University of Waterloo for the nicely done welded joints. Sincere thanks go to Professor S. D. Bhole for his helpful discussion and Professor C. R. Ravindran for his inspiring encouragement.

I would like to extend my sincere thanks to all my friends and colleagues at Ryerson University especially Md. Saki Mursalin Chowdhury, Gaganpreet Sidhu and Himesh Patel for endlessly helping me and keeping my spirits up. Special thanks are owed to A. Machin, Q. Li, J. Amankrah and R. Churaman for their extraordinary cooperation in conducting the experiments.

Words cannot express my deepest gratitude towards my dear parents and my younger brother, the biggest soccer fan of the world. Last but not least I like to thank all my friends and relatives from Bangladesh. Very special thanks to a very special friend, Subrina Sultana, for her persistent support and impelling encouragement. 


\section{To}

\section{My Parents}

Md. Nazib \& Mrs. Nazma Begum 


\section{TABLE OF CONTENTS}

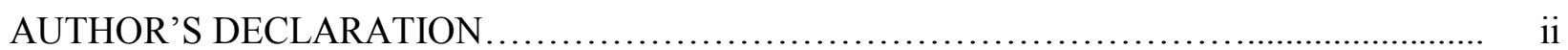

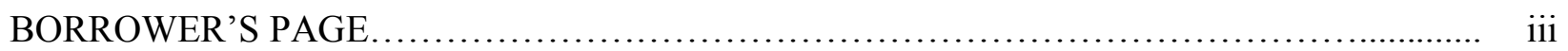

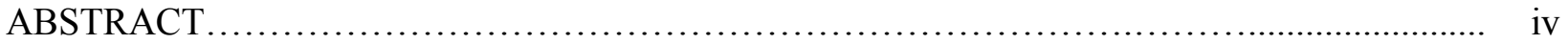

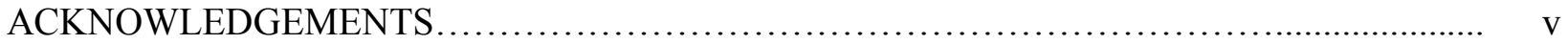

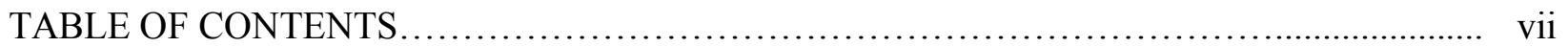

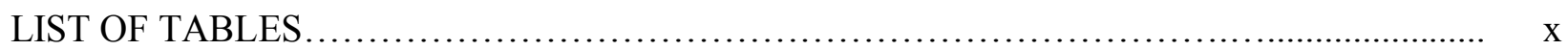

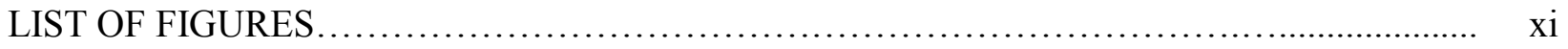

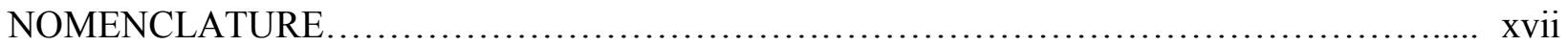

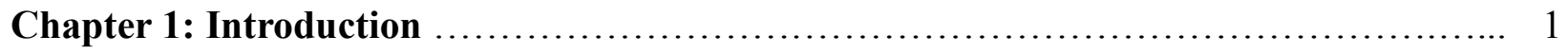

Chapter 2: Literature Review.................................................... 4

2.1 Advanced high strength steels (AHSS) f...................................................... 4

2.1.1 Advanced high strength steels background $\ldots \ldots \ldots \ldots \ldots \ldots \ldots \ldots \ldots \ldots \ldots . \quad 4$

2.1.2 Dual phase (DP) steels ................................................................... 5

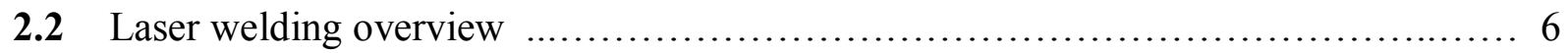

2.2.1 Introduction to laser welding ..................................... 6

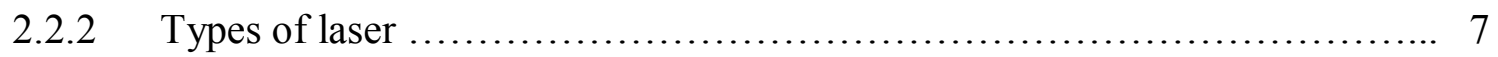

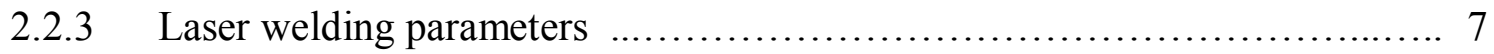

2.3 Recent studies on laser welded DP steel joints .............................. 9

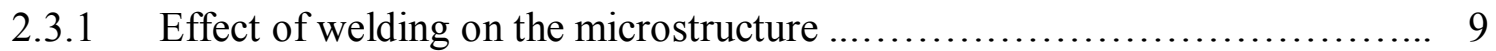

2.3.2 Microhardness profile and formation of soft zone ..................... 10

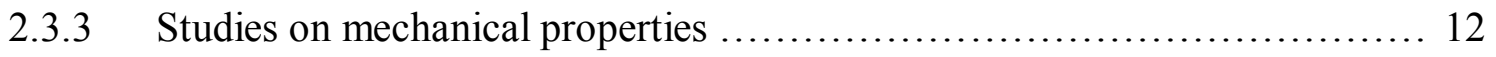




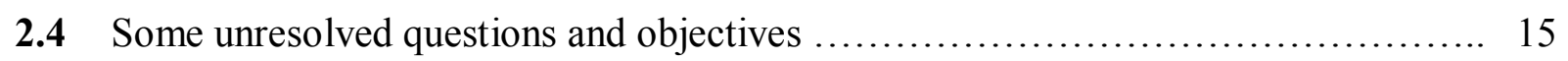

Chapter 3: Materials and Experimental Procedure .............................. 17

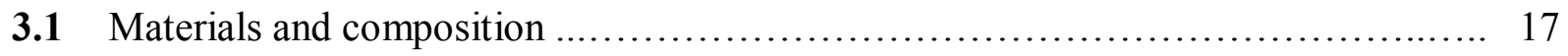

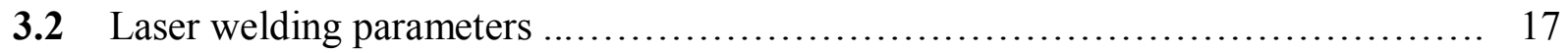

3.3 Sample preparation ................................................. 19

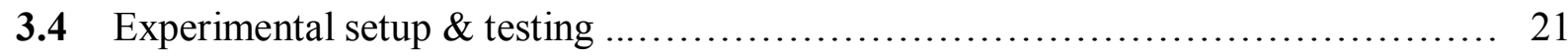

3.4.1 Optical microscopy and image analysis ........................... 21

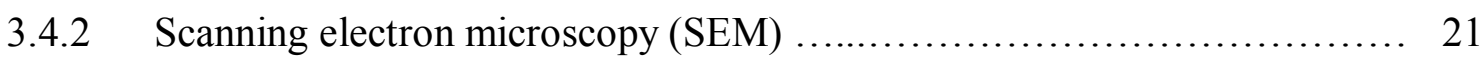

3.4.3 Microhardness test ............................................... 23

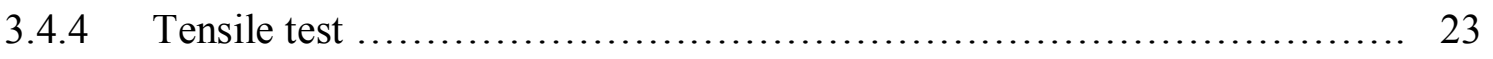

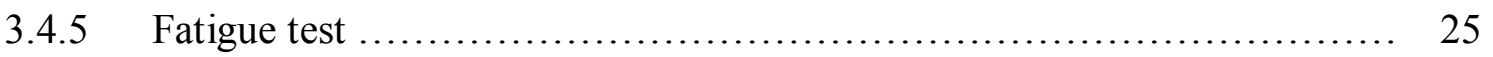

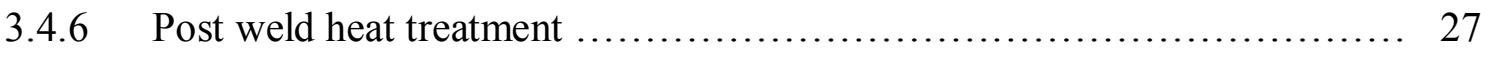

Chapter 4: Results and Discussion .......................................... 28

4.1 Mechanical properties of laser welded similar DP steel joints.................. 28

4.1.1 Microstructural evolution ...................................... 28

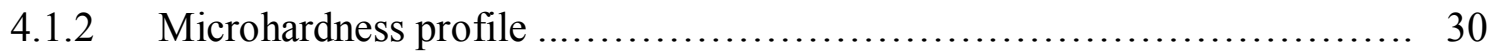

4.1.3 Tensile properties of laser welded similar DP steel joints ............... 32

4.1.3.1 Effect of welding on the tensile properties .................. 33

4.1.3.2 Work hardening behavior of laser welded similar DP steel

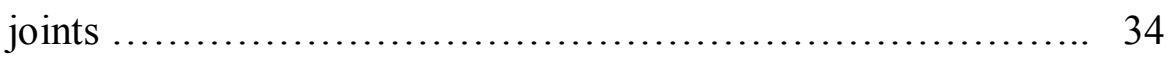

4.1.3.3 Tensile failure location and fractography .................. 40

4.1.4 Fatigue behavior of laser welded similar DP steel joints ............... 43

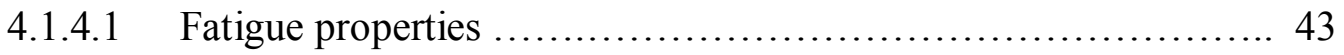


4.1.4.2 Fatigue failure location and mechanism .................... 46

4.1.4.3 Fractographic analysis of fatigue fracture ................... 48

4.2 Mechanical properties of laser welded dissimilar DP Steel joints ............... 51

4.2.1 Microstructural evolution ..................................... 51

4.2.2 Microhardness profile ....................................... 51

4.2.3 Tensile properties of laser welded dissimilar DP steel joints ............ 53

4.2.3.1 Effect of welding on the tensile properties .................. 54

4.2.3.2 Work hardening characteristics of dissimilar DP steel joints ..... 56

4.2.3.3 Tensile failure location and fractography ................... 59

4.2.4 Fatigue performance of laser welded Dissimilar DP steel joints ............ 60

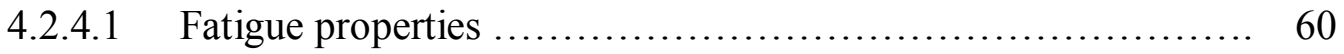

4.2.4.2 Fatigue failure location.............................. 62

4.2.4.3 Fractographic analysis of fatigue fracture .................. 63

4.3 Effect of heat treatment on the laser welded DP980 joints $\ldots \ldots \ldots \ldots \ldots \ldots \ldots \ldots \ldots$

4.3.1 Effect of heat treatment on the microhardness and microstructure ......... 66

4.3.2 Effect of heat treatment on the tensile properties ............. 69

4.3.3 Effect of heat treatment on the fatigue properties .............. 73

4.3.4 Fractographic analysis .................................. 75

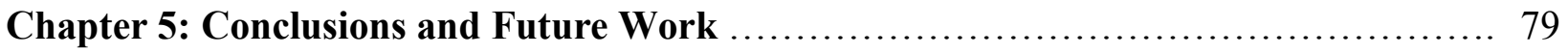

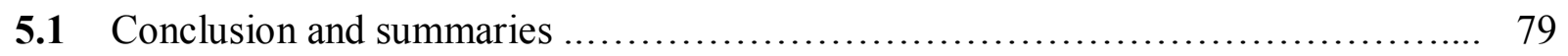

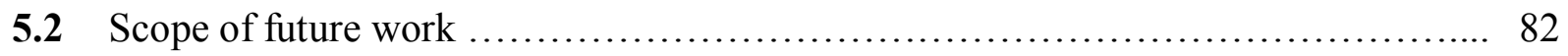

References............................................................ 85

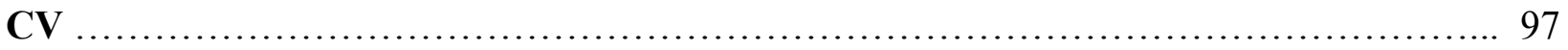




\section{LIST OF TABLES}

Table 2.1 Measured width of hardened and softened zones in laser welds [33]............12

Table 3.1 Chemical composition of the DP steels selected in the present study (in

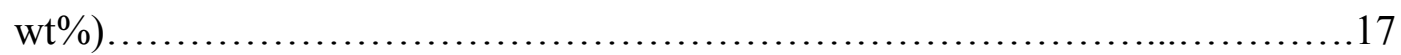

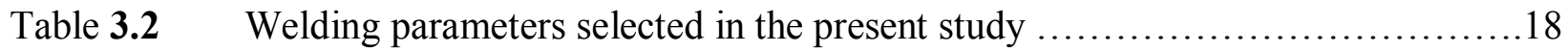

Table 3.3 Machining parameters used for the machining of samples......................20

Table 4.1 Fatigue limit and fatigue ratio of the base metals and laser welded joints of DP600 and DP980 steels tested at $\mathrm{R}=0.1,50 \mathrm{~Hz}$ and room temperature .45

Table 4.2 Fatigue parameters $\sigma_{f}^{\prime}$ and $b$ for the base metals and laser welded joints of DP600 and DP980 steels tested at $\mathrm{R}=0.1,50 \mathrm{~Hz}$ and room temperature

Table 4.3 Fatigue limit and fatigue ratio of the DP600 and DP980 base metals as well as DP600/DP980 dissimilar welded joints.

Table 4.4 Tensile properties of the DP980 base metal, welded joints and PWHT joints

Table 4.5 Fatigue limit and fatigue ratio of the DP980 base metal, welded joints without and with PWHT. 


\section{LIST OF FIGURES}

Figure 2.1 Comparison of welding modes (a) conduction and (b) penetration

Figure 2.2 (a) Microstructure of DP980 base metal comprised of martensite in ferrite matrix, (b) Fusion zone microstructure of DP980 steel comprised of mostly martensite [13]

Figure 2.3 Hardness profile across welds: (a) Nd:YAG laser welding with $6 \mathrm{~m} / \mathrm{min}$ and (b) diode laser welding with speed of $1.3 \mathrm{~m} / \mathrm{min}[4]$

Figure 2.4 Side views of dome tested samples where the dome heights of the parent metal and welded specimen are 30.4 and $13.2 \mathrm{~mm}$ for DP980 [33]

Figure 3.1 The Nuvonyx ISL4000L diode laser head mounted on a Panasonic VR6 robotic arm (Laser welding setup) .18

Figure 3.2 Geometry and dimensions of the tensile and fatigue specimens used in the present study.

Figure 3.3 Image analysis systems.......

Figure 3.4 The JSM-6380LV SEM system with EDS

Figure 3.5 A Buehler Micromet-5100 microhardness tester. .23 
Figure 3.6 A fully-computerized United tensile tester.

Figure 3.7 A fully-computerized Instron 8801 servo-hydraulic fatigue testing system .25

Figure 3.8 Heat treatment procedure applied for the laser welded joints. .27

Figure 4.1 SEM micrographs showing the microstructural change of laser welded DP steel joints, (a) DP600 base metal, (b) DP600 fusion zone, (c) DP600 HAZ (soft zone), (d) DP980 base metal, (e) DP980 fusion zone, and (f) DP980 HAZ (soft zone).

Figure 4.2 Typical microhardness profile of the laser welded (a) DP600 steel joint and (b) DP980 steel joint

Figure 4.3 Engineering tensile stress-strain curves obtained at different strain rates for (a) DP600 base metal, (b) DP600 welded joint, (c) DP980 base metal, and (d) DP980 welded joint.

Figure 4.4 Effect of laser welding on (a) yield strength, (b) ultimate tensile strength (UTS), and (c) ductility of the DP steels tested at different strain rates.

Figure 4.5 Work hardening rate vs. net flow stress at a strain rate of $1 \times 10^{-2} \mathrm{~s}^{-1}$ for (a) DP600 base metal and welded joint and (b) DP980 base metal and welded joint. 
Figure 4.6 Work hardening exponents obtained at different strain rates for the DP base metals and welded joints, evaluated according to (a) Hollomon equation [48], (b) Jaoul-Crussard analysis [49-50] and (c) equation proposed by Afrin et al.[67]

Figure 4.7 Failure location of a typical tensile test sample for the laser welded DP980 steel joint

Figure 4.8 Typical SEM micrographs of tensile fracture surfaces of the welded joints tested at a strain rate of $1 \times 10^{-2} \mathrm{~s}^{-1}$, (a) center of DP600 welded joint, (b) near-edge area of DP600 welded joint, (c) center of DP980 welded joint and (d) near-edge area of DP980 welded joint

Figure 4.9 EDS analysis of particles in the dimples on the fracture surface of a laser welded DP980 steel joint, (a) a SEM image with larger and deeper dimples, and (b) EDS spectrum.

Figure 4.10 S-N curves obtained for the base metals and laser welded joints of DP600 and DP980 steels tested at $\mathrm{R}=0.1,50 \mathrm{~Hz}$ and room temperature where the data points with arrow marks indicate the run-out samples.

Figure 4.11 Typical fatigue failure location of the DP600 welded samples tested at a stress amplitude of (a) above $250 \mathrm{MPa}$, and (b) below $250 \mathrm{MPa}$

Figure 4.12 Fatigue fracture surface of a DP980 welded joint tested at a stress amplitude of $225 \mathrm{MPa}$, (a) Overall view of the fracture surface at a low 
magnification, (b) crack initiation site, (c) crack propagation area, and (d) fast fracture area.

Figure 4.13 Fatigue fracture surface of a DP600 welded sample tested at a stress amplitude of $250 \mathrm{MPa}$ (a) deformation bands near both specimen surfaces, (b) a magnified view of the boxed area in (a). 50

Figure 4.14 SEM micrographs showing the microstructural change of a laser welded dissimilar dual-phase steel joint, (a) DP600 base metal, (b) HAZ (DP600), (c) fusion zone, (d) HAZ (DP980), (e) DP980 base metal.

Figure 4.15 A characteristic unsymmetrical microhardness profile of the laser welded DP600/DP980 dissimilar joint .54

Figure 4.16 (a) Typical stress-strain curves obtained at a strain rate of $1 \times 10^{-2} \mathrm{~s}^{-1}$, (b) effect of laser welding on the yield strength (YS) and ultimate tensile strength (UTS). 55

Figure 4.17 Work hardening rate vs. net flow stress for the DP600 and DP980 base metals as well as DP600/DP980 dissimilar welded joints tested at a strain rate of $1 \times 10^{2} \mathrm{~s}^{-1}$

Figure 4.18 Work hardening exponents of dissimilar welded joints compared with base metals at different strain rates evaluated using the Hollomon equation [48]. .58 
Figure 4.19 Typical SEM micrographs of the tensile fracture surface of the DP600/DP980 dissimilar welded joints tested at a strain rate of $1 \times 10^{-2} \mathrm{~s}^{-1}$, (a) in the specimen center and (b) near the specimen edge

Figure 4.20 S-N curves of the base metals and the dissimilar welded joints tested at $\mathrm{R}=0.1,50 \mathrm{~Hz}$ and room temperature where the run-out samples were indicated by arrow marks.

Figure 4.21 Fatigue failure locations of the dissimilar welded joints tested at a stress amplitude of (a) $275 \mathrm{MPa}$, (b) $200 \mathrm{MPa}$.

Figure 4.22 Typical fatigue fracture surface of the dissimilar welded joint tested at a stress amplitude of $225 \mathrm{MPa}$, (a) overall view of the fracture surface at a low magnification, (b) magnified view of the dashed box in (a) showing the crack initiation site, (c) crack propagation near the crack initiation site at an intermediate magnification, (d) crack propagation near the crack initiation site at a higher magnification, (e) crack propagation with secondary cracks at a higher magnification, (f) center of the fracture surface showing the final rapid crack propagation.

Figure 4.23 Effect of heat treatment on the microhardness profile of the laser welded DP980 steel joints

Figure 4.24 Typical microstructures of the laser welded DP980 steel joints after postweld heat treatment at (a) $750^{\circ} \mathrm{C}$, (b) $780^{\circ} \mathrm{C}$, (c) $810^{\circ} \mathrm{C}$ and (d) $840^{\circ} \mathrm{C}$ .68 
Figure 4.25 Typical stress-strain curves of the DP980 base metal, welded joints without and with PWHT obtained at a strain rate of $1 \times 10^{-4} \mathrm{~s}^{-1}$.

Figure 4.26 Work hardening rate vs. net flow stress for the DP980 base metal, welded joints without and with PWHT tested at a strain rate of $1 \times 10^{-4} \mathrm{~s}^{-1}$

Figure 4.27 S-N curves of the DP980 base metal, welded joints without and with PWHT tested at $\mathrm{R}=0.1,50 \mathrm{~Hz}$ and room temperature where the run-out samples were indicated by arrow marks. .74

Figure 4.28 Typical SEM micrographs of the tensile fracture surface tested at a strain rate of $1 \times 10^{-4} \mathrm{~s}^{-1}$, (a) center of DP980 base metal (b) edge of DP980 base metal, (c) center of PWHT $750^{\circ} \mathrm{C}$ joints and (d) edge of PWHT $750^{\circ} \mathrm{C}$ joints

Figure 4.29 Typical fatigue fracture surface of the PWHT $810^{\circ} \mathrm{C}$ joints tested at a stress amplitude of $250 \mathrm{MPa}$, (a) overall view of the fracture surface at a low magnification, (b) magnified view of the crack initiation site, (c) crack propagation zone with fatigue striations and secondary cracks at a higher magnification and (d) center of the fracture surface showing the final rapid crack propagation. 77 


\section{NOMENCLATURE}

$\underline{\text { Acronym }}$

3D

AHSS

Al

ASTM

BIW

C

$\mathrm{CFH}$

C-J

$\mathrm{CNC}$

$\mathrm{CP}$

$\mathrm{Cr}$

$\mathrm{Cu}$

CW

DC-J

DP

EDS

FB

$\mathrm{Fe}$

FZ

GDP

\section{Definition}

Three dimensional

Advanced high strength Steel

Aluminum

American society for testing and materials

Body in white

Carbon

Cubic feet per hour

Crussard-Jaoul

Computer numerical control

Complex phase steel

Chromium

Copper

Continuous weld

Differential Crussard-Jaoul

Dual phase steel

Energy dispersive X-ray spectrometry

Ferritic bainitic

Iron

Fusion zone

Gross domestic product 


\begin{tabular}{|c|c|}
\hline GHG & Green house gas \\
\hline GMAW & Gas metal arc welding \\
\hline GUI & Graphical user interface \\
\hline HAZ & Heat affected zone \\
\hline $\mathrm{HCF}$ & High cycle fatigue \\
\hline HSLA & High strength low alloy steels \\
\hline HSS & High strength steels \\
\hline ISO & International standard organization \\
\hline LASER & Light amplification by stimulated emission of radiation \\
\hline LCF & Low cycle fatigue \\
\hline LSW & Laser spot welding \\
\hline MC-J & Modified Crussard-Jaoul \\
\hline $\mathrm{Mg}$ & Magnesium \\
\hline $\mathrm{Mn}$ & Manganese \\
\hline Mo & Molybdenum \\
\hline MS & Martensitic \\
\hline $\mathrm{Nd}$ & Nobidium \\
\hline $\mathrm{OM}$ & Optical microscopy \\
\hline P & Phosphorus \\
\hline PWHT & Post weld heat treated \\
\hline $\mathrm{RD}$ & Rolling direction \\
\hline RPM & Revolution per minute \\
\hline RSW & Resistance spot welding \\
\hline
\end{tabular}




$\begin{array}{ll}\text { S } & \text { Sulphur } \\ \text { S-N } & \text { Stress vs. Number of cycle to failure } \\ \text { SCFH } & \text { Standard cubic feet per hour } \\ \text { SEM } & \text { Scanning electron microscopy } \\ \text { Si } & \text { Silicon } \\ \text { TRIP } & \text { Transformation induced plasticity } \\ \text { TWIP } & \text { Twinning induced plasticity } \\ \text { TS } & \text { Tensile strength } \\ \text { TWB } & \text { Tailored welded blanks } \\ \text { UTS } & \text { Ultimate tensile strength } \\ \text { VHN } & \text { Vickers hardness number } \\ \text { WJ } & \text { Welded joint } \\ \text { XRD } & \text { X-ray diffraction analysis } \\ \text { YAG } & \text { Yttrium-Aluminum-Garnet } \\ \text { YS } & \text { Yield strength }\end{array}$


$A_{c}$

$A c_{1}$

K

$K_{1}$

$K^{8}$

$n$

$n_{1}$

$n^{*}$

$P$

$P_{\text {max }}$

$P_{\text {mean }}$

$R$

$T_{0}$

$T_{\max }$

$\sigma$

$\sigma_{\min }$

$\sigma_{\max }$

$\sigma_{a}$

$\sigma_{m}$

$\sigma_{y}$

$\varepsilon$

$\varepsilon_{y}$
Cross-sectional area of the specimen

$\mathrm{mm}^{2}$

Critical temperature for reaustenization

K

Strength coefficient according to Hollomon equation

Strength coefficient according to Ludwik equation

Strength coefficient according to modified equation

Strain hardening exponent according to Hollomon equation

Strain hardening exponent as per ludwik equation

Strain hardening exponent as per modified equation

Laser power

$\mathrm{kW}$

Maximum applied load by fatigue tester on test samples

$\mathrm{kN}$

Average load applied by fatigue tester on test samples

$\mathrm{kN}$

Stress ratio

Ambient temperature

K

Maximum temperature

K

True stress

$\mathrm{MPa}$

Minimum stress

$\mathrm{MPa}$

Maximum stress

$\mathrm{MPa}$

Stress amplitude

$\mathrm{MPa}$

Mean stress

$\mathrm{MPa}$

Yield strength

$\mathrm{MPa}$

True Strain

Yield strain 


\section{Chapter 1}

\section{Introduction}

Increasing concern of environmental safety and reduction of fuel consumption motivate car manufacturers to use new lightweight materials having a higher tensile strength coupled with better ductility. By reducing the weight of a car, less fuel consumption along with less $\mathrm{CO}_{2}$ emission can be achieved. Considering the safety standards required in the automobile industry, advanced high strength steels (AHSS) can be an auspicious solution as these steels have a higher tensile strength, in conjunction with higher elongation, compared to the conventional steels of similar yield strength [1]. It has been shown in a case study of the world steel association that replacing conventional steels with AHSS for the car body resulted in $17 \%$ to $25 \%$ mass savings which corresponded to a total vehicle weight reduction of $9 \%$. This reduction in the vehicle mass leads to a reduction in fuel consumption and GHG emission by $5.1 \%$ and $5.7 \%$, respectively, over the full life cycle of the vehicle. When applied to a typical five-passenger family car, this would result in an overall reduction in the car weight by $117 \mathrm{~kg}$, corresponding to a lifetime saving of 2.2 tonnes of $\mathrm{CO}_{2}$ equivalents per vehicle [2].

Dual phase (DP) steel is a member of the family of AHSS. The microstructure of DP steel consists of soft and ductile ferrite matrix which is strengthened by a hard martensitic phase and possibly bainitic phase with an addition of a very little amount of retained austenite [3-7]. The ductility of the steel arises from ferrite and the martensite accounts for the strength. Compared with high strength low alloy (HSLA) steels, DP steel shows slightly lower yield strength but the continuous flow behavior in dual phase steel results in larger and more uniform total elongation and a higher initial work hardening rate, along with considerably higher ultimate tensile strength 
[8]. All these favorable mechanical characteristics have made DP steel intriguing to automobile manufacturers.

It is often stated that more than $50 \%$ of a country's gross domestic product (GDP) is related to welding in one way or another [9] and in the case of the automobile body structure, welding is the most used joining operation. In previous auto body designs, the most typical material used was mild steel. These car bodies were assembled via resistance spot welding (RSW), a method which fulfilled the demand of automobile manufacturers for high process speed and high volume scenario. But, due to the changed material scenario, other welding methods are also gaining popularity in the industry. Due to ease of automation and flexibility, laser welding has already gained its reputation in the metal joining field. A lot of work can be found on the laser welding of DP steel coupled with the effect of welding on the tensile properties $[10,11]$. But very limited studies on the fatigue properties of these kinds of joints have been reported. In structural applications, laser welded joints would be prone to failure under cyclic loading conditions, so the characterization of fatigue resistance of the welded joints is necessary.

Previous studies on DP steels showed that the welding led to the formation of a soft zone in the subcritical area of the heat-affected zone (HAZ), and the mechanical properties of the welded joints were significantly affected by this area $[12,13]$. The tensile properties and formability of the welded joints were seriously hindered by the formation of this softened zone [12-15]. Then the questions arose on whether the soft zone would lead to a reduction in the fatigue resistance and to what extent. Detailed studies concerning the fatigue properties and the effect of the soft zone on the failure behavior of the welded DP joints are lacking. For the effective applications of 
DP steels, a comprehensive study of their fracture characteristics and mechanisms under both monotonic and cyclic loads is of vital importance.

Therefore, the present study was aimed at evaluating the microstructure and mechanical properties with an emphasis on the failure mechanisms of the laser welded DP steel joints under both monotonic and cyclic loading. This investigation also involves developing an effective postweld heat treatment procedure to overcome the negative effect of the soft zone and improve the mechanical properties.

A literature survey is presented in Chapter 2 where a brief overview on advanced high strength steels (AHSS) \& laser welding is followed by the previous research work evaluating the mechanical properties of laser welded DP steel joints and the significance and aim of this work. Chapter 3 explains the experimental procedures involved in this study. Chapter 4 depicts the test results obtained in this work, in conjunction with a corresponding discussion. Chapter 5 presents conclusions and the future scope of this work. 


\section{Chapter 2}

\section{Literature Review}

\subsection{Advanced high strength steels (AHSS)}

\subsubsection{Advanced high strength steels background}

Automotive steels can be classified in several different ways. One is a metallurgical designation. The common designation includes low strength steels, conventional high strength steels (HSS) and the newer types of advanced high strength steels (AHSS). The principal difference between the conventional HSS and the AHSS is their microstructure. Conventional HSS are the single phase ferritic steels (such as carbon-manganese, bake hardenable, high strength interstitial free and high strength low alloy steels). On the other hand, AHSS are primarily steels with a microstructure containing a phase other than ferrite or pearlite such as martensite, bainite, austenite and/or retained austenite in quantities sufficient to produce unique mechanical properties. Some types of AHSS have a higher strain hardening capacity resulting in a strength ductility balance superior to conventional steels. Other types have ultra high yield and tensile strength and show a bake hardening behavior. All AHSS are commonly produced by controlling the cooling rate from the austenite or austenite plus ferrite phase, either on the run out table or hot mill (for hot rolled products) or in the cooling section of the continuous annealing furnace (continuously annealed or hot dipped products) [1].

The common types of AHSS are: dual phase (DP) steels, transformation induced plasticity (TRIP) steels, complex phase (CP) steels, martensitic (MS) steels, ferritic bainitic (FB) steels, twinning induced plasticity (TWIP) steels. 


\subsubsection{Dual phase (DP) steels}

DP steels normally contain dispersed islands of martensite in the ferrite matrix [5,16-20]. The ductility arises from ferrite, while martensite accounts for the strength. Usually ferritemartensite DP steels are produced by intercritical annealing followed by rapid cooling [21,22]. During the intercritical annealing small pools of austenite are formed in the ferrite matrix, which subsequently transform into martensite upon rapid cooling. The austenite-to-martensite transformation, accompanied by a volume expansion, leads to mobile dislocations into the surrounding ferritic matrix. The mobility of these dislocations is responsible for the high initial work hardening rate and continuous deformation behavior in the DP steels [16,22].

The excellent combination of higher tensile strength with significant ductility resulted into better acceptance of these steels compared to conventional steels. DP steels also exhibits higher initial work hardening rate, higher ultimate tensile strength and lower YS/UTS ratio than the similar yield strength of HSLA (high strength low alloy) steel. Another benefit of DP steels over the conventional steels is the bake hardening effect ${ }^{*}$. In DP steels, carbon enables the formation of martensite at practical cooling rates by increasing the hardenability of the steel. Manganese, chromium, nickel and vanadium are added individually or in combination to increase the hardenability as well. Carbon also strengthens the martensite as a ferrite solute strengthener as silicon or phosphorus does. These additions are carefully balanced to not only produce unique mechanical properties but also maintain better weldability [1].

\footnotetext{
* The increase in yield strength resulting from elevated temperature aging.
} 


\subsection{Laser welding overview}

\subsubsection{Introduction to laser welding}

Laser welding is a process by which heat is generated to join metals by using a focused laser beam. The laser is a device that produces a concentrated coherent light beam by stimulating electronic or molecular transitions to lower energy levels. Laser welding can be done by using or not using a shielding gas and also it is used with or without the application of the pressure. Laser welding represents a delicate balance between heating and cooling within a spatially localized volume overlapping two or more solids such that a liquid pool is formed and remains stable under solidification. The objective of laser welding is to create the liquid melt pool by absorption of incident radiation, allow it to grow to desired size and then propagate this melt pool through the solid interface eliminating the original seam between the components to be joined [23].

The two fundamental modes of laser welding are: a) conduction welding and b) keyhole or penetration welding. The basic difference between these two modes is that the surface of the weld pool remains unbroken during conduction welding and opens up to allow the laser beam to enter the melt pool in keyhole welding. Conduction welding is less susceptible to gas entrapment during welding as the laser radiation does not penetrate into the material being weld whereas in the keyhole welding the intermittent closure of the keyhole can result in porosity [23]. The schematic diagrams of these two modes are given in Figure 2.1. The portion of the work piece which is actually get melted during welding is called the fusion zone (FZ). The portion of the work piece which does not melt but get affected by the heat generated in FZ is called heat affected zone (HAZ). 


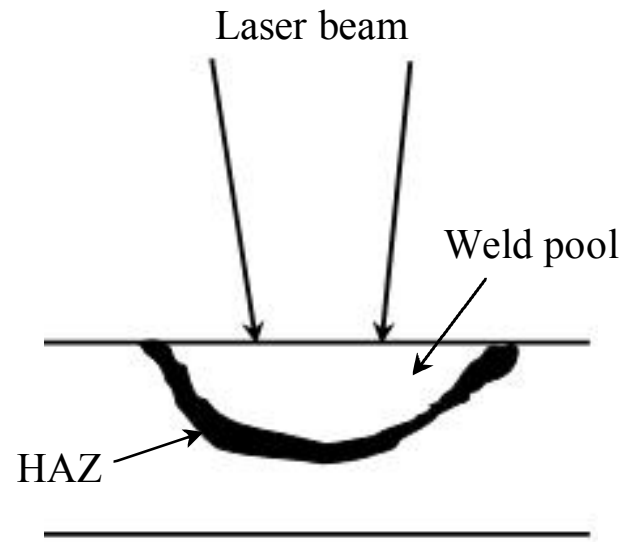

(a)

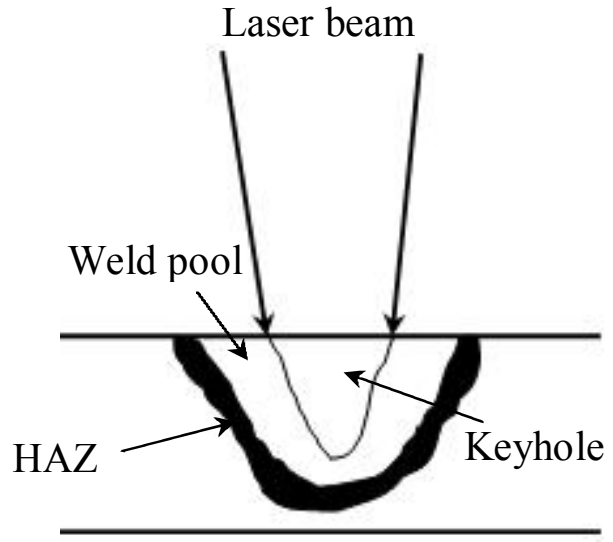

(b)

Figure 2.1 Comparison of welding modes (a) conduction and (b) penetration.

\subsubsection{Types of laser}

There are two basic types of lasers used in metal joining. These are the solid state lasers and gas lasers. Solid state laser uses a solid medium whereas the gas lasers use a mixture of helium, nitrogen and $\mathrm{CO}_{2}$ in the tube. The most commonly used gaseous laser is $\mathrm{CO}_{2}$ laser. The widely used solid state lasers are YAG laser, diode laser, disk laser, fiber laser, etc. Although the gas laser usually generates high power, the solid state lasers are reputed for higher efficiency and better weld properties [24].

\subsubsection{Laser welding parameters}

The weld quality depends on the laser parameter extensively. By manipulating these laser parameters the manufacturer can have good weld joints. Some primary laser welding parameters are discussed below in brief. 
The term laser modes describe the distribution of laser intensity within the beam. For instance the transverse mode or distribution of intensity in the plane perpendicular to the optic axis is determined by the nature of the mirrors used in the laser construction. There are four types of laser modes: stable, unstable, wavelength and hybrid stable-unstable. Lasers are invariably rated by their power output, measured in watts or kilowatts. This rating refers to the power generated at the output mirror or window of the laser and is usually measured by an internal power meter and displayed on a mirror. In case of pulsed laser, the relevant parameter is not the power but the energy per pulse, which is similarly diminished between the laser output and the work piece [24].

The beam width is defined as the diameter of a circle that includes up to $85 \%$ of total power of the beam. The quality of a beam is measured by its ability to be focused to a small spot size, raising the intensity or power per unit area (or energy per unit area for pulsed beams) to a high value to do useful work. The beam diameter at the focus, also called the spot size determines not only the fitness of the features that can be cut or welded but also determines the intensity or power per unit area at the focus. Considering the material which will be welded, welding speed is a very important parameter. This parameter means how much distance the laser beam will cover per unit time while welding. Laser welding is normally an autogenous welding procedure which means no filler material is usually used. However filler materials can be used to relax the edge preparation of the pieces and also to improve the weld metallurgy. Usually shielding gas is used to protect the weld from oxidation and contamination [24]. Depending upon the type of materials to be welded, the positioning of the focal beam of the laser was also found to play a dominant role for steel joints [25]. 


\subsection{Recent studies on laser welded DP steel joints}

As mentioned earlier, about half of a country's GDP is related to welding and joining in one way or another and in the case of autobody structures welding is the most-widely used joining operation, it is obvious to find considerable amount of research work on welding processes of automotive steels. A significant amount of work has been conducted on the mechanical property of the welded DP steel joined by other welding processes, such as resistance spot welding (RSW) [26-28], laser spot welding (LSW) [29], gas metal arc welding (GMAW) [30], and friction stir welding [31]. Mentionable work can be found on the tensile properties $[4,11]$ and formability $[12,13,15]$ of the laser welded DP steel joints as well. A brief background related to the previous studies on laser welded DP steel joints is described in the following sections.

\subsubsection{Effect of welding on the microstructure}

The microstrucrtural matrix of soft ferrite is strengthened with metastable hard martensite and possibly bainitic phase particles in the dual phase steel [4,5,19,20,32] (Fig. 2.2(a)). Previous studies pertaining to laser welding of DP steel joints showed formation of mostly martensitic structure in the fusion zone as that area experiences very high cooling rate during solidification corresponding to the optical micrograph representing the FZ microstructure of laser welded DP980 joints shown in Fig. 2.2(b). The HAZ just outside the fusion boundary is heated above the austenitic transition temperature and upon cooling forms a hardened microstructure that generally consists of lower transformation products of martensite and bainite. Further from the fusion boundary, the maximum local temperature is too low to produce austenite but exposure to 
elevated temperature results in tempering of the martensite phase and leads to a soft microstructure [12]. This soft microstructure is believed to have a detrimental effect on the mechanical properties of laser welded DP steel joints.
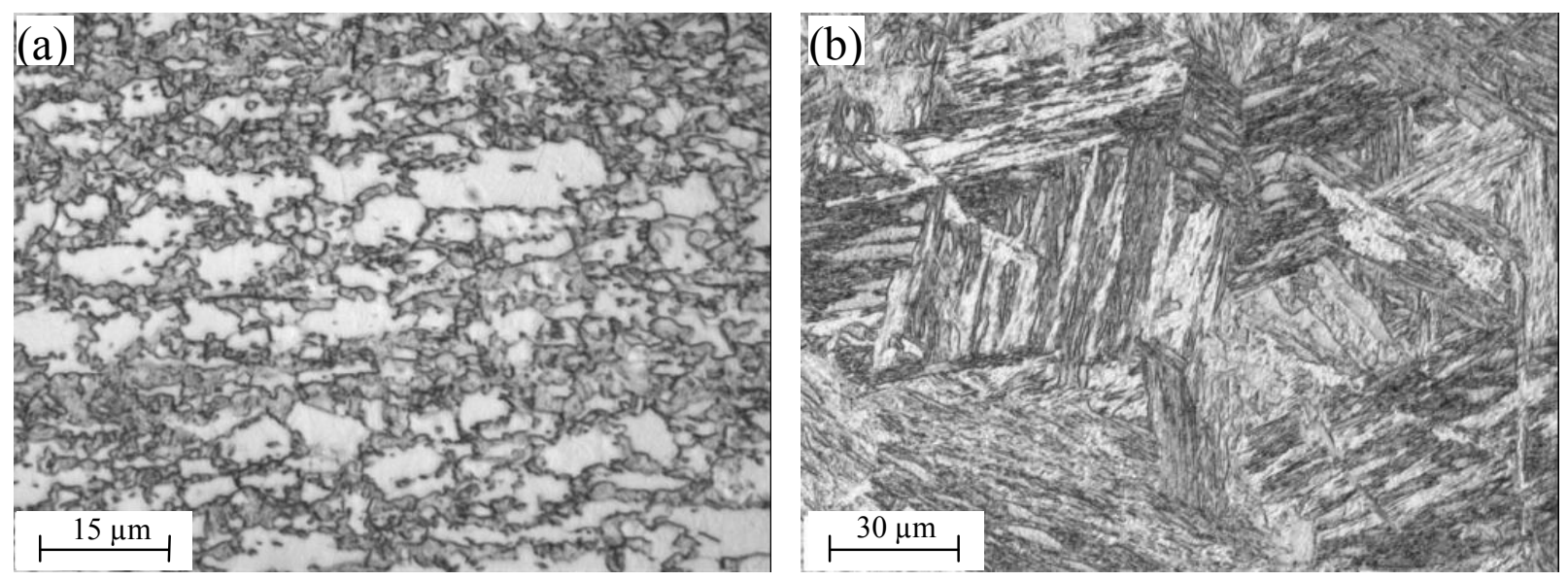

Figure 2.2 (a) Microstructure of DP980 base metal comprised of martensite in ferrite matrix,

(b) Fusion zone microstructure of DP980 steel comprised of mostly martensite [13].

\subsubsection{Microhardness profile and formation of soft zone}

Due to formation of mostly martensitic structure in the fusion zone, it shows higher hardness values compared to base metal. However, recent studies showed that the welding led to formation of a soft zone in the subcritical area of the heat effected zone (HAZ) which is typically referred to as HAZ softening $[4,13,14]$. This softening is believed to occur due to the tempering of preexisting martensite phase during the welding process [4,13-15]. In this region, the peak temperature during the welding cycle was below the $\mathrm{Ac}_{1}$ temperature (the critical temperature for re-austenisation during heating process), and as a result, no austenisation of the $\mathrm{C}$ rich martensite phase occurred. The high temperature exposure promoted martensite decomposition [15]. The 
fusion zone hardness was found to increase with increasing heat input by the laser [4]. Figure 2.3 shows the hardness profile of three different grades of dual phase steel welded by two different types of welding.

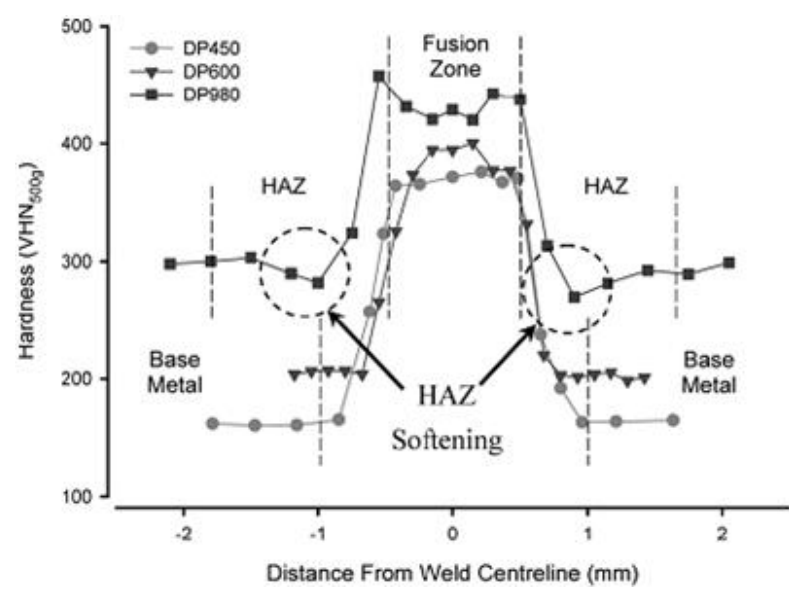

(a)

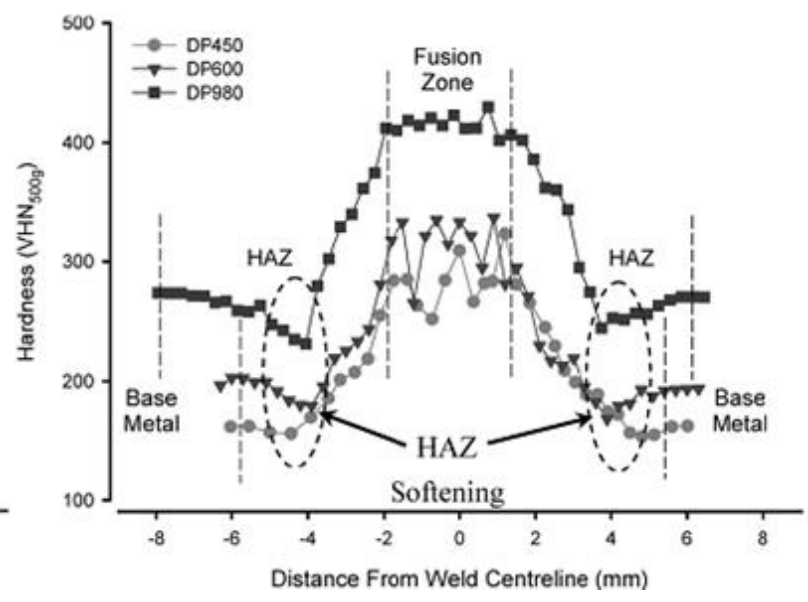

(b)

Figure 2.3 Hardness profile across welds: (a) Nd:YAG laser welding with $6 \mathrm{~m} / \mathrm{min}$ and (b) diode laser welding with speed of $1.3 \mathrm{~m} / \mathrm{min}$ [4].

The welding parameters and volume fraction of base metal martensite have a major effect on this softening phenomenon [4,33]. With higher strength grades of DP steels the degree of softening usually increases (Fig. 2.3). The HAZ softened region becomes smaller in width and depth as welding speed increases due to the reduced heat input at higher welding speeds. The reduced heat input shortens the thermal cycle so that it cannot fully temper the martensite in the dual phase steel [33]. Table 2.1 shows the effect of welding speed, type of laser and laser specific energy on hardened and softened zone widths. According to Uchihara and Fukui [34] this hardness change or softening is caused by the unstable microstructure during welding thermal cycle where it should be mentioned that these DP steels are produced through a controlled thermal cycle to obtain hard microstructure in steel production mill. 
Table 2.1 Measured width of hardened and softened zones in laser welds [33].

\begin{tabular}{ccccc}
\hline Laser & $\begin{array}{c}\text { Weld speed } \\
(\mathrm{m} / \mathrm{min})\end{array}$ & $\begin{array}{c}\text { Laser specific energy } \\
\left(\times 10^{3} \mathrm{~kJ} / \mathrm{m}^{2}\right)\end{array}$ & $\begin{array}{c}\text { Experimental zone width } \\
(\mathrm{mm})\end{array}$ \\
\hline Diode & 0.7 & 381 & Softened zone & Hardened zone \\
Diode & 1.3 & 205 & 2.5 & 3.5 \\
Diode & 1.9 & 140 & 2.0 & 3.2 \\
Nd:YAG & 3.0 & 100 & 0.75 & 3.2 \\
Nd:YAG & 6.0 & 50 & 0.5 & 0.75 \\
\hline
\end{tabular}

\subsubsection{Studies on mechanical properties}

The tensile strength of DP steels has a relationship with the hardness. Huh et al. [35] conducted a detailed study on the dynamic tensile test characteristics of DP600 and DP800 steels along with similar grades of TRIP steels and observed that DP type steels are more sensitive to strain rate compared with TRIP type steel but the work hardening rate of these steels are not that much sensitive to the strain rate. They also reported that the elongation of DP-type steel sheets increases monotonically as the strain rate increases. Similar type of result is also observed by Peixinho et al. [36] who conducted tensile test with different strain rates on DP600 and TRIP600 steel grades and reported that the DP steel exhibits better strain hardening properties where the UTS has a slightly increased response relative to its yield strength on increasing strain rate. Tensile properties of these kinds of steels were observed to be mainly dependent on the volume fraction [37, 38], strength [39], morphology [40,41] of martensite.

However, in the case of welded dual phase steel Kang et al. [11] showed that welded DP600 steel showed higher yield strength and also higher ultimate tensile strength compare to 
the base metal. But they reported that the elongation of the welded sample get reduced after welding and in all cases the sample failed in the base metal which actually leads to a conclusion that the effect of soft zone was not evident in their study. Similar type of failure trend is also observed by Uchihara \& Fukui [34] but in their case the tensile strength got reduced after welding compared to the base metal. In the case of higher strength grades of DP steel Sreenivasan et al. [12] conducted the tensile tests of laser welded DP980 steel and observed that both the yield strength and UTS decreased after welding and the fracture always occurred in the outer HAZ in the soft zone. Similar result was also reported by Xia et al. [15] for DP980 welded joints which actually indicates that the effect of soft zone is more dominant on the higher strength grades of DP steel.

Xia et al. $[13,15]$ did the formability test of laser welded DP980 joints and concluded that in case of the welded blanks the HAZ softened zone in DP980 weldments completely dominated the fracture pattern. This zone is the vulnerable region in which the failure always initiated. They also observed that the formability result or limiting dome height of the welded sample is lower than the base metal. In Figure 2.4 the comparison between the limiting dome heights of laser welded DP980 joints and their respective base metal is given.

Sreenivasan et al. $[12,14]$ conducted detailed research on the formability of different grades of laser welded AHSS including DP steel. The major finding in their study was the formability ratio of laser welded dual phase sheet steels generally decreased with increasing base metal strength. Reduction in welded blank formability is related to HAZ softening and formability ratio decreased with increasing softening response. Panda et al. [42] also observed that the formability of welded DP steel decreased after welding and they believed that the reason behind this was the localized strain accumulated at the soft zone in HAZ. 


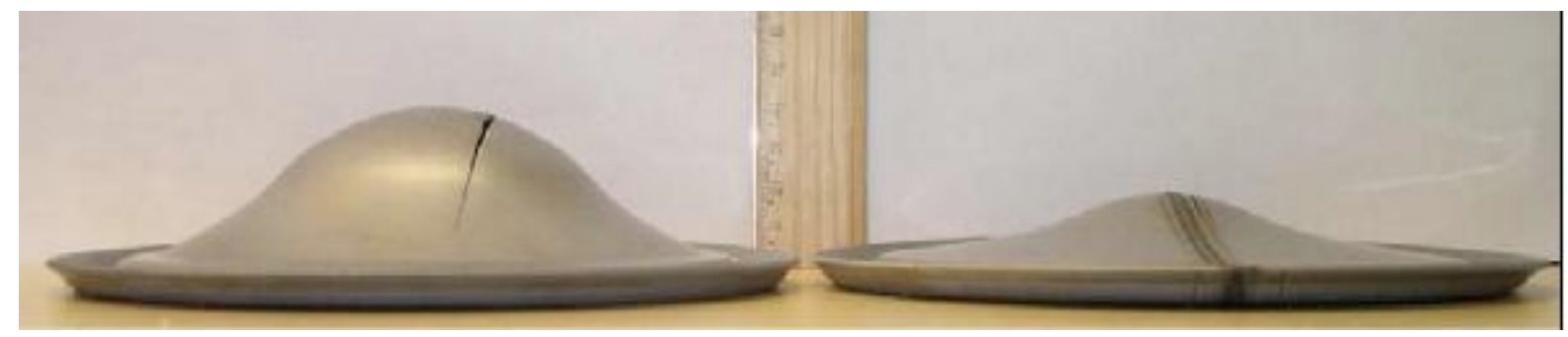

Figure 2.4 Side views of dome tested samples where the dome heights of the parent metal and welded specimen are 30.4 and $13.2 \mathrm{~mm}$ for DP980 [33].

Unlike tensile tests and formability tests very limited work related to fatigue properties of laser welded DP steel joints has been reported. Hadianfard [43] conducted low cycle fatigue test of dual phase steel and found that all specimens tested at different strain amplitudes showed hardening for most of the fatigue life with higher rates of hardening at the first few cycles followed by hardening of gradual decreasing trend.

Galtier \& Duchet [44] studied the fatigue property of different kind of joints made of AHSS. They found that laser butt welding provided very satisfactory joints as the fatigue property of the joints were as same as that of the base metal. They also concluded that the joints made by laser welding was better than the joints made by other joining methods such as resistance spot welding (RSW) in terms of fatigue property. In terms of tensile fatigue tests Uchihara \& Fukui [34] reported that the fatigue strength of base metal and laser welded tailored blanks of advanced AHSS increased with the increasing tensile strength. They also concluded that the fatigue property of laser welded joints was comparatively better than that of other welding such as mash seam welding. 


\subsection{Some unresolved questions and objectives}

A lot of investigations have been directed towards the mechanical properties and work hardening behavior of DP steels in relation to their microstructure. Some empirical laws of stress-strain relationships have been proposed to describe the work hardening behavior of these steels [21,37,45-47]. Among these most popular are Hollomon analysis [48] and Crussard-Jaoul (C-J) analysis [49-50] based on Ludwik [51] and Swift [52] equations, popularly known as differential C-J (DC-J) [55,54] and modified C-J (MC-J) [55-56] techniques, respectively $[40,46]$. But the effect of laser welding on the hardening characteristics of such steels is still limited. A detailed study on the effect of laser welding on the tensile and hardening properties of DP steels is thus necessary.

Previous studies on laser welded similar DP steel joints $[4,13,14,42]$ indicated that welding led to formation of a soft zone in the heat-affected zone (HAZ) and the tensile properties of the welded joints were significantly affected by the presence of soft zone. However, the mechanical properties of dissimilar grades of laser welded DP steel joints have not yet been reported. As an autobody or body in white (BIW) structure involves steels having different strength levels, it is necessary to ascertain how the laser welding changes the microstructure and affects the mechanical properties in the dissimilar DP steel joints. Questions arose on if such a soft zone is still present, how the soft zone changes and to what extent the soft zone affects the mechanical properties in the laser welded dissimilar DP steel joints.

Moreover, it is a matter of great concern on how this soft zone manipulates the fatigue properties of laser welded DP steel joints. While a significant amount of work has been reported on the tensile properties of laser welded DP steel joints $[11,13,57]$, the knowledge on the fatigue 
properties of this kind of joints is very limited. As components of structural applications the laser welded DP steel joints with soft zones might be prone to failure under cyclic loading condition. Therefore it is necessary to evaluate the fatigue resistance and fracture characteristics of laser welded DP steel joints under cyclic loading.

One would then ask if we can find an effective way to get rid of the effect of the detrimental soft zone present after welding. A possible solution to this problem would be the application of post-weld heat treatment (PWHT) to the welded joints. Previous work elaborating the effect of PWHT involved tempering of high carbon high strength steel joints [58,59]. In the case of the laser welded DP steel joints hardening/strengthening of the joints (or the elimination of the soft zone) is more desirable instead of tempering. However, no such study on the PWHT aiming at eliminating the soft zone in the laser welded high strength steel joints and improving the mechanical properties has been reported in the literature.

Based on the queries discussed in the above sections, the research objectives of this thesis can be summarized into two major divisions:

a) To evaluate the microstructural changes, tensile and fatigue properties with emphasis on work hardening behavior and the fracture characteristics of the laser welded similar and dissimilar DP steel joints.

b) To conduct proper PWHT on the laser welded DP steel joints for the recovery of mechanical properties degraded by the welding through the evaluation of microstructure, microhardness profile, tensile properties and fatigue strength. 


\section{Chapter 3}

\section{Materials and Experimental Procedure}

This chapter describes the materials used in this thesis, welding related information, sample preparation and the experimental setup used for mechanical property evaluation.

\subsection{Materials and composition}

$1.2 \mathrm{~mm}$ thick DP600 steel sheet with a galvannealed coating $\left(46 \mathrm{~g} / \mathrm{m}^{2}\right.$ at the top and 47 $\mathrm{g} / \mathrm{m}^{2}$ at the bottom) and $1.2 \mathrm{~mm}$ thick DP980 steel sheet with a galvannealed coating $\left(60 \mathrm{~g} / \mathrm{m}^{2}\right.$ at the top and $67 \mathrm{~g} / \mathrm{m}^{2}$ at the bottom) were selected in the present study. The chemical composition of the selected steels in $\mathrm{wt} \%$ is summarized in Table 3.1 .

Table 3.1 Chemical composition of the DP steels selected in the present study (in wt\%).

\begin{tabular}{cccccccccc}
\hline Steel grade & $\mathrm{C}$ & $\mathrm{Mn}$ & $\mathrm{Si}$ & $\mathrm{Al}$ & $\mathrm{Mo}$ & $\mathrm{Cr}$ & $\mathrm{Cu}$ & $\mathrm{S}$ & $\mathrm{P}$ \\
\hline DP600 & 0.09 & 1.84 & 0.36 & 0.05 & 0.01 & 0.02 & 0.03 & 0.005 & 0.01 \\
DP980 & 0.15 & 1.50 & 0.31 & 0.05 & 0.006 & 0.02 & 0.02 & 0.006 & 0.01 \\
\hline
\end{tabular}

\subsection{Laser welding parameters}

The laser welding was done using a diode laser at the Center of Advanced Materials Joining (CAMJ) in University of Waterloo. The welding parameters used in the present study are shown in Table 3.2. The Nuvonyx ISL4000L diode laser head was mounted on a Panasonic VR6 robotic arm (Fig. 3.1). The beam had a rectangular shape with dimensions of $12 \mathrm{~mm} \times 0.9 \mathrm{~mm}$ 
with a focal length of $90 \mathrm{~mm}$. Also, due to the power density of the diode laser it was restricted to conduction mode welding. During welding of DP600 steels, ultra-high purity argon was used as a shielding gas at a flow rate of $16.5 \mathrm{l} / \mathrm{min}$ on both surfaces of the blanks whereas for both DP980 similar welding and DP600/980 dissimilar welding, the flow rate was $14.2 \mathrm{1} / \mathrm{min}$. Welding was conducted at a welding speed of $1 \mathrm{~m} / \mathrm{min}$ in full penetration bead on a plate mode $\#$.

Table 3.2 Welding parameters selected in the present study.

\begin{tabular}{cccccc}
\hline Laser system & $\begin{array}{c}\text { Laser } \\
\text { source }\end{array}$ & $\begin{array}{c}\text { Laser power } \\
(\mathrm{kW})\end{array}$ & $\begin{array}{c}\text { Welding speed } \\
(\mathrm{m} / \mathrm{min})\end{array}$ & $\begin{array}{c}\text { Focal length } \\
(\mathrm{cm})\end{array}$ & $\begin{array}{c}\text { Beam dimension } \\
\left(\mathrm{mm}^{2}\right)\end{array}$ \\
\hline Nuvonyx ISL-4000 & Diode & 4 & 1 & 9 & $12 \times 0.9$ \\
\hline
\end{tabular}

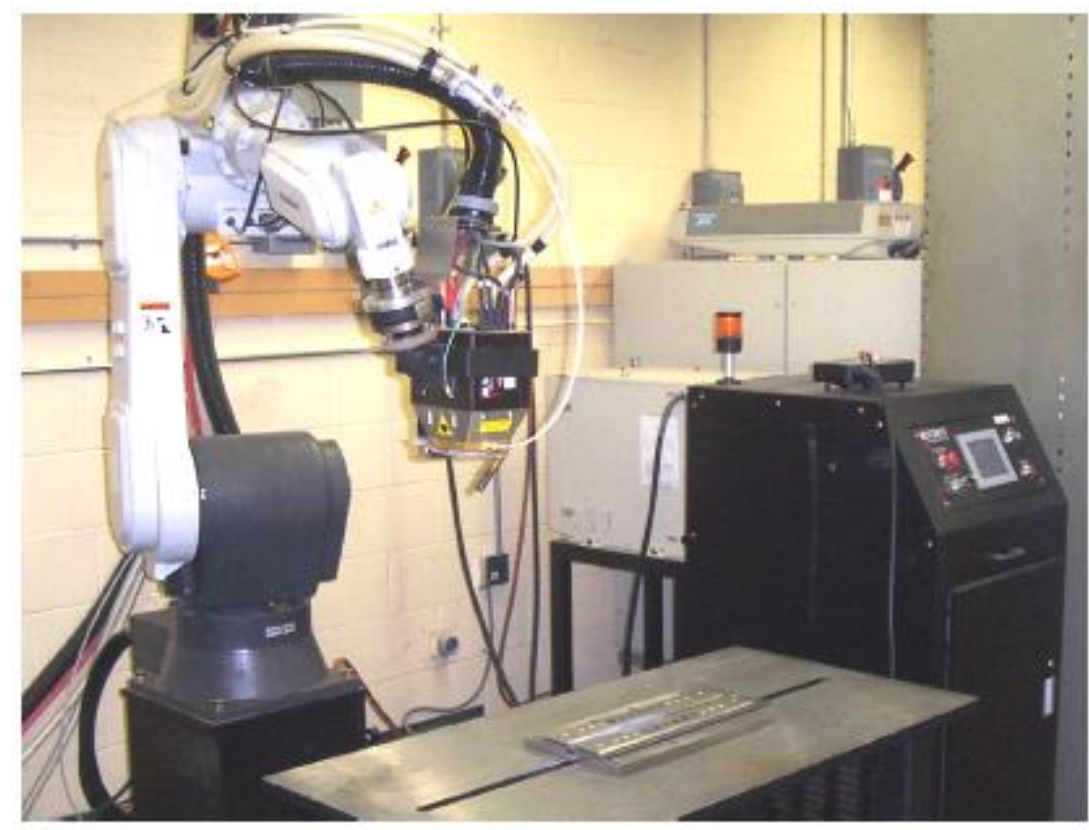

Figure 3.1 The Nuvonyx ISL4000L diode laser head mounted on a Panasonic VR6 robotic arm (Laser welding setup).

\footnotetext{
" Bead-on-plate means a butt weld with full penetration on the blanks of uniform thickness.
} 


\subsection{Sample preparation}

The microscopic specimens were cut using the saw cut and then ground on 120 grit silicon carbide paper for removing nicks. Then the samples were mounted using Bakelite powder into Buehler Simpliment 2000 automatic mounting press and hot mounting was used for all the microscopic samples. The temperature and pressure used for hot mounting were $150{ }^{\circ} \mathrm{C}$ and 4200 psi respectively and water was used for cooling. After finishing mounting the microscopic samples were ground again on silicon carbide paper of 120 grit followed by 320 grit, 600 grit \& 1200 grit. For polishing the samples Leco VP-160 automatic polishing machine was used. The polishing was done on 8 " diameter Leco polishing cloth by using diamond paste of $6 \mu$ followed by $3 \mu$ and $1 \mu$ with diamond extender. The etchant used for the optical microscopy was $4 \%$ Nital and the etching time was 4-5 seconds.

For the tensile and fatigue tests ASTM E8M sub-sized specimens were used. The dimensions of sub sized test sample are given in Figure 3.2. The samples were initially cut by shear or band saw cutter at parallel to the rolling direction (RD) and initially machined by a vertical milling machine. The final machining was done by Mori Seki MV35 CNC machine. The cutter of the CNC machine was high speed steel with titanium nitride coating having a diameter of $0.5^{\prime \prime}$. The machining parameters used for both base metal and welded samples are given in Table 3.3. After machining the samples, two different grits of silicon carbide paper ( $320 \& 600)$ were used carefully to grind the surface of the test samples to remove machining marks. Attention was given in order to avoid any additional fillet on the test samples while grinding. Finally the samples were cleaned with ethanol to remove oils and dirt adhering on them and necessary marks were drawn on the samples to facilitate the alignment during mounting the samples on the testing machine. 


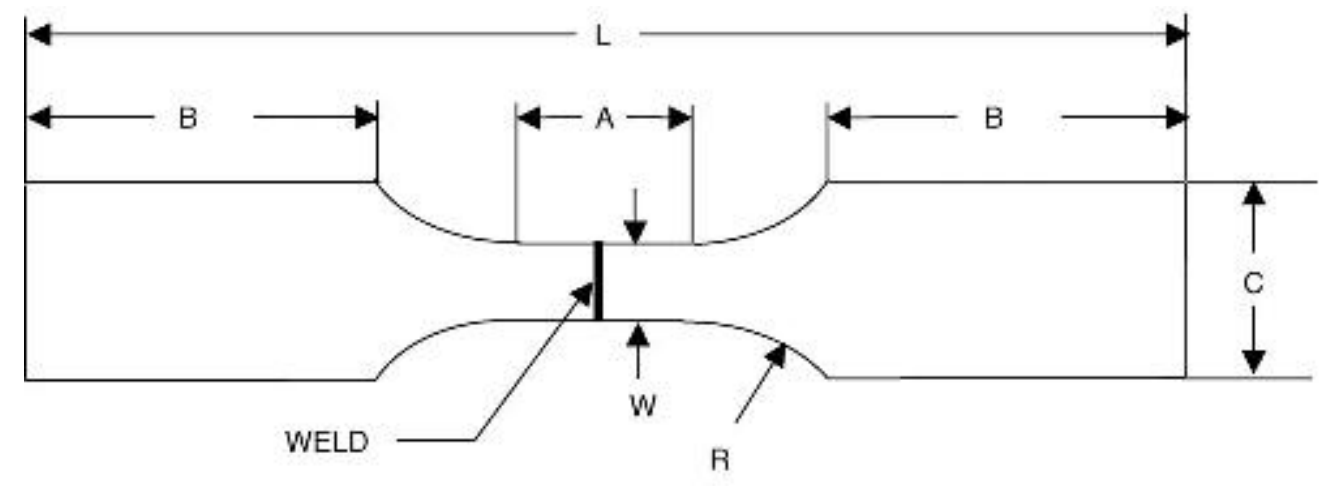

\begin{tabular}{lccccccc}
\hline Name & L & A & W & R & B & C & Thickness \\
\hline Dimension $(\mathrm{mm})$ & 140 & 32 & 6 & 6 & $\sim 50$ & 9.5 & 1.2 \\
\hline
\end{tabular}

Figure 3.2 Geometry and dimensions of the tensile and fatigue specimens used in the present study.

Table 3.3 Machining parameters used for the machining of samples.

\begin{tabular}{lccc}
\hline \multicolumn{1}{c}{ Materials } & Feed rate (inch/minute) & RPM & Cutting speed (inch/minute) \\
\hline DP600 base metal & 3.5 & 500 & 62.5 \\
DP600 welded joints & 1.8 & 305 & 38.125 \\
DP980 base metal & 1.8 & 305 & 38.125 \\
DP980 welded joints & 1.8 & 300 & 38.125 \\
DP600/980 welded joints & 1.8 & 300 & 38.125 \\
\hline
\end{tabular}




\subsection{Experimental setup \& testing}

\subsubsection{Optical microscopy and image analysis}

A light microscope coupled with a Clemex image analysis system shown in Figure 3.3 was used in the optical microscopic observations. It is composed of Clemex software adapted to ASTM and ISO standard, a Nikon optical microscope (10x eye piece, five different object lens with the magnification of $5 x, 10 x, 20 x, 40 x$ and 100x), a high resolution digital camera and a high performance computer to carry out the detailed investigation.

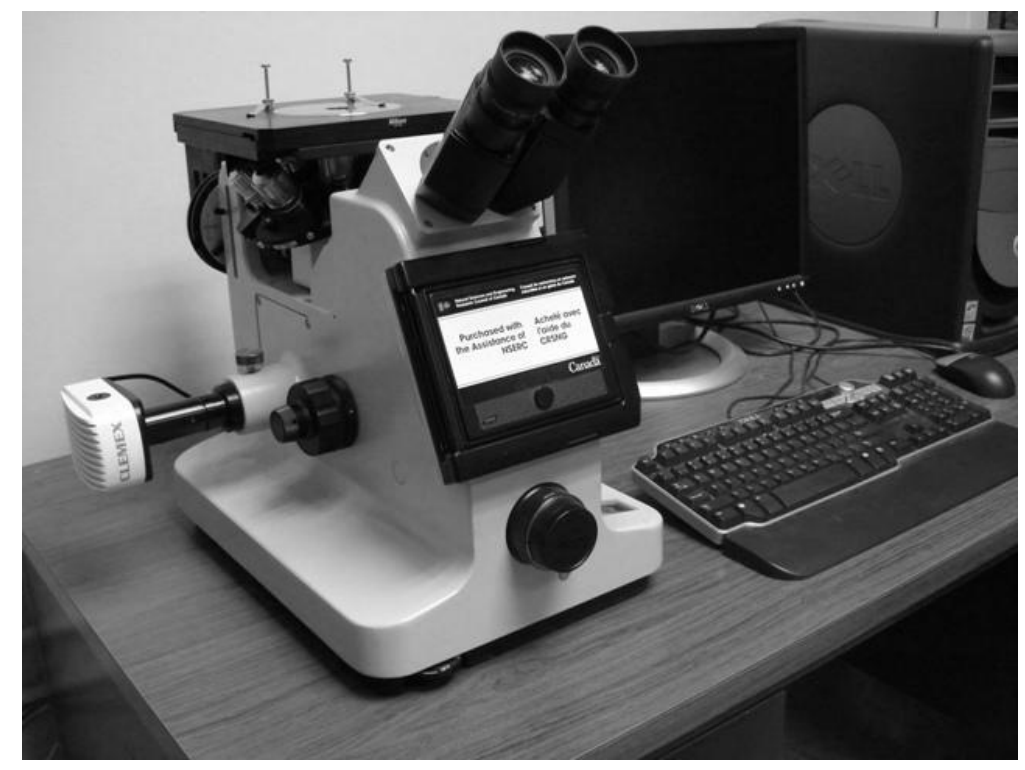

Figure 3.3 Image analysis systems.

\subsubsection{Scanning electron microscopy (SEM)}

The microstructures of the base metal and the welded joints were also observed via scanning electron microscope. The fractured surfaces were examined by SEM as well and the chemical composition in the area of interest was determined by electron dispersive spectroscopy 
(EDS), including line scan and high resolution mapping. The JSM-6380LV shown in Figure 3.4 is a high performance scanning electron microscope with an embedded energy dispersive X-Ray analyzer which allows for seamless observations and has a resolution of $3.0 \mathrm{~nm}$. The customizable graphical user interface (GUI) allows the instrument to be intuitively operated, and Smile Shot ${ }^{\mathrm{TM}}$ software ensures optimum operation settings. Standard automated features include auto focus, auto stigmator, auto gun (saturation, bias and alignment), and automatic contrast and brightness [60]. The resolution of the SEM is much higher than an optical microscope (OM) because the electrons accelerated to $10,000 \mathrm{keV}$ have a wavelength of 0.12 Angstrom, while the visible light has wavelength from 4000 to 7000 angstroms. Depending upon the situation the equipped three detectors - secondary electron detector, backscattered electron detector, energy dispersive X-ray detector were used [60].

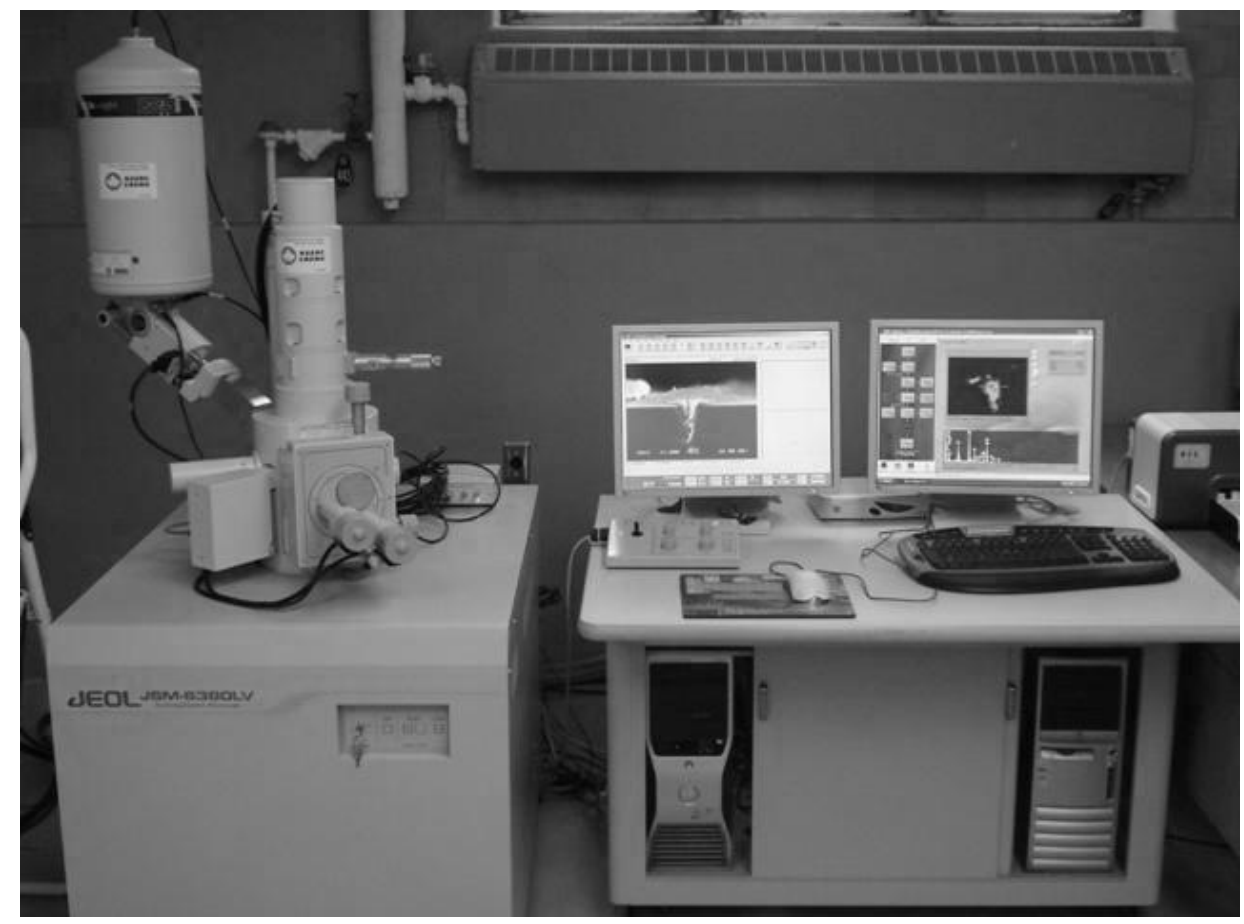

Figure 3.4 The JSM-6380LV SEM system with EDS. 


\subsubsection{Microhardness tests}

Vickers microhardness tests were performed on the unetched samples using a Buehler Micromet-5100 microhardness tester (Fig. 3.5). A load of $500 \mathrm{gm}$ and a dwell time of 15 seconds were used during testing. All the values presented were an average of three series of values taken on the same specimen. The center point of the fusion zone was determined by carefully observing the weld geometry under microscope and all the indentations were adequately spaced to avoid any potential effect of strain fields caused by adjacent indentations.

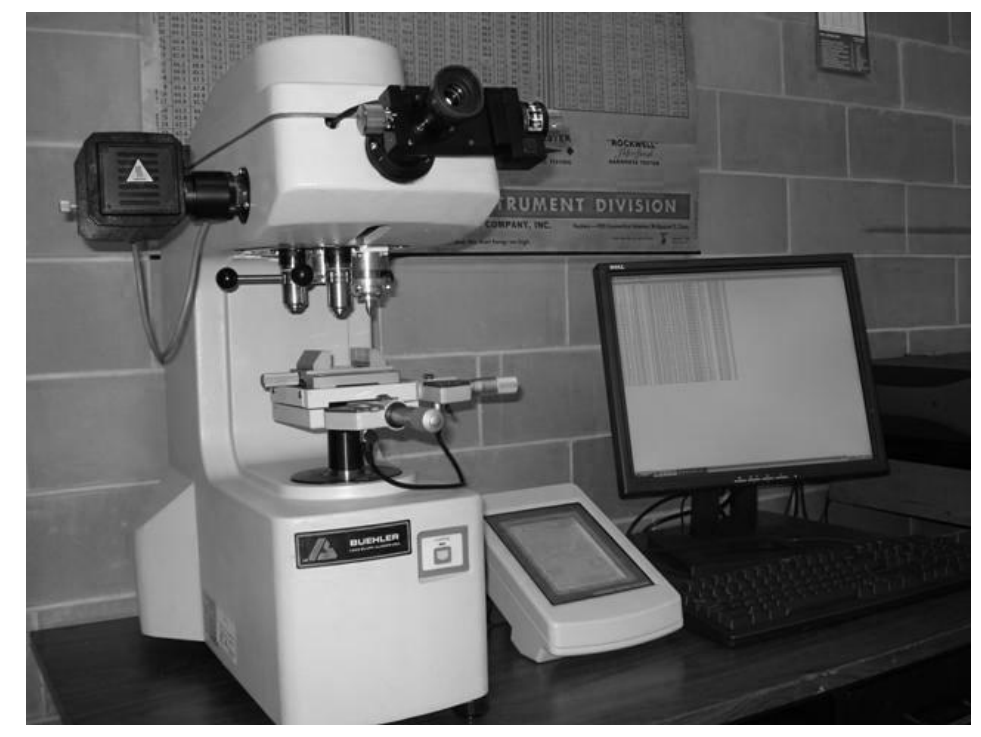

Figure 3.5 A Buehler Micromet-5100 microhardness tester.

\subsubsection{Tensile tests}

Tensile tests were performed at room temperature using a fully computerized United tensile testing machine shown in Fig. 3.6. The strain rates selected in the present study were $1 \times 10^{-2} \mathrm{~s}^{-1}, 1 \times 10^{-3} \mathrm{~s}^{-1}, 1 \times 10^{-4} \mathrm{~s}^{-1}$ and $1 \times 10^{-5} \mathrm{~s}^{-1}$. 
An extensometer with a gauge length of $25 \mathrm{~mm}$ was used to measure the strain during the tests. At least two samples were tested at each strain rate. The $0.2 \%$ offset yield strength, ultimate tensile strength and elongation to failure and engineering stress-strain curves were recorded and using these data the tensile properties and work hardening characteristics were evaluated. The JSM-6380LV scanning electron microscope equipped with Oxford energy dispersive X-ray spectroscopy (EDS) system and 3D fractographic analysis was used to observe the tensile fracture characteristics.

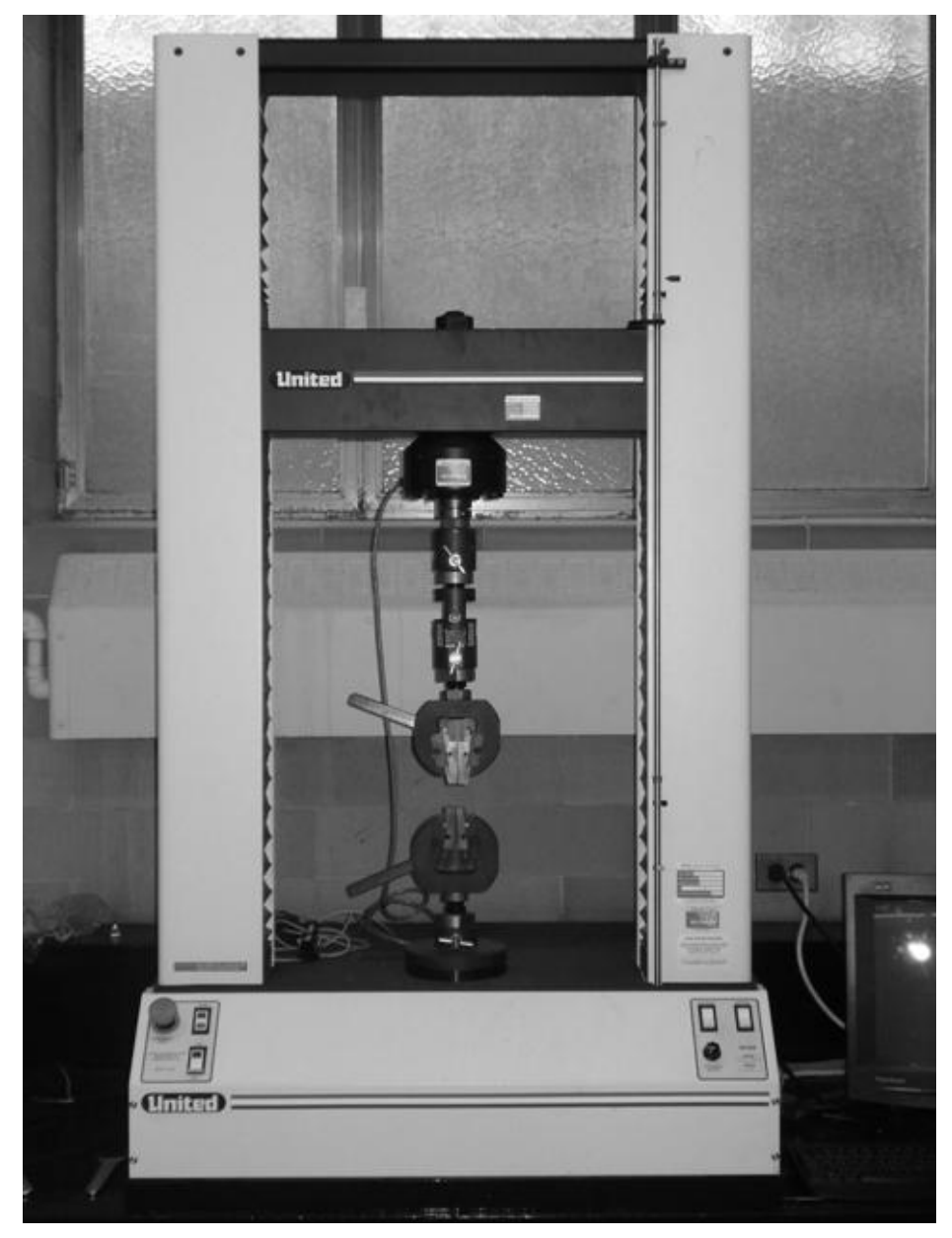

Figure 3.6 A fully-computerized United tensile tester. 


\subsubsection{Fatigue tests}

The fatigue tests were performed using a fully computerized Instron 8801 servo-hydraulic testing system (Fig. 3.7). Load controlled fatigue tests were performed at more than 6 stress amplitudes. At each stress level 2 or more than two samples were used. The stress ratio of R $\left(\sigma_{\min } / \sigma_{\max }\right)$ equal to 0.1 , sinusoidal waveform, and a frequency of $50 \mathrm{~Hz}$ were selected in all the tests which were performed at room temperature. The fatigue fracture surface was examined using SEM/EDS to identify fatigue crack initiation sites and propagation mechanisms.

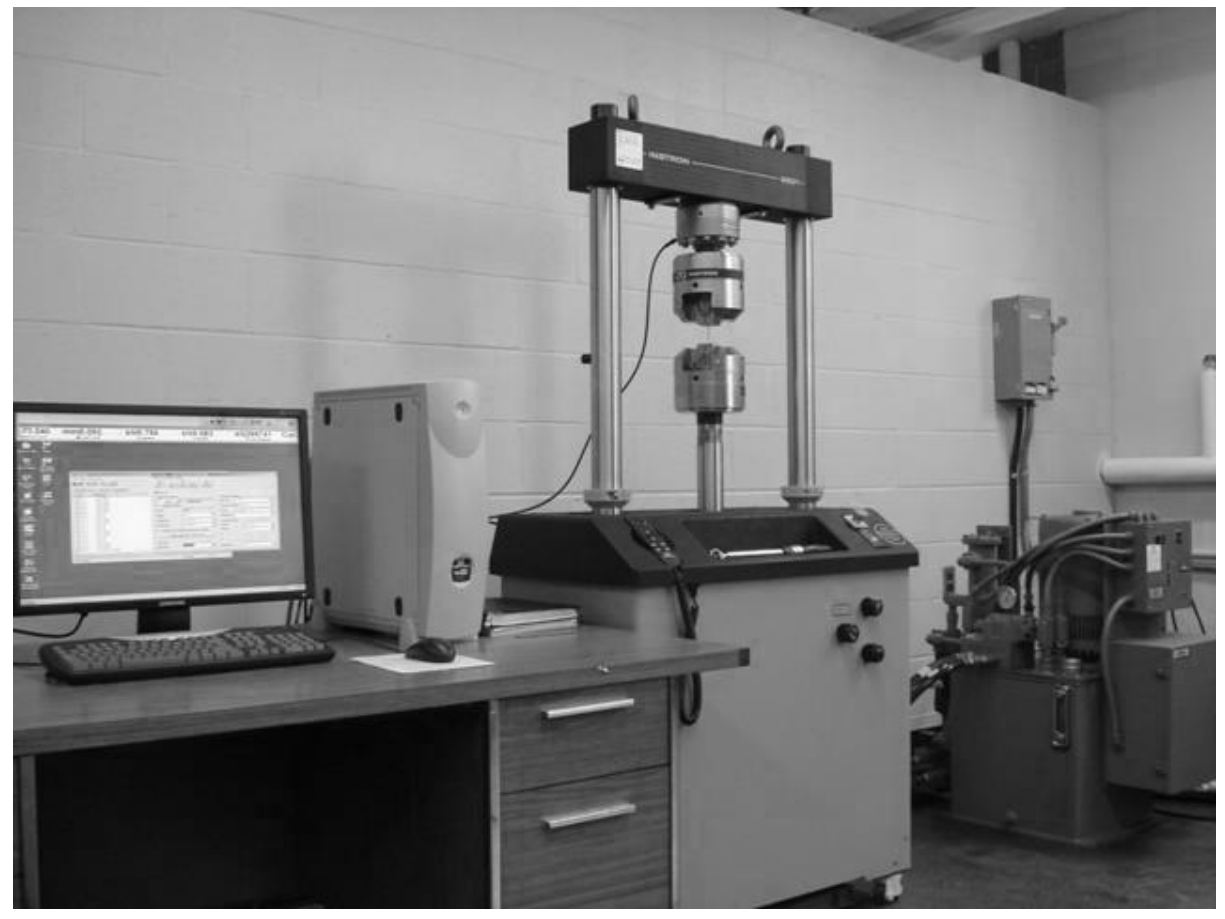

Figure 3.7 A fully-computerized Instron 8801 servo-hydraulic fatigue testing system.

At the beginninig of the test, the value of the maximum applied load, $\mathrm{P}_{\max }$, was selected to be about one third of the tensile strength. The mean load, $\mathrm{P}_{\text {mean, }}$ which was one of the input parameters, can be calculated as follows: 


$$
\begin{gathered}
R=\frac{\sigma_{\min }}{\sigma_{\max }}=0.1, \\
\sigma_{m}=\frac{\sigma_{\text {max }}+\sigma_{\text {min }}}{2}=\left(\frac{1+R}{2}\right) \sigma_{\text {max }}, \\
\sigma_{a}=\frac{\sigma_{\text {max }}-\sigma_{\text {min }}}{2}=\left(\frac{1-R}{2}\right) \sigma_{\text {max }}, \\
\frac{\sigma_{m}}{\sigma_{a}}=\frac{1+R}{1-R}, \\
\sigma_{m}=1.22 \times \sigma_{a}, \\
P_{\text {mean }}=A_{c} \times \sigma_{m},
\end{gathered}
$$

where,

$\sigma_{\min }=$ Minimum stress

$\sigma_{\max }=$ Maximum stress

$\sigma_{m}=$ Mean stress

$\sigma_{\alpha}=$ Stress amplitude

$\boldsymbol{P}_{\text {mean }}=$ Applied mean load

$A_{c}=$ Cross-sectional area of the specimen 


\subsubsection{Post weld heat treatment}

Post weld heat treatment (PWHT) was carried out at four different temperatures $\left(750^{\circ} \mathrm{C}\right.$, $780^{\circ} \mathrm{C}, 810^{\circ} \mathrm{C}$, and $840^{\circ} \mathrm{C}$ ) in an atmosphere-controlled furnace for 15 minutes, followed by water quenching. The heat treatment procedure is shown Fig. 3.8, which is similar to the intercritical annealing followed by rapid cooling used to produce the DP steels $[21,22]$. To ensure the accuracy of heat treatment temperatures, the furnace was calibrated using $\mathrm{K}$ type thermocouple prior to the PWHT. To maintain an oxygen-free environment inside the furnace chamber, disassociated $\mathrm{NH}_{3}$ and natural gas were supplied at a flow rate of $12 \mathrm{CFH}$ (cubic feet per hour) and $1 \mathrm{CFH}$, respectively.

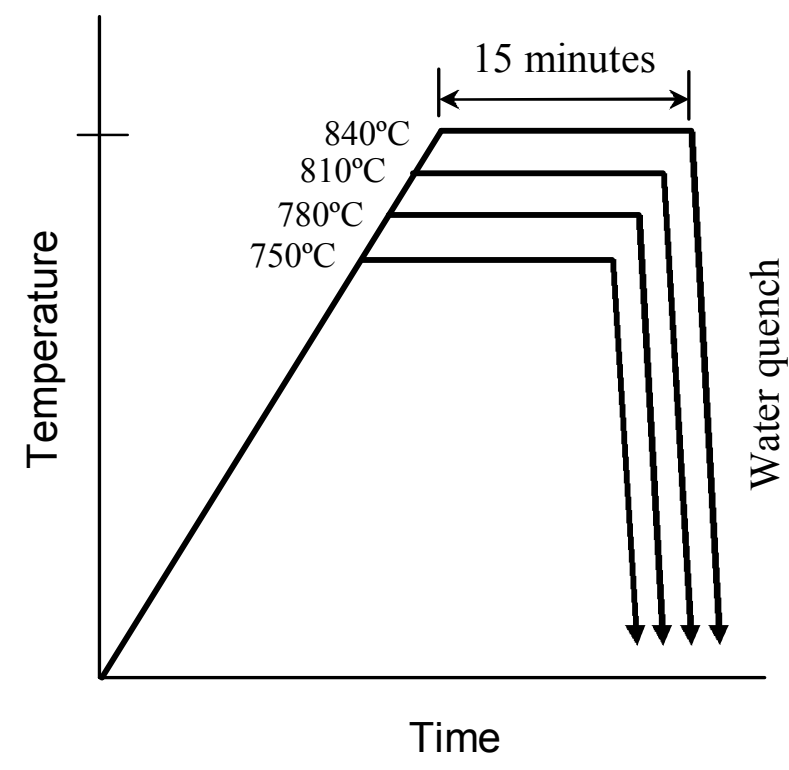

Figure 3.8 Heat treatment procedure applied for the laser welded joints. 


\section{Chapter 4}

\section{Results and Discussion}

This chapter presents the results and relevant discussion on the microstructure and mechanical properties of laser welded DP600 joints, DP980 joints and DP600/DP980 dissimilar joints. The mechanical properties were evaluated by means of microhardness tests, tensile and fatigue tests, including the fracture characteristics and mechanisms of the joints under both monotonic and tensile loading. The last part of this chapter depicts the results on the effect of heat treatment on the microstructure and mechanical properties of DP980 welded joints aimed at eliminating the soft zone.

\subsection{Mechanical properties of laser welded similar DP steel joints}

\subsubsection{Microstructural evolution}

The SEM micrographs shown in Fig. 4.1 represent the microstrauctural evolution that occurred during the welding process. The microstructure of the DP600 base metal can be seen from Fig. 4.1(a) which contained martensite islands in the ferrite matrix. The SEM examination of fusion zone (FZ) of the laser welded DP600 indicated that the microstructure in this zone consisted of predominantly martensite in conjunction with some sideplate ferrite and bainite (Fig. 4.1(b)). The formation of martensite in the FZ resulted from the rapid cooling of the weld pool during laser welding process. The HAZ of the welded joints contained tempered martensite and possibly bainite in the ferrite matrix which can be seen from Fig. 4.1(c). 

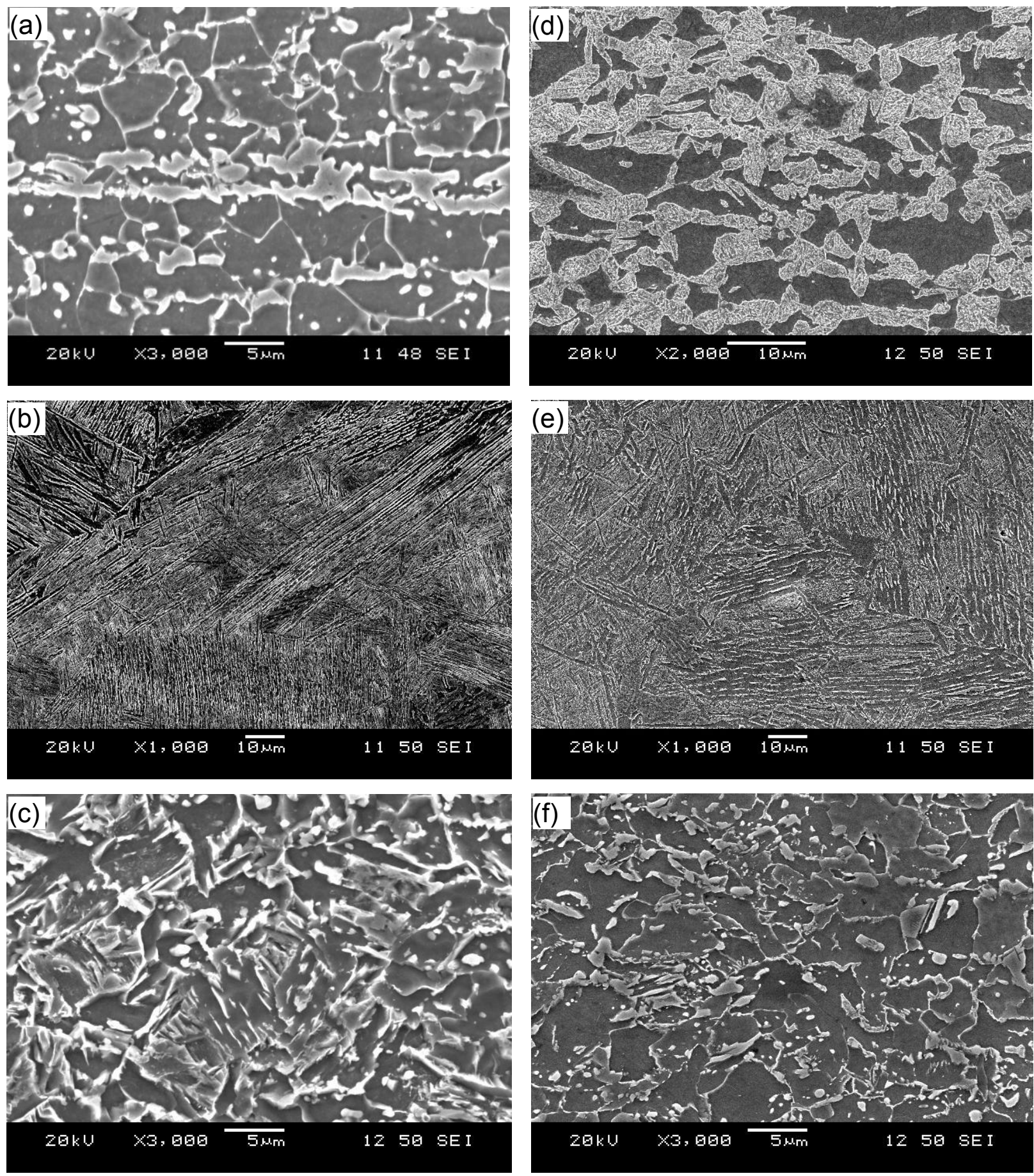

Figure 4.1 SEM micrographs showing the microstructural change of laser welded DP steel joints, (a) DP600 base metal, (b) DP600 fusion zone, (c) DP600 HAZ (soft zone), (d) DP980 base metal, (e) DP980 fusion zone, and (f) DP980 HAZ (soft zone). 
Like the DP600 base metal, the micrograph of DP980 base metal can be characterized by martensitic islands in the ferrite matrix (Fig. 4.1(d)) but the volume fraction of martensite was more compared to DP600.

The image analysis indicated that DP600 steel had a martensitic volume fraction of $25 \%$ while DP980 steel had a martensitic volume fraction of $52 \%$. Predominantly martensitic phase along with bainite and ferrite sideplates were found to be the micro-constituents in the fusion zone of DP980 welded joints which is shown in Fig. 4.1(e). The HAZ of these kinds of joints contains tempered martensite along with some possibly bainites in the ferrite matrix (Fig. 4.1(f)).

\subsubsection{Microhardness profile}

The micro indentation hardness profiles of laser welded DP600 and DP980 steel joints are shown in Fig. 4.2(a) and Fig. 4.2(b), respectively. Significantly higher hardness values, approximately 1.5 times higher than that in the base metal were observed in the case of the welded DP600 joint (Fig. 4.2(a)) due to the formation of mostly martensitic structure (Fig. 4.1(a)). In the case of welded DP980 steel the hardness value in the FZ was seen to be slightly higher than that in the base metal.

As seen in Fig. 4.2, a slight decrease (DP600) and a strong decrease (DP980) in the hardness were present in the HAZ, which were called the soft zone. The presence of the soft zone was mainly due to partial disappearance and tempering of pre-existing martensite $[4,13,15,61]$ which could be seen in Fig. 4.1(c). The degree of softening in the welded DP980 joints was more severe and also the size of the soft zone was larger than the DP600 steel joints. This is due to the disappearance and tempering of more martensite existing in the DP980 steel. 
(a)

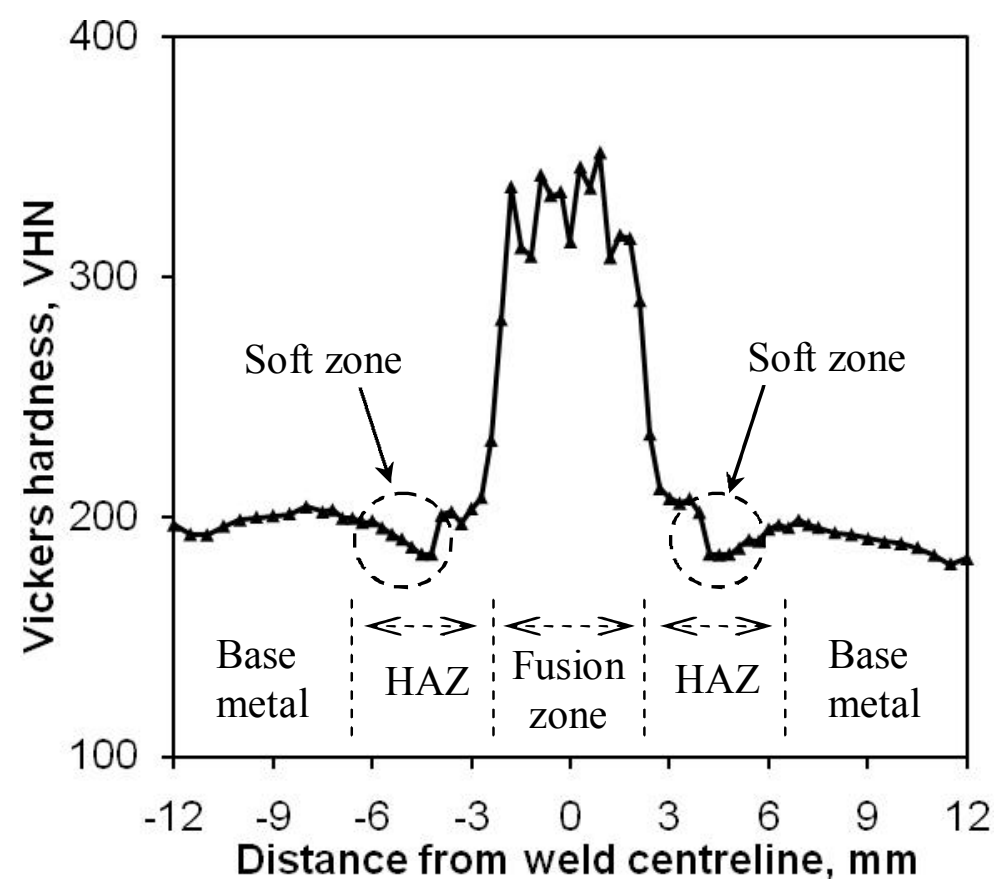

(b)

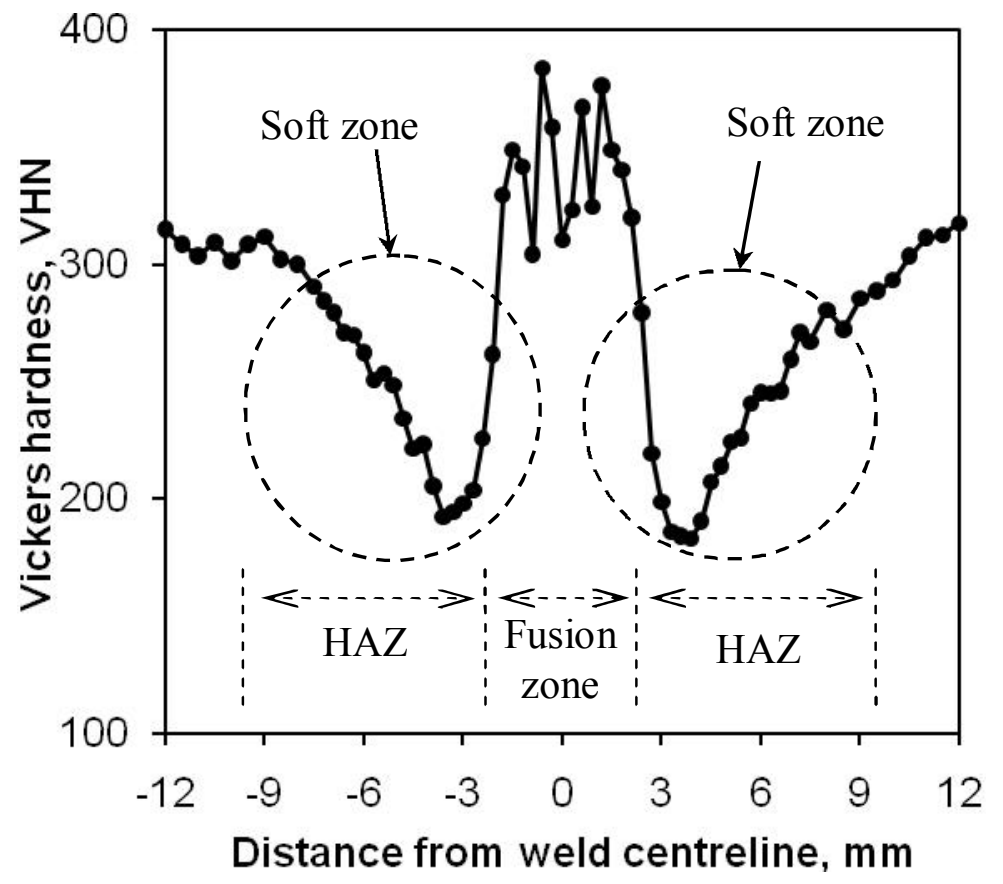

Figure 4.2 Typical microhardness profile of the laser welded (a) DP600 steel joint and (b) DP980 steel joint. 


\subsubsection{Tensile properties of laser welded similar DP steel joints}

Fig. 4.3 shows the engineering stress-strain curves obtained from both the base metals and their respective welded joints. Both of the base metals DP600 and DP980 showed basically smooth and continuous stress-strain curves which could be seen from Fig. 4.3(a) and Fig. 4.3(c). However, the DP600 welded joints exhibited an obvious yield point phenomenon at all the strain rates (Fig. 4.3(b)), while the smooth and continuous plastic flow remained in the DP980 welded joints (Fig. 4.3(d)).
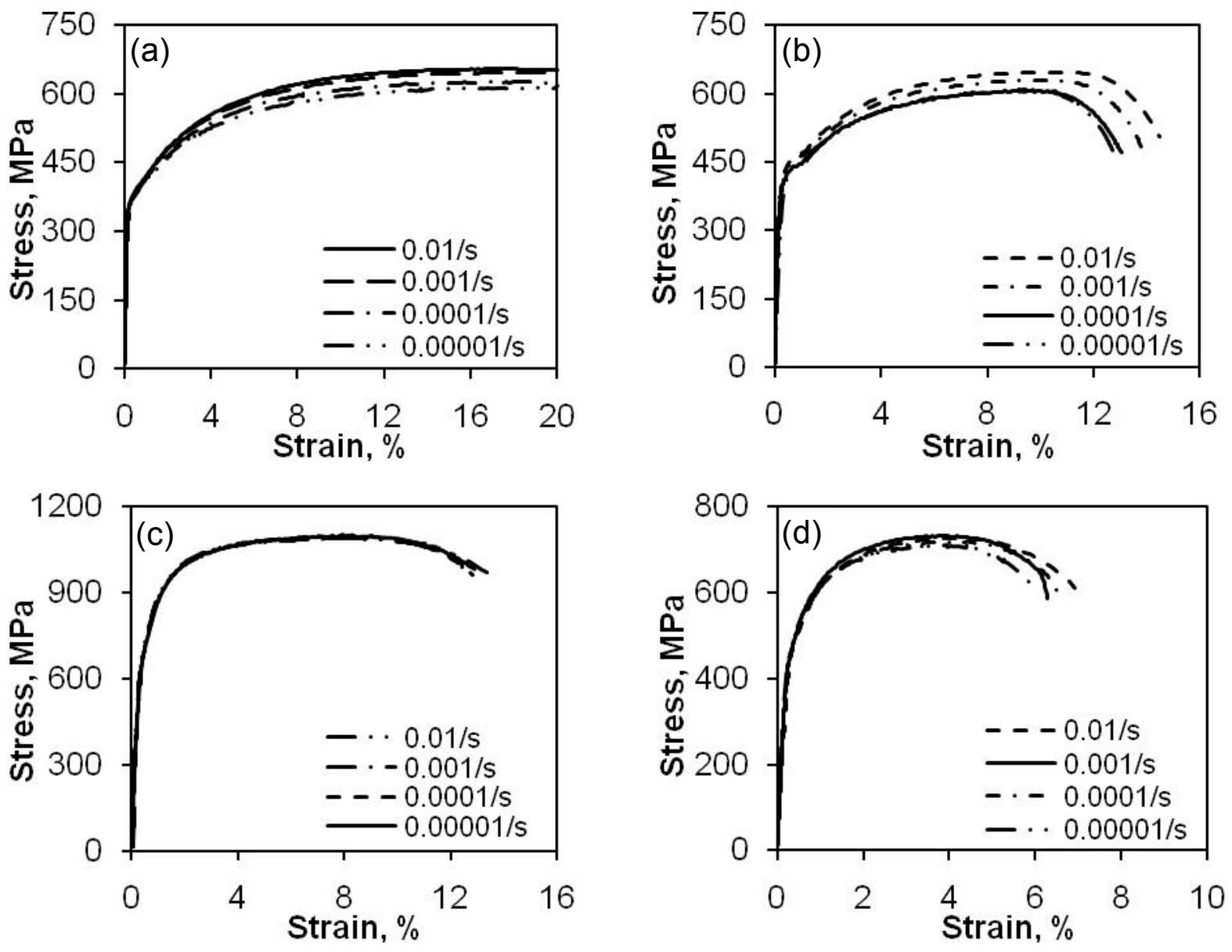

Figure 4.3 Engineering tensile stress-strain curves obtained at different strain rates for (a) DP600 base metal, (b) DP600 welded joint, (c) DP980 base metal, and (d) DP980 welded joint. 
The presence of yield point phenomena in the welded samples was likely due to interstitial diffusion which might occur during the laser welding process. The high temperature generated from laser was high enough to drive the carbon or nitrogen atoms in iron to diffuse to the position of high energy just below the extra plane of atoms in a positive edge dislocation. The strong elastic interaction alleviated the impurity atmosphere to become completely saturated and condense into a row of atoms along the core of the dislocation. When such a sample with dislocations pinned by interstitials (i.e., the welded samples in this study) was loaded, a higher stress was required to start the dislocation movement representing the onset of plastic deformation. Once the dislocation line was pulled free from the influence of the solute atoms, slip occurred at a lower stress exhibiting yield point phenomena as seen in Fig. 4.3(b) [62-64].

\subsubsection{Effect of welding on the tensile properties}

The effect of laser welding on the yield strength of the material can be seen from Fig. 4.4(a). DP600 welded joints were observed to have higher yield strength than the base metal due to the presence of yield point phenomena, whereas DP980 welded joints had lower yield strength compared to the DP980 base metal. The absence of yield point phenomena and the presence of more tempered martensite in the HAZ, in conjunction with the partial disappearance of existing martensite resulted in a reduction in the yield strength of DP980 welded joints. The ultimate tensile strength (UTS) of DP600 welded joints was observed to be only marginally lower than that of the base metal, whereas the welding led to a significant reduction in the UTS in the DP980 welded joints (Fig. 4.4(b)). The tensile strength of steel is usually related to its hardness. As the degree of softening was very small in the DP600 welded joints (Fig. 4.2(a)), the reduction

of the UTS was also hardly visible, but in the case of DP980 welded joints the degree of 
softening in the HAZ was significant (about $130 \mathrm{VHN}$ ) which eventually resulted in a lower tensile strength in the DP980 welded joints. The strength obtained for both the welded joints in this study was in good agreement with that reported in the literature [11,15,31] (Fig. 4.4 (b)), in spite of some differences in the welding parameters in different publications.

In all the cases both the YS and UTS showed only weak strain rate sensitivity with the strength increasing by a very small amount with increasing strain rate. At higher strain rates the dislocation movement was delayed which resulted in an increased YS and UTS. Similar kind of increasing trend with increasing strain rate was also reported by Huh et al. [35] and Samuel [46] for DP steels. From Fig. 4.4(c) it can be seen that the DP600 base metal was much more ductile than the DP980 base metal. This was due to the increased martensitic volume fraction in the DP980 steel compared to DP600 steel, as mentioned above. Welding led to a reduction in the elongation of both steels, as seen in Fig. 4.4(c).

\subsubsection{Work hardening behavior of laser welded similar DP steel joints}

Fig. 4.5 shows a Kocks-Mecking type plot [65] of strain hardening rate $\theta(=d \sigma / d \varepsilon)$ vs. net flow stress $\left(\sigma-\sigma_{y}\right)$ at a strain rate of $1 \times 10^{-2} \mathrm{~s}^{-1}$. Initially DP600 base metal and welded joints showed a similar sort of trend - stage III hardening (Fig. 4.5(a)), i.e., $\theta$ decreased almost linearly with increasing net flow stress. When the net flow stress exceeded about $240 \mathrm{MPa}$ the base metal of DP600 steel showed stage IV work hardening behavior despite the small change of the $\theta$ value, but it was absent in the DP600 welded joints. Unlike DP600 base metal, DP980 base metal showed a clear stage II work hardening by maintaining almost constant work hardening rate up to a net flow stress of about $120 \mathrm{MPa}$ (Fig. 4.5(b)). Then a linear decraese with increasing 
(a)

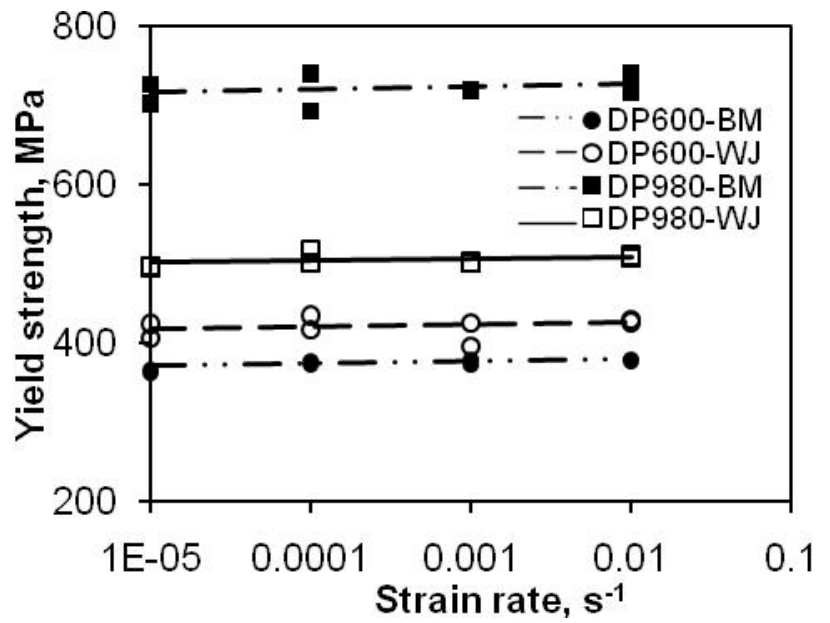

(b)

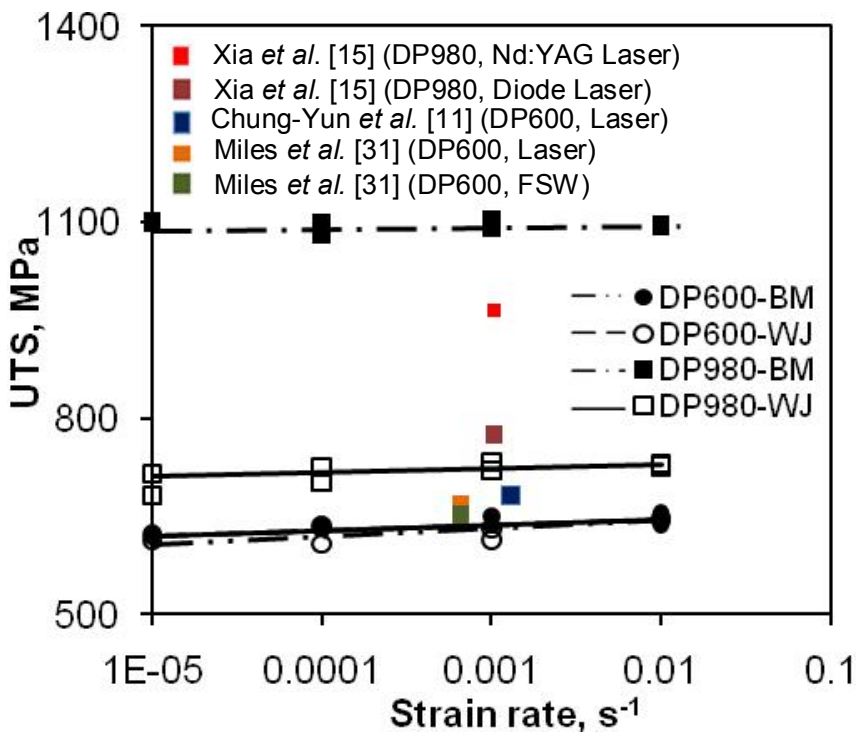

(c)

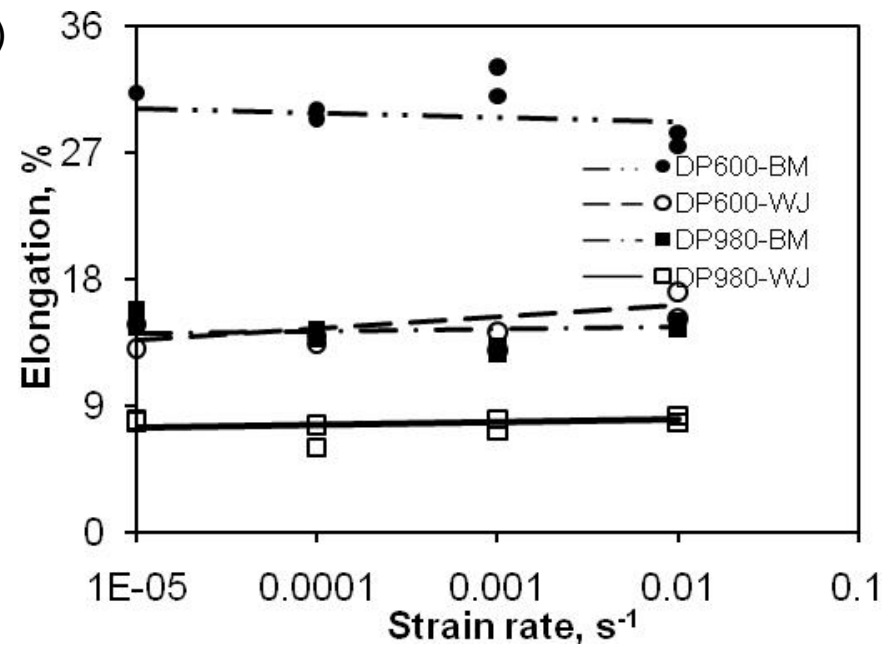

Figure 4.4 Effect of laser welding on (a) yield strength, (b) ultimate tensile strength (UTS), and (c) ductility of the DP steels tested at different strain rates. 
net flow stress (i.e., stage III hardening) occurred until the onset of stage IV hardening at a net flow stress of approximately $260 \mathrm{MPa}$. The occurrence of stage IV hardening in both DP980 and DP600 base steels was in agreement with the observation reported in the literature [65], where it was reported that stage IV hardening typically appeared in two phase alloys. Again, like the DP600 welded joints, only stage III hardening occurred in the DP980 welded joints Fig. 4.5(b). The three stages of work hardening behavior could be understood as follows: In stage II the constant work hardening rate was due to the deformation of constrained ferrite with possible transformation of retained autenite to martensite $[21,37,40]$. The linear decrease of work hardening rate in stage III arose from simultaneous deformation of ferrite and martensite with attendant cross-slip of dislocations and dynamic recovery of ferrite $[21,37,40]$. In stage IV the low work hardening rate originated from increased dislocation mobility via profuse cross-slip [66].

After yielding the stress-strain relationship in the uniform deformation stage could be expressed by Hollomon equation [48],

$$
\sigma=K \varepsilon^{n}
$$

where $\sigma$ is the true stress, $\varepsilon$ is the true strain, $n$ is the strain hardening exponent and $K$ is the strength coefficient. The evaluated $n$ values following Eqn. 4.1 as a function of strain rate are shown in Fig. 4.6(a) . It is seen that DP600 base metal possesed a higher work hardening exponent than the DP980 base metal. The stronger deformation ability in the DP600 base metal was attributed to the presence of a larger amount of deformable ferrite in the material. With increasing volume farction of martensite in a dual-phase steel the value of $n$ usually decreases [21]. 
(a)

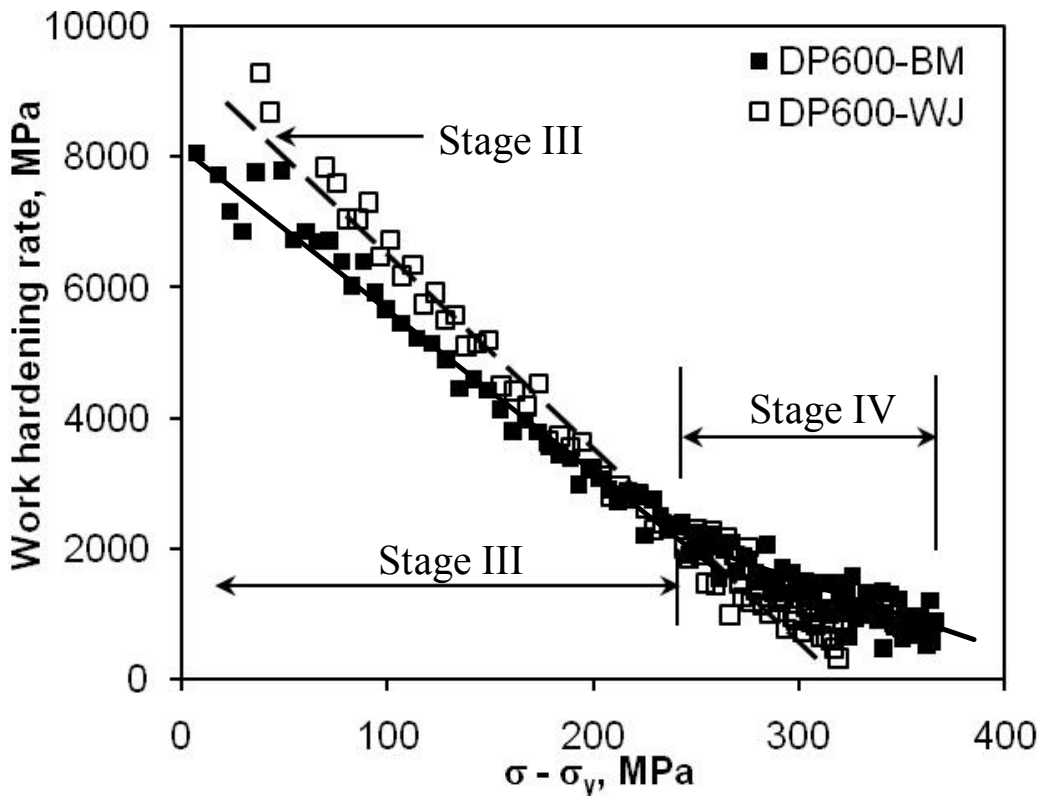

(b)

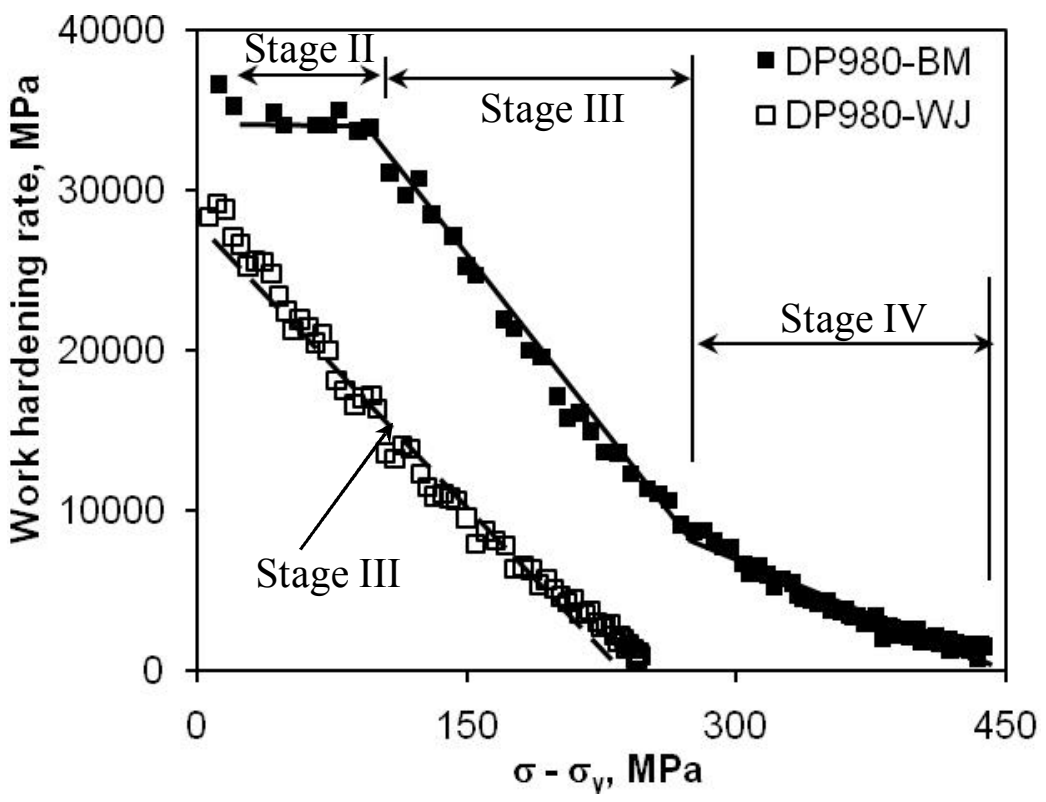

Figure 4.5 Work hardening rate vs. net flow stress at a strain rate of $1 \times 10^{-2} \mathrm{~s}^{-1}$ for (a) DP600 base metal and welded joint and (b) DP980 base metal and welded joint.

After welding, the DP600 welded joints showed a lower work hardening exponent compared to the DP600 base metal. However, the DP980 welded joints had a slightly higher value of $n$ than the DP980 base metal. This might be related to the appreciable softness in the 
HAZ (Fig.4.2(b)), which would give rise to a higher dislocation storage or hardening capacity. The higher the value of $n$, the higher the material could be deformed before instability [62]. This could be seen in Fig. 4.4(c) and Fig. 4.6(a), where a higher $n$ value corresponded to a better ductility in the DP600 steel. In all cases the value of $n$ showed only a weak strain rate dependence, i.e., it increased slightly with increasing strain rate.

To qualify better the strain hardening response, the differential Crussard-Jaoul analysis $[49,50]$ of the work hardening exponent was used, which was based on the following Ludwik relation [51],

$$
\sigma=\sigma_{y}+K_{1} \varepsilon^{n_{1}}
$$

where $\sigma_{y}$ is the yield stress, $n_{l}$ is the strain hardening exponent and $K_{l}$ is the strength coefficient which reperesents the increment in strength due to strain hardening at $\varepsilon=1$. The evaluation of strain hardening exponent based upon this equation excludes the yield strength. Fig. 4.6(b) shows the strain hardening exponent $n_{l}$ versus the strain rate for both the base metals and the welded joints. Due to the exclusion of the yield stress in this analysis the work hardening exponents of both the welded joints were seen to become higher than those of the respective base metals.

In the present study the work hardening exponent was also evaluated according to the following equation proposed by Afrin et al. [67],

$$
\sigma-\sigma_{y}=K^{*}\left(\varepsilon-\varepsilon_{y}\right)^{n^{*}}
$$

where $n^{*}, \sigma, \varepsilon, \sigma_{y}$ and $\varepsilon_{y}$ are the strain hardening exponent, true stress, true strain, yield strength, and yield strain of a material, respectively. $K^{*}$ is the strength coefficient which reflects the increment in strength due to strain hardening corresponding to $\left(\varepsilon-\varepsilon_{y}\right)=1$. 

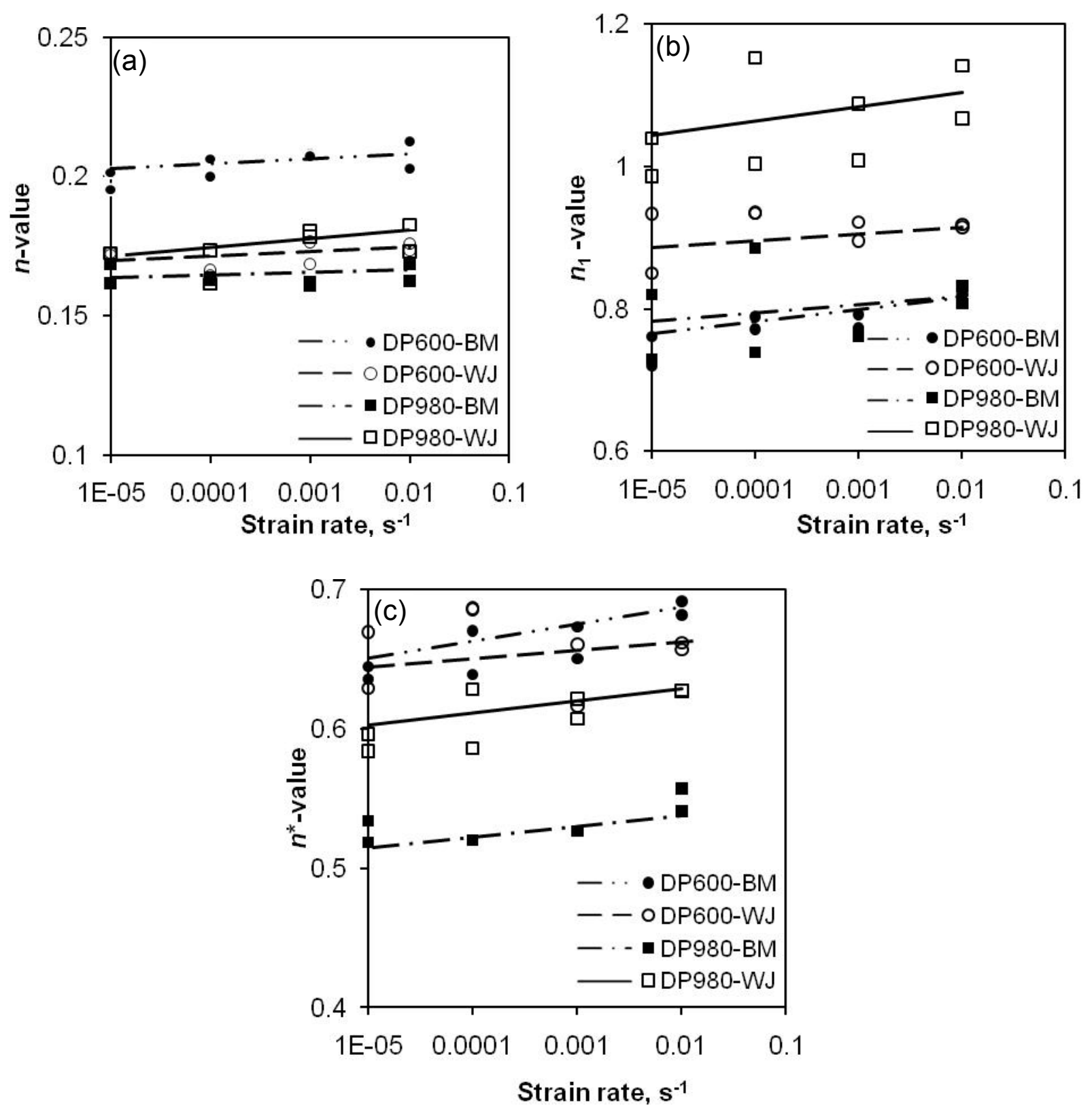

Figure 4.6 Work hardening exponents obtained at different strain rates for the DP base metals and welded joints, evaluated according to (a) Hollomon equation [48], (b) Jaoul-Crussard analysis [49-50] and (c) equation proposed by Afrin et al. [67].

Equ. (4.3) represented the exclusion of both yield stress and yield strain. That is, this relationship reflected a relationship between net flow stress vs. plastic strain in the plastic 
deformation in which the elastic deformation stage was no longer included in the evaluation of the strain hardening exponent [67]. The strain hardening expoent $n^{*}$ evaluated in terms of Equ. (4.3) is shown in Fig. 4.6(c). It is seen that in all cases the values of the work hardening exponents were observed to increase with increasing strain rate to a certain extent . Higher strain rates would lead to a stronger restriction to the dislocation motion which in turn increased the work hardening of a material, since the higher strain rate was observed to generate a dislocation morphology with a greater number of tangles in the cell walls and the more refined cell size contributed to stronger work hardening [68].

\subsubsection{Tensile failure location and fractography}

All the welded samples failed in the HAZ with an example shown in Fig. 4.7 for a welded DP600 tensile sample. Careful observation during the tensile tests showed that the onset of yielding occurred in the softened zone and then the majority of the plastic deformation was accumulated in that zone (i.e., in the HAZ) until final failure.

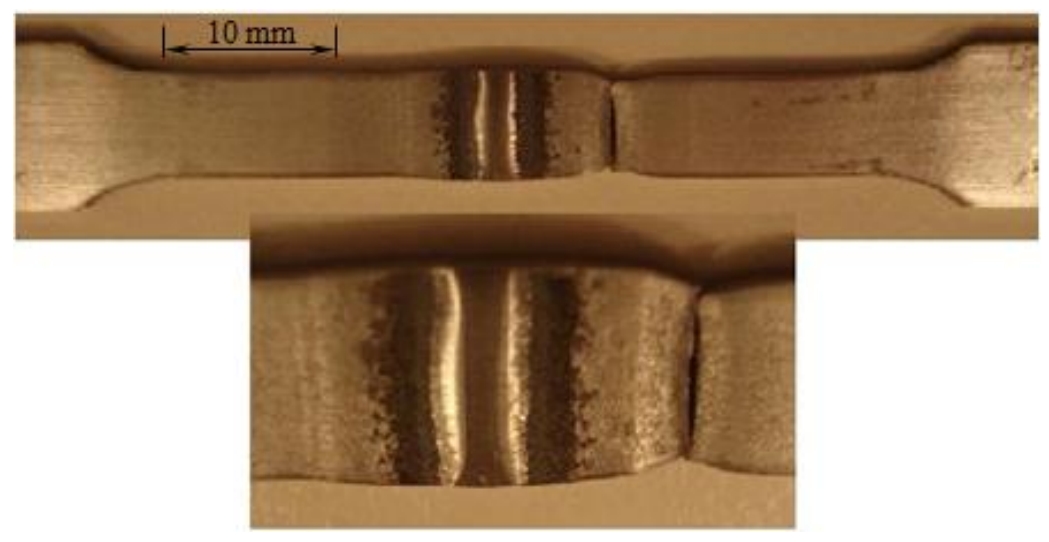

Figure 4.7 Failure location of a typical tensile test sample for the laser welded DP980 steel joint. 
The fracture surface characteristics were basically similar in both the base metals and their welded joints. Ductile type of failure mode was represented by cup-like dimple rupture which was the main feature of the fracture surface. Typical SEM micrographs of the fracture surface of the welded samples are shown in Fig. 4.8, where the center and the edge of DP600 welded samples were shown in Fig. 4.8(a) and Fig. 4.8(b) and the similar location of the fracture surface of DP980 welded samples were illustrated in Fig. 4.8(c) and Fig. 4.8(d), respectively.
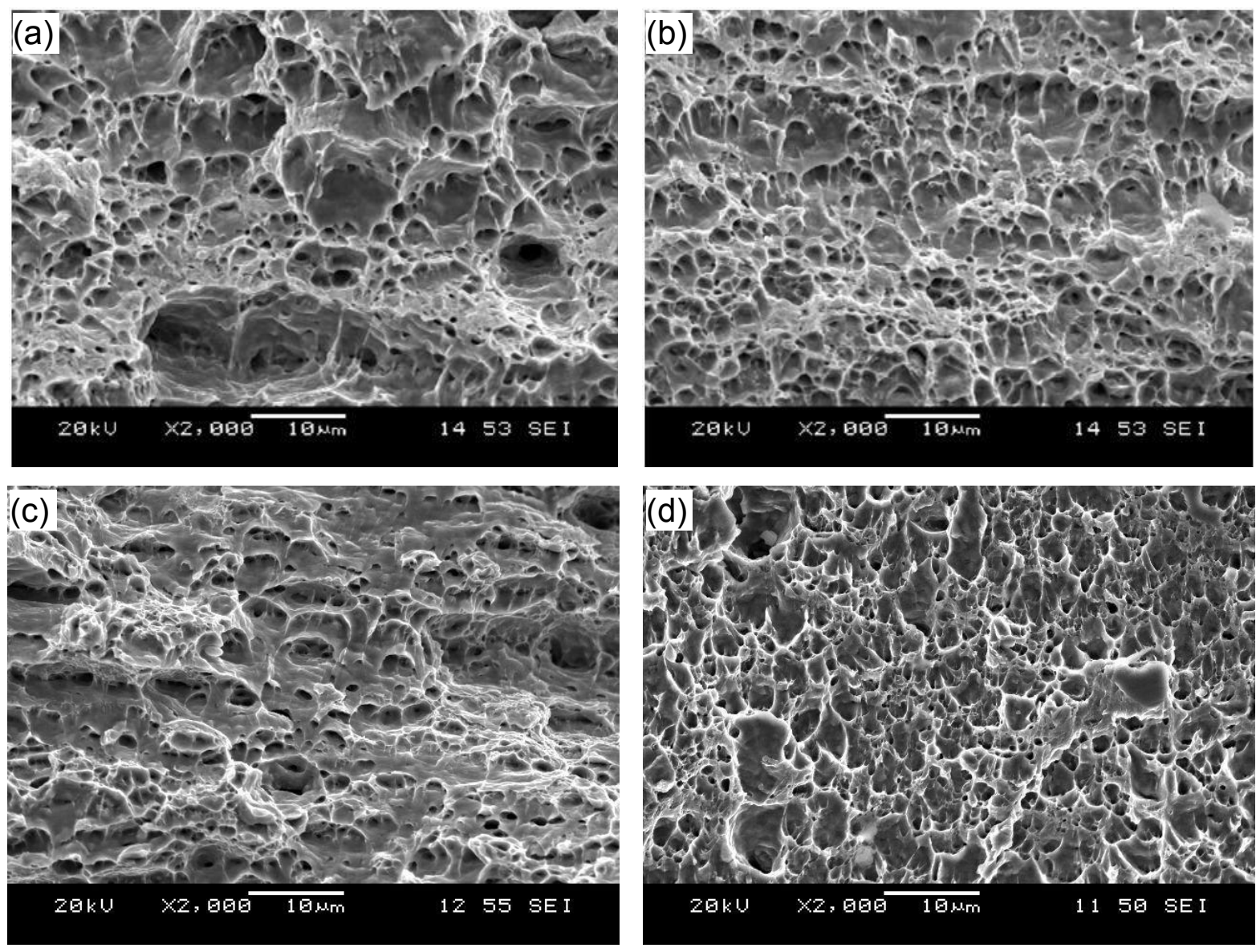

Figure 4.8 Typical SEM micrographs of tensile fracture surfaces of the welded joints tested at a strain rate of $1 \times 10^{-2} \mathrm{~s}^{-1}$, (a) center of DP600 welded joint, (b) near-edge area of DP600 welded joint, (c) center of DP980 welded joint and (d) near-edge area of DP980 welded joint. 
(a)

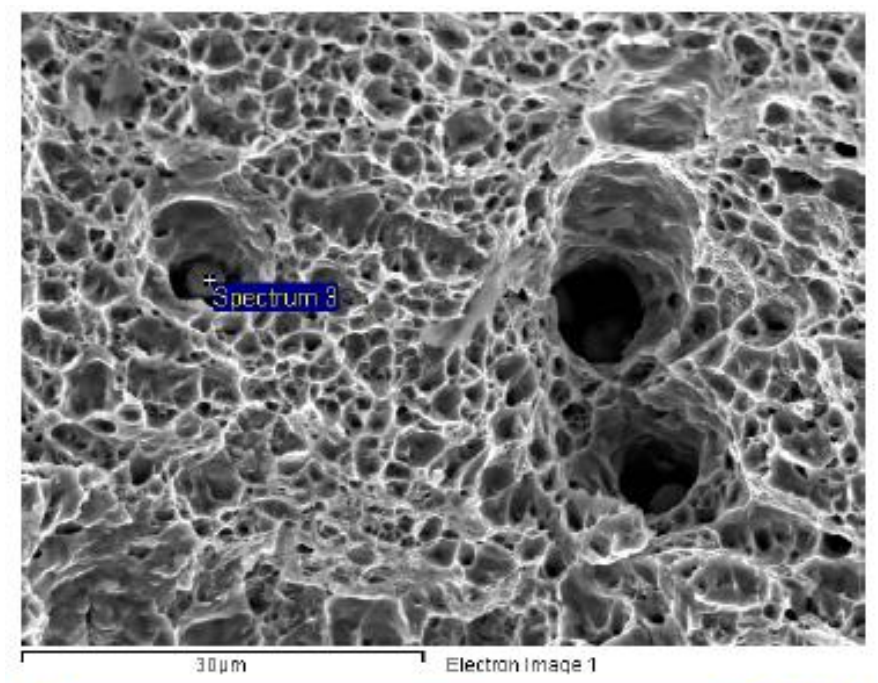

(b)

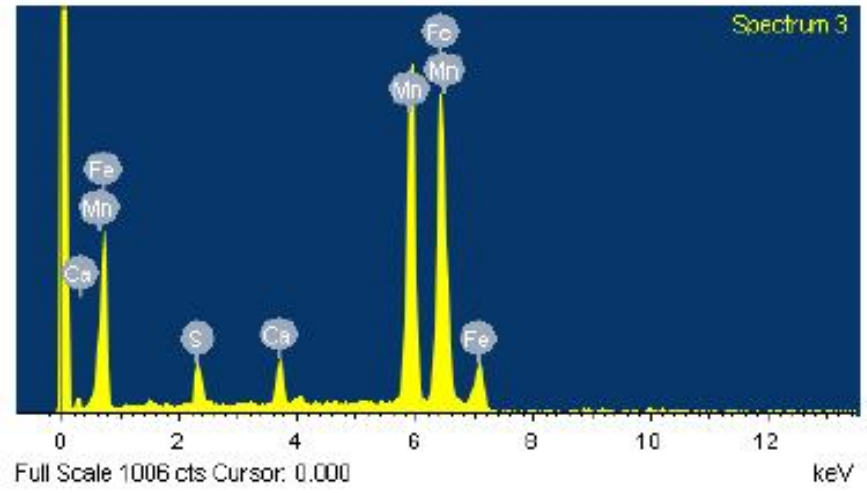

Figure 4.9 EDS analysis of particles in the dimples on the fracture surface of a laser welded

DP980 steel joint, (a) a SEM image with larger and deeper dimples, and (b) EDS spectrum.

The fracture surface at the center (Fig. 4.8(a) \& 4.8(c)) contained basically equiaxed dimples indicating typical ductile fracture caused by simple tensile loading. However, careful observations of these two SEM images indicated that the size of the dimples on the fracture surface of the DP600 welded joints (Fig. 4.8(a)) was larger than that of the DP980 welded joints (Fig. 4.8(c)). This was due to the fact that the DP600 welded joints contained more deformable ferrite and exhibited a larger elongation than the DP980 welded joints (Fig. 4.4(c)). The fracture surface near the edge (Fig. 4.8(b) and (d)) showed a combination of both equiaxed and shear dimples as it had a network of dimpled impressions of equiaxed appearance along with dimples 
having an elongated parabolic shape indicating the occurrence of shearing motion in conjunction with the simple tensile load. The fracture surface of the welded joints was observed to have some deeper dimples. Energy dispersive X-ray spectroscopic point analysis indicated the presence of manganese-containing particles residing in the deep dimples, as shown in Fig. 4.9. While the DP980 steel had less manganese content than the DP600 steel (Table 3.1), the higher carbon content would promote to generate more carbide during welding [69], which might also be another factor contributing to the lower elongation of the DP980 welded joints (Fig. 4.4(c)).

\subsubsection{Fatigue behavior of laser welded similar DP steel joints}

\subsubsection{Fatigue properties}

The S-N curves obtained from the load control fatigue tests are shown in Fig. 4.10. The DP600 welded joints were found to have a slightly lower fatigue limit than that of the base metal. Indeed the DP600 base metal and the welded joints showed almost the same fatigue life within the experimental scatter at higher stress amplitudes.

This indicated that for the DP600 welded joints the slight drop in the hardness (Fig. 4.2(a)) in the HAZ was not large enough to reduce the fatigue strength at higher stress amplitudes, and thus the effect of laser welding on the fatigue resistance of DP600 steel could be negligible. On the other hand, DP980 welded joints showed a lower fatigue life than the DP980 base metal at both higher and lower stress amplitude levels. This corresponded well to the effect of the severe soft zone with a significant reduction in the hardness (Fig. 4.2(b)). Due to this significant softening in the HAZ the DP980 welded joints showed a considerably ( 100 MPa) lower fatigue limit than the DP980 base metal. 


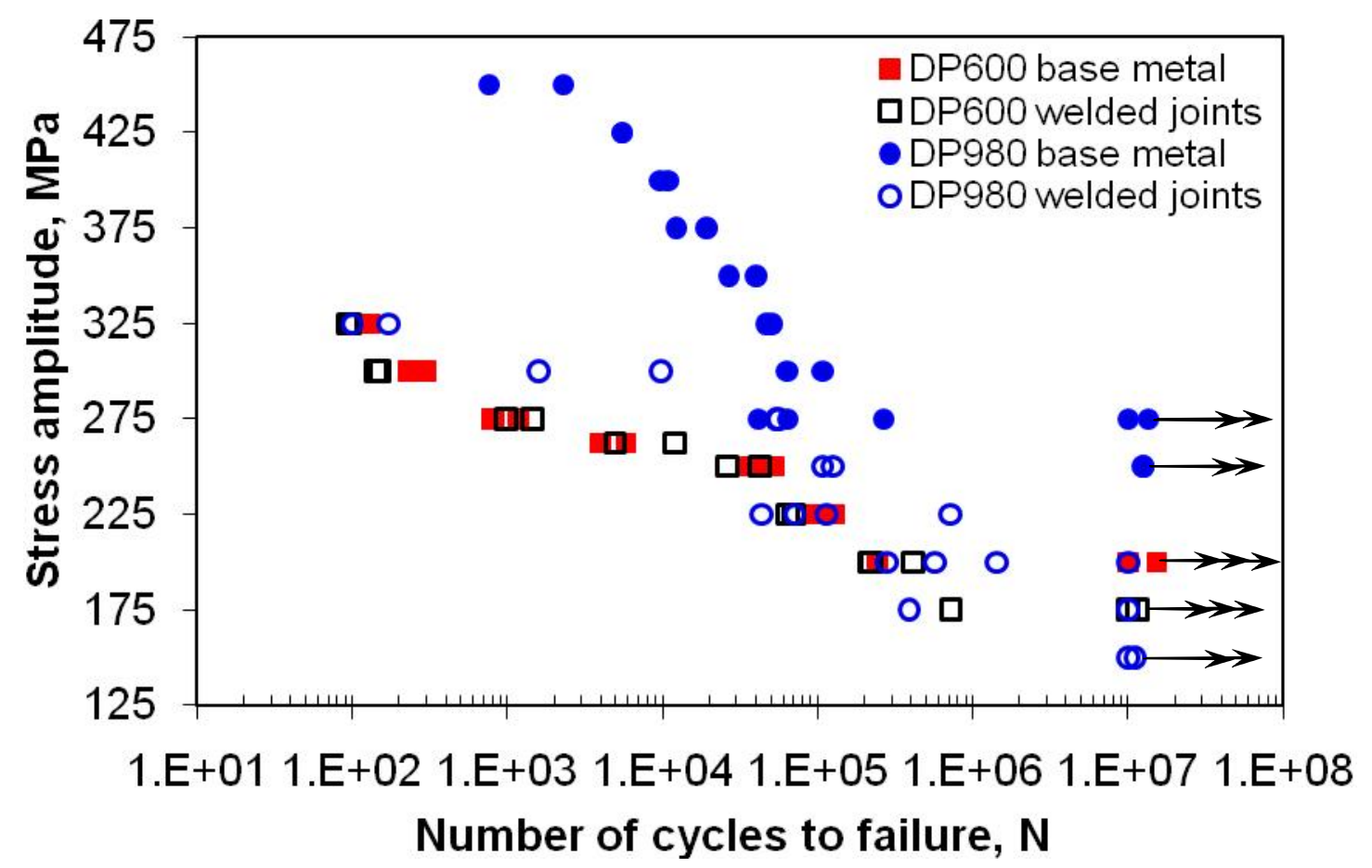

Figure 4.10 S-N curves obtained for the base metals and laser welded joints of DP600 and DP980 steels tested at $\mathrm{R}=0.1,50 \mathrm{~Hz}$ and room temperature where the data points with arrow marks indicate the run-out samples.

It should be noted that the softening in the DP980 welded joints was so severe that the lowest hardness in the soft zone was even slightly lower than that of DP600 welded joints (Fig. 4.2(a) and (b)), which also resembled to the findings from the fatigue tests (Fig. 4.10) where the DP980 welded joints showed even a fatigue limit lower than that of the DP600 welded joints. However, even though the negative effect of the soft zone on the fatigue resistance of the DP980 welded joints in comparison with the DP980 base metal was large, the fatigue life of the DP980 welded joints was basically longer than that of both the DP600 welded joints and DP600 base metal at the higher stress amplitudes (Fig. 4.10). 
The obtained fatigue limit and fatigue ratio are tabulated in Table 4.1. The fatigue limit of the DP600 welded joints was $12.5 \%$ lower than that of the base metal, whereas the DP980 welded joints showed a $40 \%$ reduction in the fatigue limit compared to the base metal. The fatigue ratio of the DP600 welded joints and DP980 welded joints was obtained to be 0.28 and 0.21, respectively. All these results suggested that although the presence of the severe soft zone in the DP980 welded joints showed a detrimental effect, the mild soft zone present in the DP600 welded joints only exhibited a minor effect on the fatigue strength after laser welding.

Table 4.1 Fatigue limit and fatigue ratio of the base metals and laser welded joints of DP600 and DP980 steels tested at $\mathrm{R}=0.1,50 \mathrm{~Hz}$ and room temperature.

\begin{tabular}{llll}
\hline Material type & $\begin{array}{l}\text { Fatigue limit } \\
(\mathrm{MPa})\end{array}$ & $\begin{array}{l}\text { Ultimate tensile } \\
\text { strength }(\mathrm{MPa})\end{array}$ & $\begin{array}{l}\text { Fatigue } \\
\text { ratio }\end{array}$ \\
\hline DP600 base metal & 200 & 634 & 0.32 \\
DP600 welded joints & 175 & 630 & 0.28 \\
DP980 base metal & 250 & 1095 & 0.23 \\
DP980 welded joints & 150 & 724 & 0.21 \\
\hline
\end{tabular}

The obtained fatigue data plotted in Fig. 4.10 may be further fitted using the following Basquin type equation,

$$
\sigma_{a}=\sigma_{f}^{\prime}(2 N)^{b}
$$

where $\sigma_{a}$ is the stress amplitude, $\sigma_{f}^{\prime}$ is the fatigue strength coefficient defined by the stress intercept at $2 \mathrm{~N}=1, \mathrm{~N}$ is the number of cycle to failure and $\mathrm{b}$ is the fatigue strength exponent. The obtained values of $\sigma_{f}^{\prime}$ and $b$ of the base metals and laser welded joints of DP600 and DP980 steels tested at $\mathrm{R}=0.1,50 \mathrm{~Hz}$ and room temperature are given in Table 4.2. Apparently the 
fatigue life at a given stress amplitude was dependent on both fatigue strength coefficient $\sigma_{f}^{\prime}$ and fatigue strength exponent $b$.

Table 4.2 Fatigue parameters $\sigma_{f}^{\prime}$ and $b$ for the base metals and laser welded joints of DP600 and DP980 steels tested at $\mathrm{R}=0.1,50 \mathrm{~Hz}$ and room temperature.

\begin{tabular}{lcc}
\hline Material type & $\sigma_{f}(\mathrm{MPa})$ & $\mathrm{b}$ \\
\hline DP600 base metal & 415 & -0.049 \\
DP600 welded joints & 435 & -0.057 \\
DP980 base metal & 1019 & -0.098 \\
DP980 welded joints & 472 & -0.057 \\
\hline
\end{tabular}

\subsubsection{Fatigue failure location and mechanism}

In all cases of fatigue tests the DP980 welded joints failed in the soft zone/HAZ, regardless of the stress amplitudes applied. Unlike the DP980 welded joints, the DP600 welded joints failed in the HAZ at the stress amplitudes above $250 \mathrm{MPa}$, but failed far away from the weld centerline or FZ at the stress amplitudes below $250 \mathrm{MPa}$. These results corresponded to the presence of an inflection point on the S-N curves at a stress amplitude of about $250 \mathrm{MPa}$ in both the DP600 welded joint and respective base metal, as shown in Fig.4.10. The failure location of the welded samples tested at two different ranges of stress amplitudes can be seen in Fig. 4.11. The possible reason for this effect would be related to cyclic strengthening mechanisms involving deformation-induced martensite transformation [70-75]. 

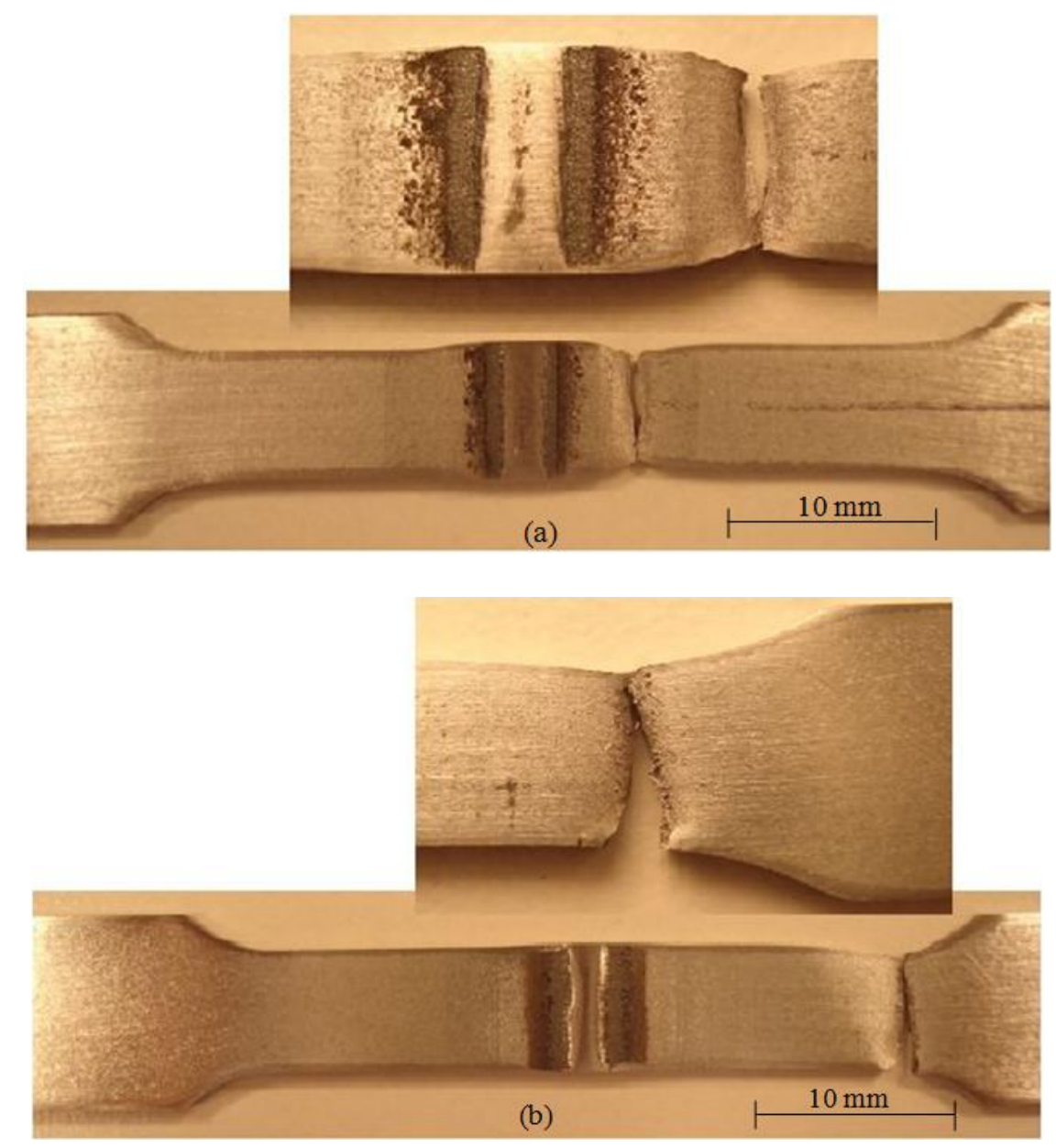

Figure 4.11 Typical fatigue failure location of the DP600 welded samples tested at a stress amplitude of (a) above $250 \mathrm{MPa}$, and (b) below $250 \mathrm{MPa}$.

The DP steel contained a small amount of retained austenite in its microstructure; during cyclic loading the retained austenite transformed to martensite and gave additional strengthening effect in the steel. These martensitic particles were considered to further pin the dislocations and dominate the cyclic deformation [76]. In the LCF region where the samples were tested at a higher stress amplitude the dislocations could overcome the martensite barriers as the applied stress magnitude surpassed the pinning force created by martensite, resulting in more cumulative damage in the gauge section of the test samples. This phenomenon would be the reason why at 
the higher level of stress amplitudes the failure occurred in the gauge section for both base metal and welded joints. More specifically for the welded samples fatigue failure occurred at the outer HAZ due to the lower hardness (Fig 4.2(a)). But in the HCF region where the sample lasted for a longer period of time at a lower level of stress amplitudes, the applied stress could not overcome the pinning force created by the martensite interacting with the dislocations. The area near the end of the gauge section became the weakest area due to potential stress concentration caused by the notch effect. Generally, the notch effect was reported to be stronger in the longer-life HCF region compared to the shorter-life LCF region [77]. In contrast, in the case of DP980 welded joints the hardness reduction in the HAZ was so severe compared with the base metal (Fig. 4.2(b)) that the role of the deformation induced martensitic transformation would be masked. As a result, the soft zone in the HAZ directly represented the location of fatigue failure at all stress amplitudes for DP980 welded joints.

\subsubsection{Fractographic analysis of fatigue fracture}

The fractographic examinations of the fracture surfaces revealed that fatigue crack initiation occurred from the specimen surface (Fig. 4.12(a) and (b)). If there was no severe defects existent inside the material, fatigue crack initiation normally occurred from the specimen surface since the surface was usually less constrained than the interior grains [78]. The back and forth fine slip movement during cyclic loading built up notches or ridges at the surface (i.e., extrusions and intrusions) [64]. These kinds of notches with a notch root of atomic dimension could act as a stress raiser and might act as the nucleation site of the fatigue crack. The fatigue crack could also result from the surface roughness. 

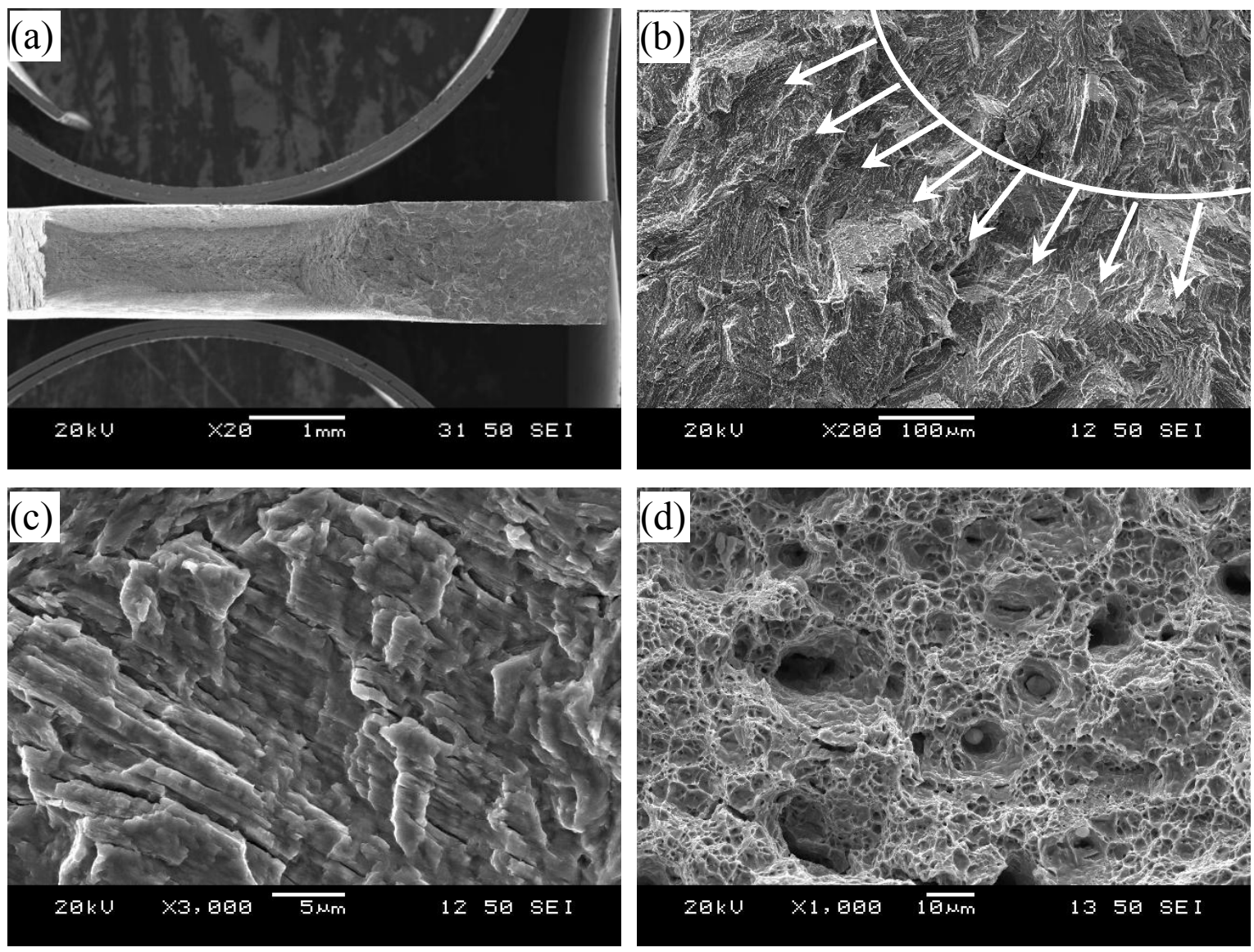

Figure 4.12 Fatigue fracture surface of a DP980 welded joint tested at a stress amplitude of $225 \mathrm{MPa}$, (a) Overall view of the fracture surface at a low magnification, (b) crack initiation site, (c) crack propagation area, and (d) fast fracture area.

The samples tested at lower stress amplitudes showed the crack initiation from the surface along with a larger crack propagation area on the fracture surfaces. The crack propagation was mainly characterized by typical fatigue striations in conjunction with secondary cracks (Fig. 4.12(c)). These striations, usually perpendicular to the propagation direction, occurred by a repeated plastic blunting-sharpening process due to the slip of dislocations in the plastic zone at the fatigue crack tip $[64,79]$. The spacing between these striations was smaller near the crack initiation site and became larger with increasing distance from the crack initiation site since the 
striation spacing was associated with fatigue crack propagation rate. The faster crack propagation at the center of the left part of fracture surface in Fig. 4.12(a) was characterized by characteristic dimple rupture (Fig. 4.12(d)), representing typical ductile type of fracture mode. The slightly elongated oval shaped dimples due to shear motion were the primary feature near the edge of the fracture surface representing final rapid failure of the sample.

Both the base metal and their respective welded samples had basically similar fracture surface characteristics. However, the DP600 base metals and their welded joints tested at or below a stress amplitude of $250 \mathrm{MPa}$ showed some deformation bands situated away from the crack initiation site shown in Fig. 4.13(a) and (b). The formation of the deformation bands was mainly due to the inhomogeneous deformation, caused by the presence of crystallographic texture in the rolled plate $[80,81]$. Further studies on the effect of texture on fatigue fracture mechanisms in the welded DP600 steel joints are needed.
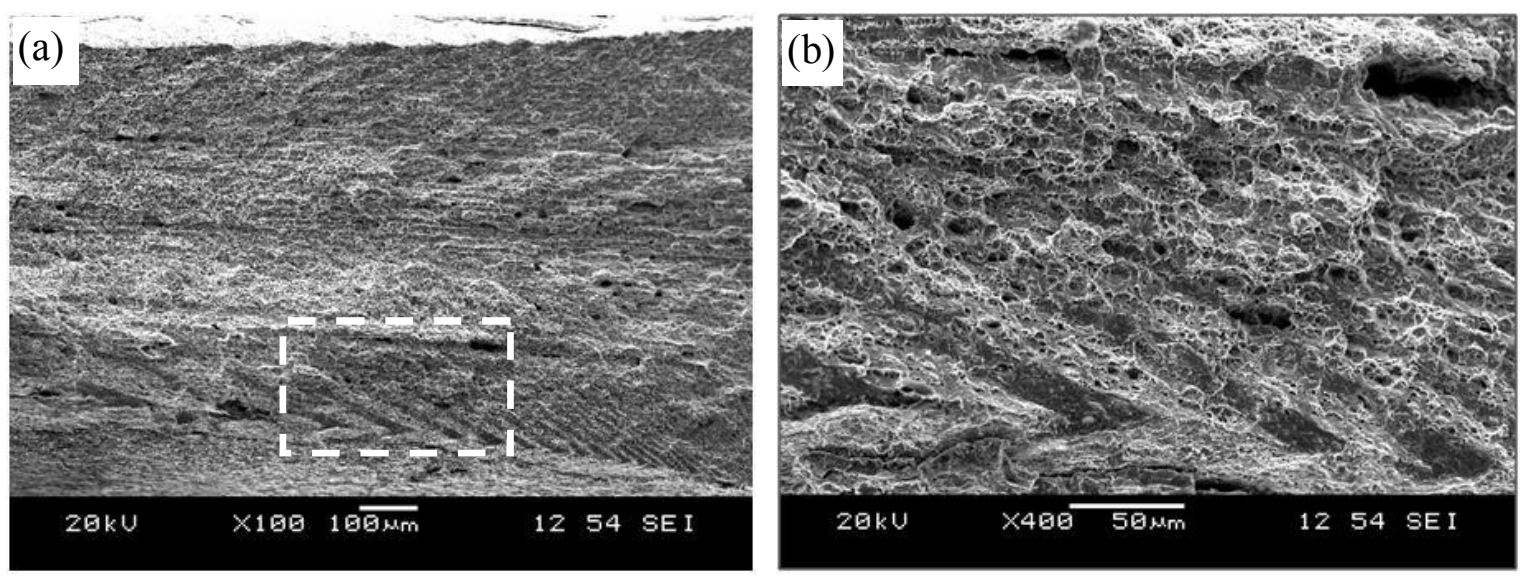

Figure 4.13 Fatigue fracture surface of a DP600 welded sample tested at a stress amplitude of $250 \mathrm{MPa}$ (a) deformation bands near both specimen surfaces, (b) a magnified view of the boxed area in (a). 


\subsection{Mechanical properties of laser welded dissimilar DP Steel joints}

\subsubsection{Microstructural evolution}

Fig. 4.14 shows SEM micrographs representing the typical microstructural changes during the laser welding process. As seen from Fig. 4.14(a) the microstructure of DP600 base metal was characterized by martensite islands in the ferrite matrix. The HAZ microstructure at the DP600 side is shown in Fig. 4.14(b), consisting of tempered martensite and possibly bainite along with some preexisting martensite in the ferrite matrix. The fusion zone (FZ) of this kind of welded joints contained mainly martensite along with sideplate ferrite as seen from Fig. 4.14(c). The formation of martensite in the FZ was a result of the rapid cooling of the weld pool containing mixed DP600 and DP980 steels during the welding. At the other side of the FZ, the HAZ of DP980 steel showed the presence of tempered martensite along with some possible bainite in conjunction with some pre-existing martensite in the ferrite matrix (Fig. 4.14(d)). Like DP600 steel, the DP980 base metal also contained martensite in the ferrite matrix, but with a higher martensitic volume fraction (Fig. 4.14(e)).

\subsubsection{Microhardness profile}

The microhardness profile of the laser welded dissimilar joint is shown in Fig. 4.15, corresponding directly to the microstructural change in Fig. 4.14. Significantly higher hardness in the FZ than that in both base metals was observed due to the formation of prevailing martensite (Fig. 4.14(c)). 

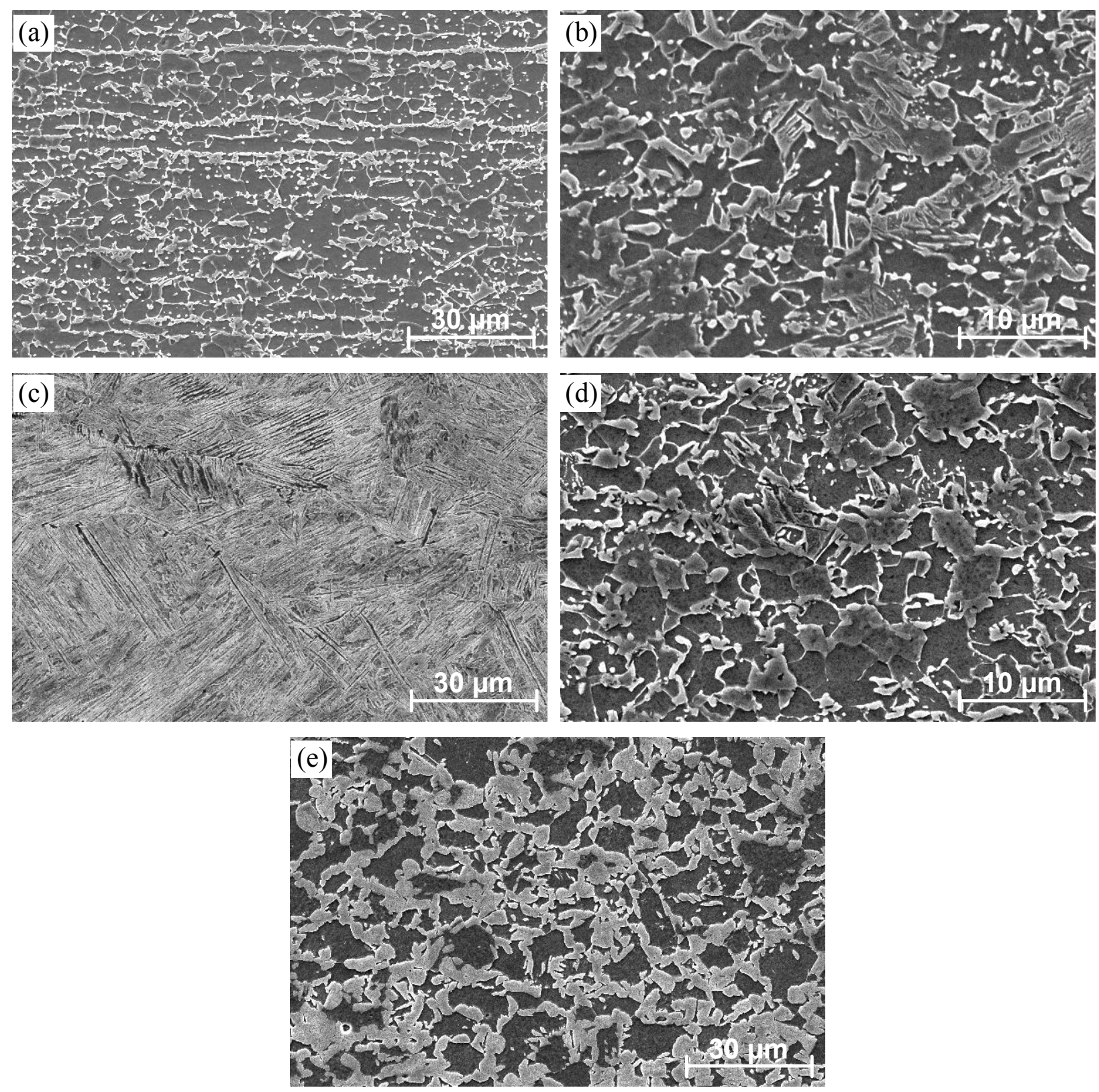

Figure 4.14 SEM micrographs showing the microstructural change of a laser welded dissimilar dual-phase steel joint, (a) DP600 base metal, (b) HAZ (DP600), (c) fusion zone, (d) HAZ (DP980), (e) DP980 base metal. 
In the HAZ there existed a significant hardness drop called "soft zone" as indicated in Fig. 4.15, in comparison with both the FZ and BM regions. The occurrence of the soft zone was partly attributed to the disappearance of martensite and partly due to tempering of the remaining martensite pre-existing in the base metals during laser welding. Similar observations have been reported in $[4,13,15,61]$. It is of interest to observe that the degree of softening was more severe and the size of the soft zone was larger at the DP980 side than at the DP600 side, exhibiting a characteristic asymmetrical hardness profile across the dissimilar joint (Fig. 4.15). This was attributed to the vanishing and tempering of more pre-existing martensite at the DP980 side. It should be noted that although the degree of softening was more acute at the DP980 side, the lowest hardness value across the entire dissimilar joint was still positioned in the HAZ of DP600 side. The hardness in the base metals was nearly constant, and as expected DP980 base metal exhibited a higher hardness than DP600 base metal due to its higher volume fraction of martensite.

\subsubsection{Tensile properties of laser welded dissimilar DP steel joints}

Fig. 4.16(a) shows typical engineering stress-strain curves for both base metals and laser welded dissimilar DP joint tested at a strain rate of $1 \times 10^{-2} \mathrm{~s}^{-1}$. Although both base metals showed smooth and continuous stress-strain characteristics, the dissimilar welded joint exhibited a yieldpoint-like phenomenon which could be better seen from the insert of Fig. 4.16(a). The presence of yield-point phenomena in the welded samples was likely due to interstitial diffusion which might occur during laser welding process $[61,62,64]$. 


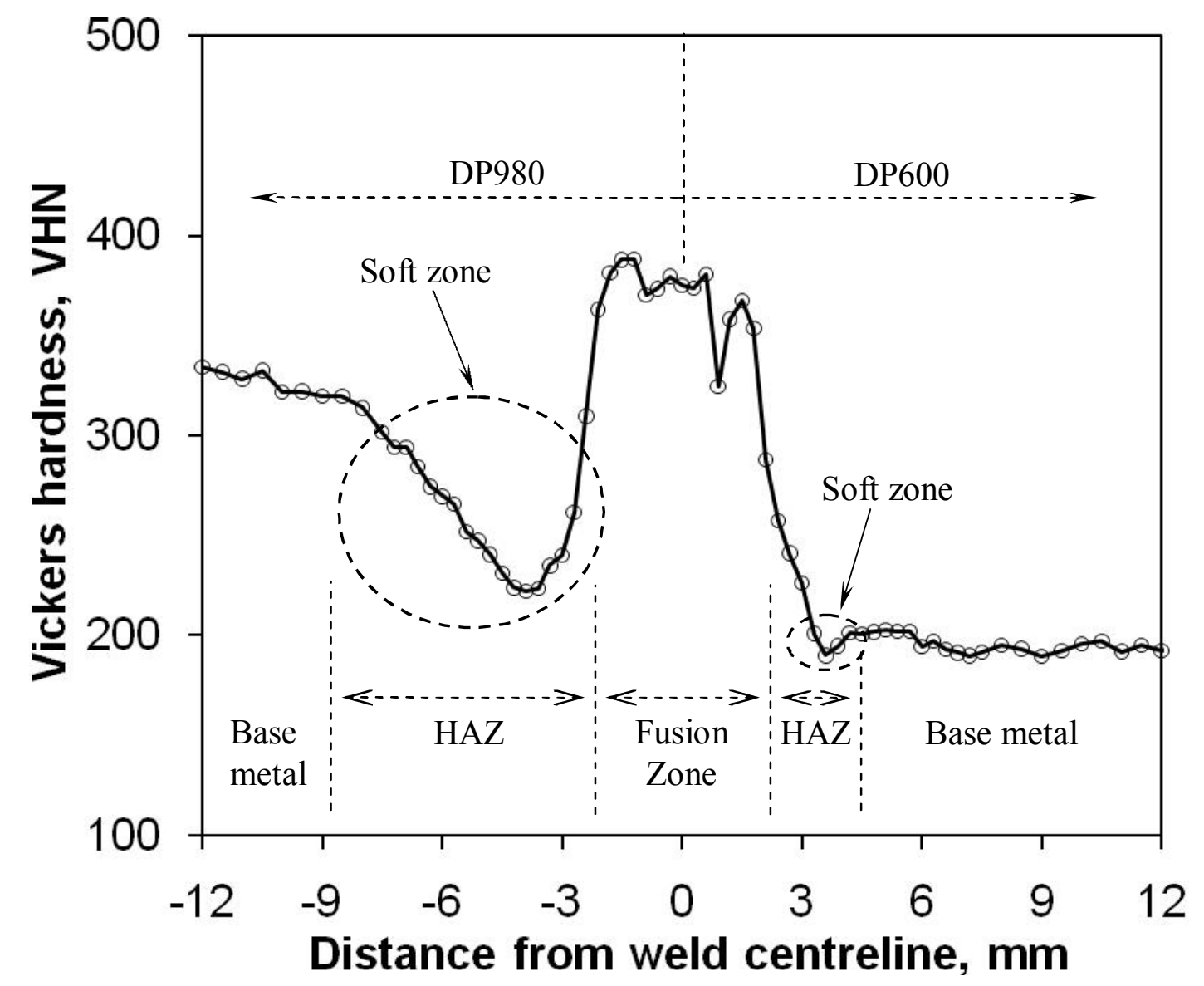

Figure 4.15 A characteristic unsymmetrical microhardness profile of the laser welded DP600/DP980 dissimilar joint.

\subsubsection{Effect of welding on the tensile properties}

While the yield-point-like phenomenon of the dissimilar welded joints was not so strong (Fig. 4.16(a)), the YS of the dissimilar welded joints were apparently higher than that of the DP600 base metal, as shown in Fig. 4.16(b). However, it was lower than the YS of DP980 base metal. The UTS of the dissimilar welded joints was observed to be essentially the same as that of the DP600 base metal. It is known that the UTS of steel is proportional to its hardness value. 
(a)

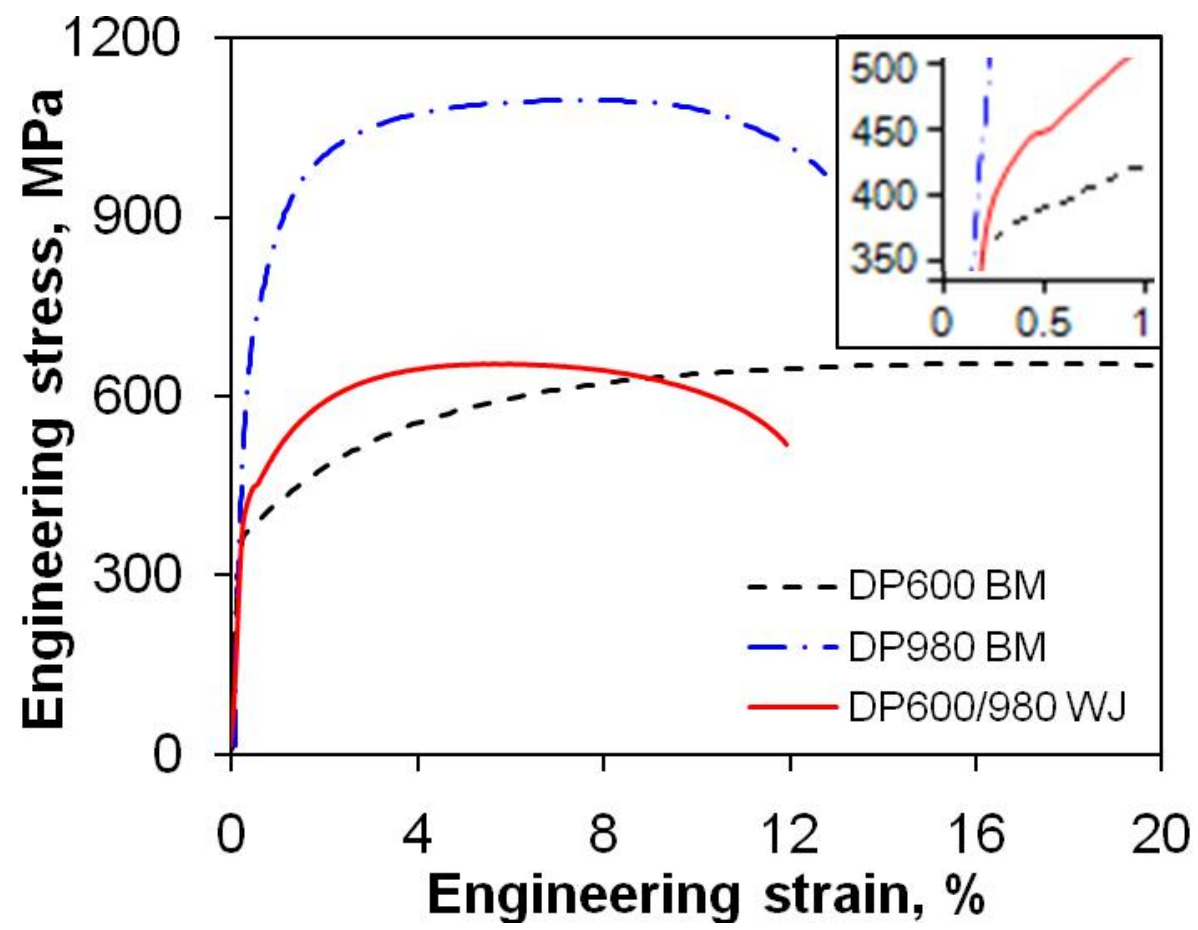

(b) 1200

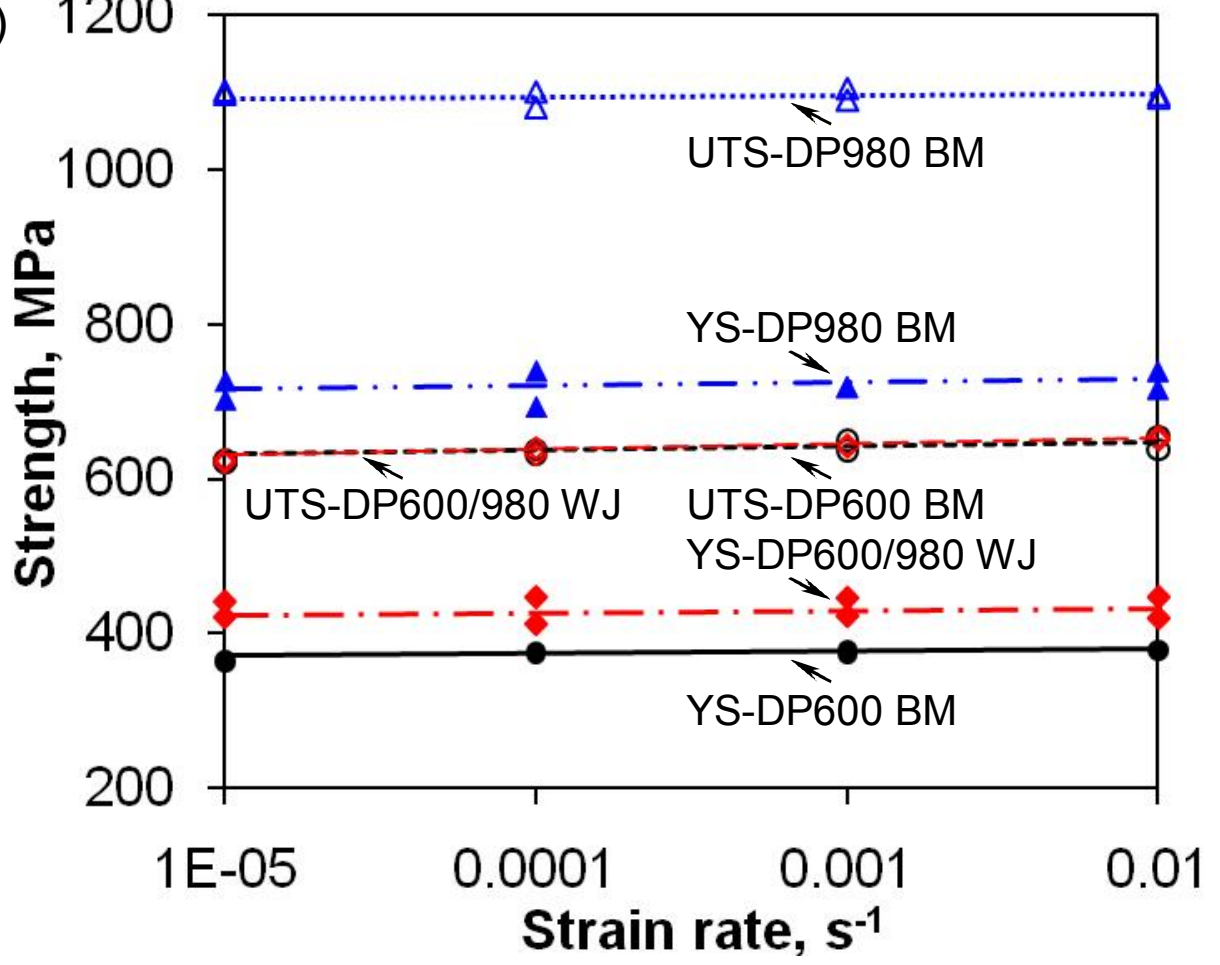

Figure 4.16 (a) Typical stress-strain curves obtained at a strain rate of $1 \times 10^{-2} \mathrm{~s}^{-1}$, (b) effect of laser welding on the yield strength (YS) and ultimate tensile strength (UTS). 
While the welded joints showed softening at both sides of FZ, the degree of softening at the DP600 side was very small or insignificant (Fig. 4.15). Thus the UTS of the welded joints were almost identical to that of the DP600 base metal. In all cases both YS and UTS exhibited only a very weak strain rate dependence in the range between $1 \times 10^{-5}$ and $1 \times 10^{-2} \mathrm{~s}^{-1}$. At higher strain rates the dislocation movement might be delayed, resulting in a slightly increased YS and UTS. It was also reported that the higher strain rate generated a dislocation morphology with more tangles in the cell walls and more refined cell size which in turn increased the strength [68]. Besides, it is seen from Fig. 4.16(a) that despite the higher YS and the same UTS, the dissimilar welded joint showed a lower ductility which was only equivalent to that of DP980 base metal but lower than that of DP600 base metal.

\subsubsection{Work hardening characteristics of dissimilar DP steel joints}

Fig. 4.17 presents a Kocks-Mecking type plot [65] of work hardening rate vs. net flow stress $\left(\sigma-\sigma_{y}\right)$ at a strain rate of $1 \times 10^{-2} \mathrm{~s}^{-1}$. It is seen that the strain hardening rate of the dissimilar welded joint basically lay in-between those of DP600 and DP980 base metals. The welded joint and DP600 base metal showed basically stage III work hardening behavior as indicated by a linear decrease of work hardening rate with increasing flow stress (Fig. 4.17). While the dissimilar welded joints showed only stage III work hardening behavior, the DP600 base metal had stage IV work hardening behavior when the net flow stress exceeded $\sim 270 \mathrm{MPa}$ although the change of the value of work hardening rate was small. Unlike the dissimilar welded joint and DP600 base metal, the DP980 base metal displayed initially stage II work hardening behavior as indicated by almost constant work hardening rate up to a net flow stress of $\sim 90 \mathrm{MPa}$ (Fig. 4), 
followed by stage III hardening until $\sim 300 \mathrm{MPa}$, and finally stage IV hardening appeared. The three stages of work hardening behavior has been already described in the section 4.1.3.2.

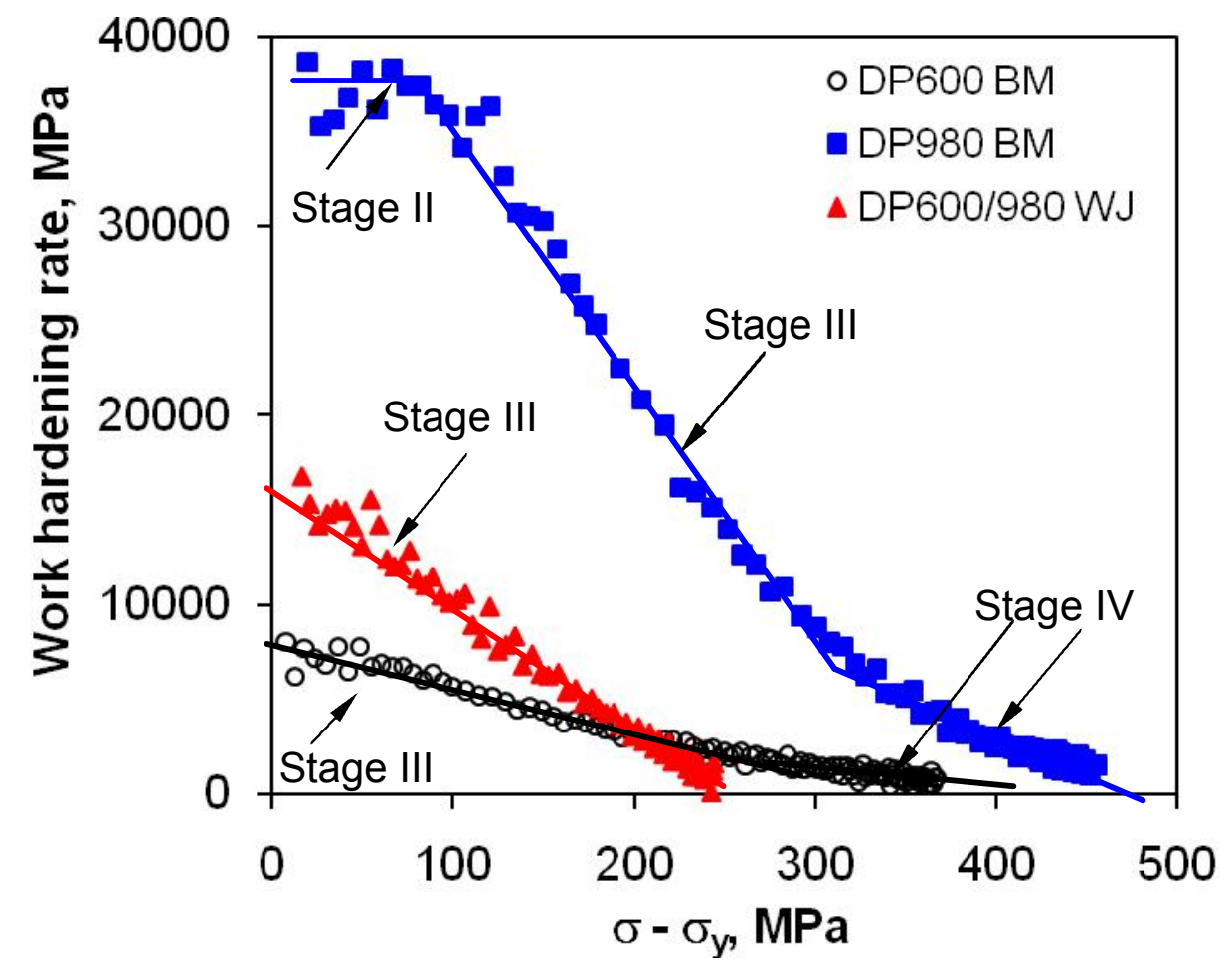

Figure 4.17 Work hardening rate vs. net flow stress for the DP600 and DP980 base metals as well as DP600/DP980 dissimilar welded joints tested at a strain rate of $1 \times 10^{-2} \mathrm{~s}^{-1}$.

After yielding the stress-strain relationship in the uniform deformation stage may be expressed by Hollomon equation [48]. The evaluated $n$ values following Eqn. 4.1 as a function of strain rate are shown in Fig. 4.18. It is seen that DP600 steel possesed higher work hardening exponent than the DP980 steel, while the $n$ value of the dissimilar welded joints lay in-between those of DP600 and DP980 base metals. This corresponded well to the results presented in Fig. 4.16(a). The work hardening exponent was also expected to be influenced by the volume fraction of martensite in the material. With increasing volume farction of martensite the value of $n$ 
usually decreased [37]. It is believed that the work hardening in the DP steels was mainly associated with the amount of ferrite which was relatively soft in comparsion to martensite - the more the ferrite (or the less the volume farction of martensite), the higher the hardening capacity, since the capacity for the storage of dislocations and their interaction was higher. In all cases the values of $n$ showed only a weak strain rate senitivity and incresed with increasing strain rate by a very small amount.

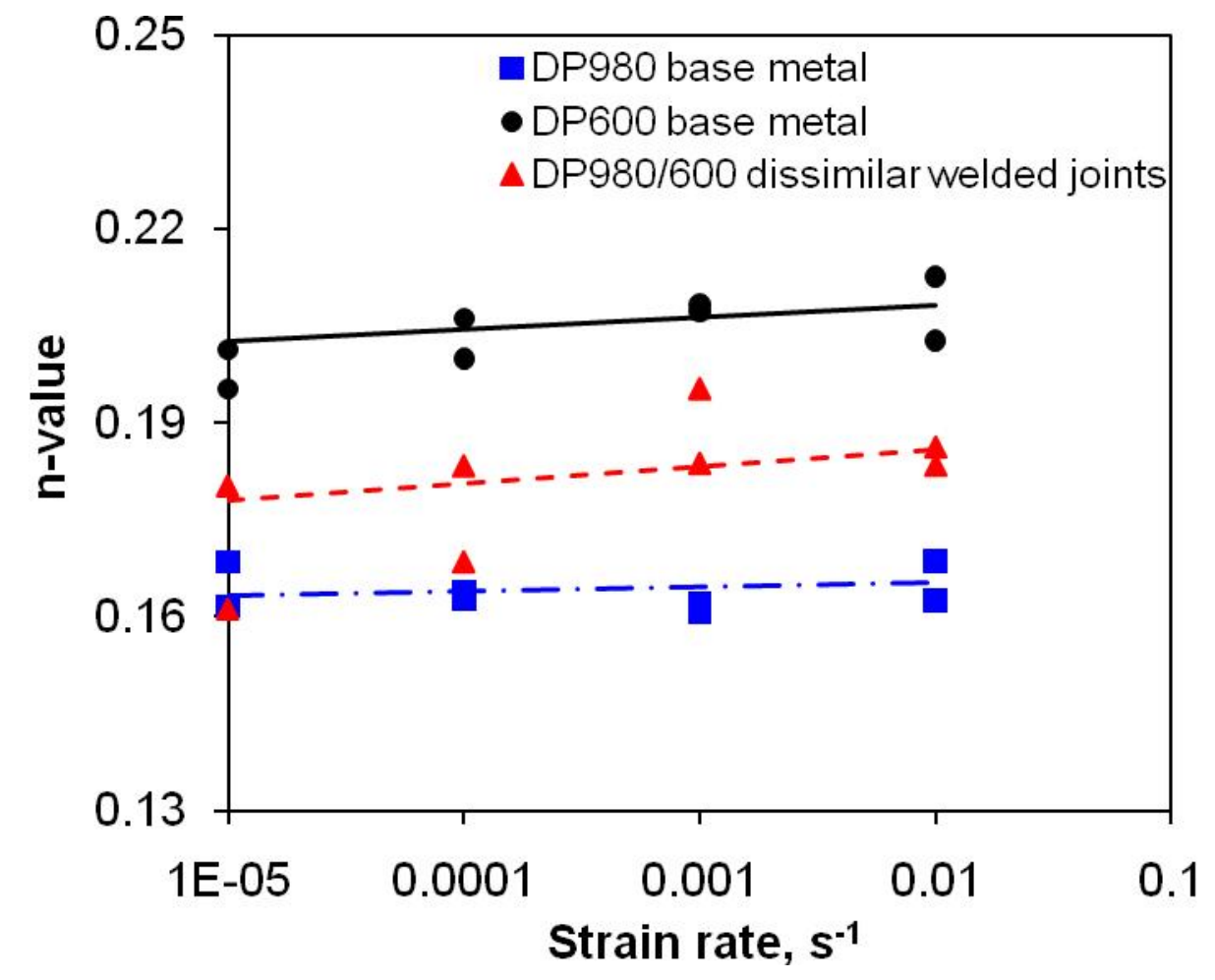

Figure 4.18 Work hardening exponents of dissimilar welded joints compared with base metals at different strain rates evaluated using the Hollomon equation [48]. 


\subsubsection{Tensile failure location and fractography}

Regarding the failure location all the dissimilar joints failed in the soft zone at the DP600 side, corresponding to the minimum hardness value in the microhardness profile across the dissimilar welded joint (Fig. 4.15).

Careful observations during tensile tests showed that yielding started from the soft zone and the subsequent plastic deformation accumulated in this zone until final failure. The tensile fracture surface characteristics were basically similar in both the welded joints and DP600 base metal. The tensile fracture surfaces showed mostly equiaxed dimples (Fig. 19(a)) at the center indicating typical ductile fracture in the DP steels, regardless of the welding. The fracture surface near the specimen surface showed a combination of both equiaxed and elongated dimples near the edge (Fig. 4.19(b)), indicating the occurrence of shearing motion.
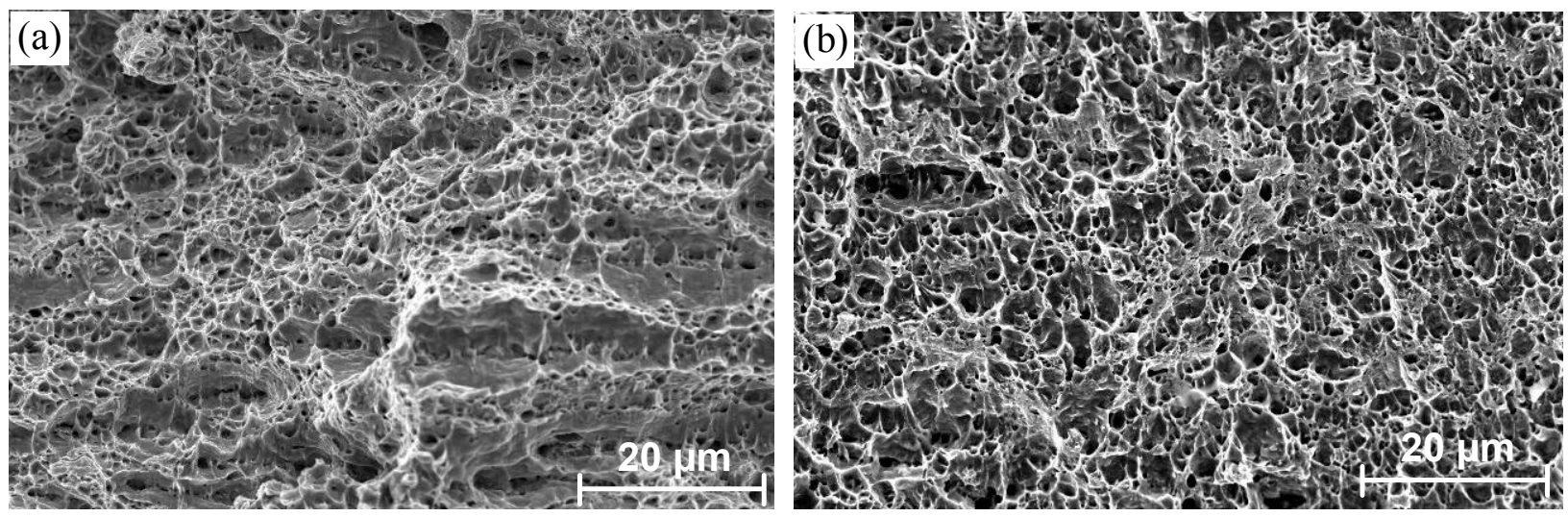

Figure 4.19 Typical SEM micrographs of the tensile fracture surface of the DP600/DP9809 dissimilar welded joints tested at a strain rate of $1 \times 10^{-2} \mathrm{~s}^{-1},(\mathrm{a})$ in the specimen center and (b) near the specimen edge. 


\subsubsection{Fatigue performance of laser welded Dissimilar DP steel joints}

\subsubsection{Fatigue properties}

Fig. 4.20 depicts the obtained S-N curve for DP600/DP980 dissimilar joints. It is seen that at higher stress amplitudes the fatigue strength of the dissimilar welded joints was basically the same as that of DP600 base metal, which was however much lower than that of DP980 base metal. This was due to the fact that the DP980 base metal was much stronger as reflected by the considerably higher hardness (left-hand side in Fig.4.15) and UTS (Fig. 4.16).

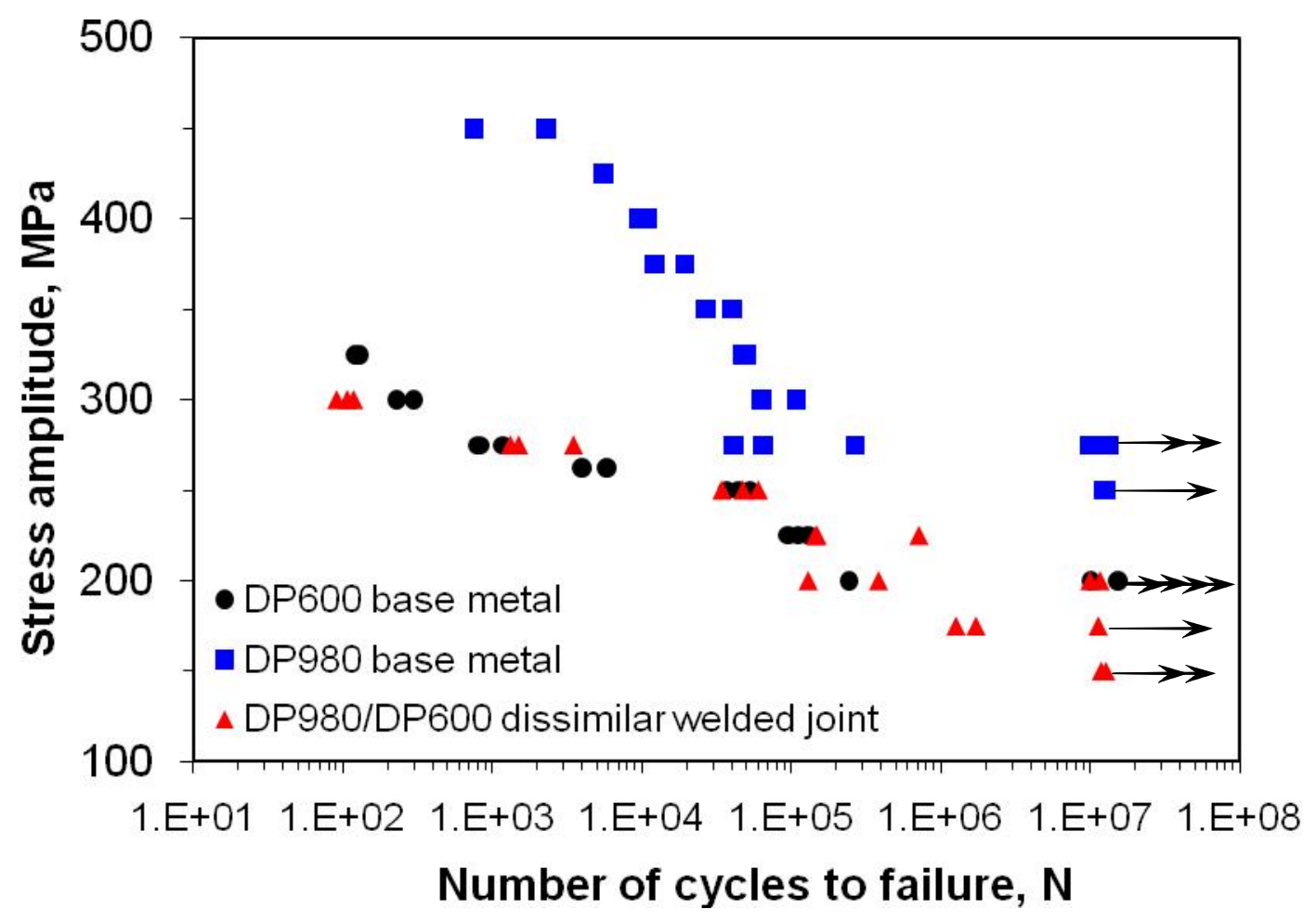

Figure 4.20 $\mathrm{S}-\mathrm{N}$ curves of the base metals and the dissimilar welded joints tested at $\mathrm{R}=0.1,50$ $\mathrm{Hz}$ and room temperature where the run-out samples were indicated by arrow marks. 
The equivalent fatigue life or strength between the dissimilar welded joints and DP600 base metal suggested that the laser welding had little effect on the fatigue performance of DP600 steel at intermediate and higher stress amplitudes in spite of the occurrence of the soft zone. This could be understood via the result shown in Fig. 4.15, where the minimum hardness in the HAZ or soft zone at the DP600 side was only marginally lower than that the average hardness value of DP600 base metal. However, the welded joints showed a lower fatigue limit than the DP600 base metal (Fig. 4.20). This suggested that the slight reduction of the hardness in the soft zone did have an effect on the fatigue strength at lower stress amplitudes.

The fatigue limit and the fatigue ratio of the materials tested in the present study are tabulated at Table 4.3. The fatigue limit of the dissimilar welded joints was observed to be lower than that of the DP600 and DP980 base metals by about $25 \%$ and $40 \%$, respectively, whereas the obtained fatigue ratio of the dissimilar welded joints lay in-between the base metals but was close to that of DP980 base metal.

Table 4.3 Fatigue limit and fatigue ratio of the DP600 and DP980 base metals as well as DP600/DP980 dissimilar welded joints.

\begin{tabular}{lccc}
\hline Material type & $\begin{array}{c}\text { Fatigue limit } \\
(\mathrm{MPa})\end{array}$ & $\begin{array}{c}\text { Ultimate tensile strength } \\
(\mathrm{MPa})\end{array}$ & Fatigue ratio \\
\hline DP600 base metal & 200 & 634 & 0.32 \\
DP980 base metal & 250 & 1095 & 0.23 \\
DP600/980 dissimilar joints & 150 & 638 & 0.24 \\
\hline
\end{tabular}

The reduction of the fatigue limit indicated that the HAZ softening of the weld played a significant role in the fatigue properties at lower stress amplitudes. Therefore, in the fatigue 
design and/or life prediction of the welded joints, it is necessary to take into account the weakening effect of welding on the fatigue limit so as to ensure the integrity and longevity of automotive components.

\subsubsection{Fatigue failure location}

While all the dissimilar welded joints failed exclusively in the soft zone at the DP600 side during tensile tests, the failure location of the welded joints was observed to be related to the applied stress amplitudes. The samples tested at lower stress amplitudes failed far away from the middle gauge section but the samples tested at higher stress amplitudes failed at the soft zone in the HAZ, as shown in Fig. 4.21.
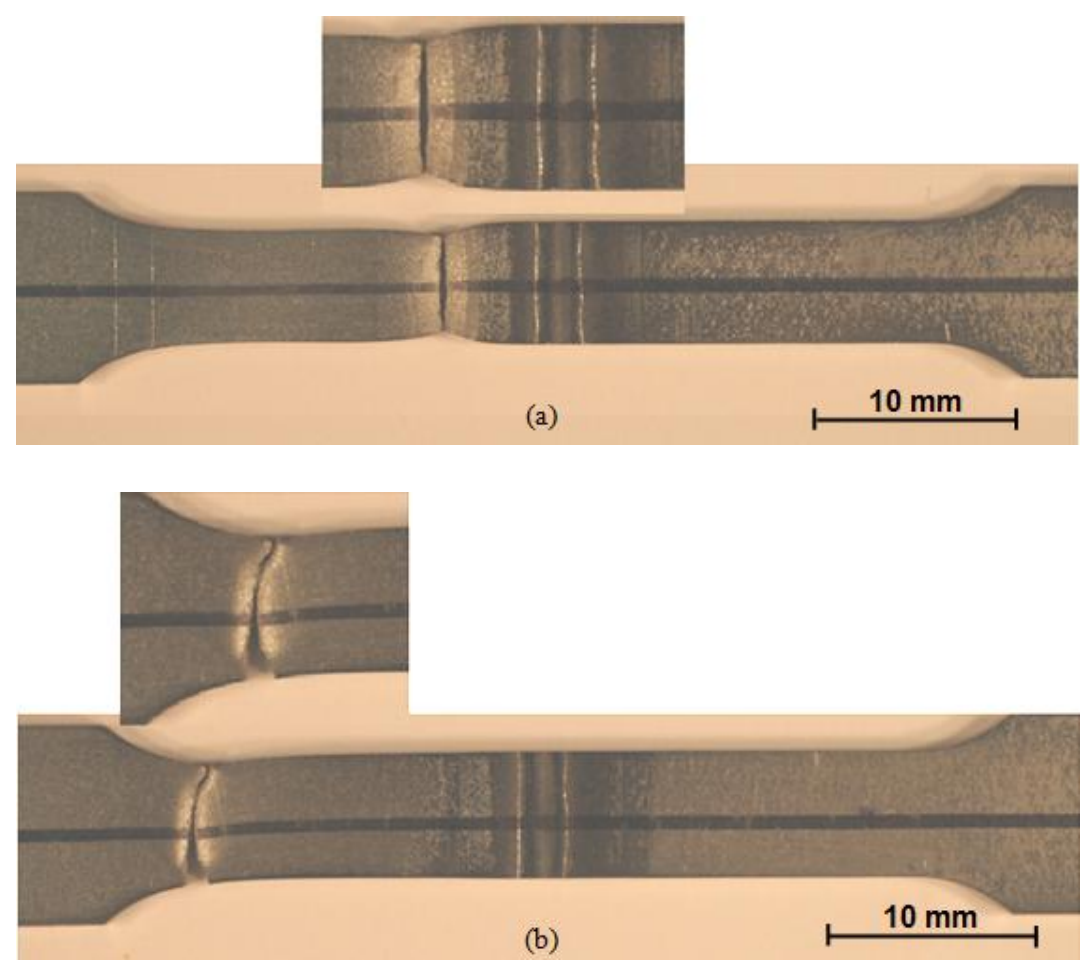

Figure 4.21 Fatigue failure locations of the dissimilar welded joints tested at a stress amplitude of (a) $275 \mathrm{MPa}$, (b) $200 \mathrm{MPa}$. 
The possible reason for the occurrence of different failure locations would be explained by

cyclic strengthening mechanism involving deformation-induced martensitic transformation ${ }^{73-75}$ [73-75]. Small amount of retained austenite contained in the DP steels could be transformed to martensite, giving rise to additional strengthening in the longer life high cycle fatigue (HCF) region. The newly formed martensite interacted with the dislocations [76] and made it tough at the relatively lower stress amplitudes to overcome the pinning force created by martensite. Then the area near the end of gauge section became the weakest due to the potential stress concentration caused by the notch effect.

Indeed it has been pointed out that the notch effect was usually stronger in the longer life HCF region compared to the shorter life low cycle fatigue (LCF) region [77]. In the LCF region where the samples were tested at higher stress amplitudes the dislocations could more easily overcome the martensitic barriers as the magnitude of applied stress was high enough to cause more cumulative damage in the soft zone of the test samples. As a result, the welded dissimilar DP steels failed in the soft zone of DP600 side at higher stress amplitudes.

\subsubsection{Fractographic analysis of fatigue fracture}

The fatigue samples tested at lower and intermediate stress amplitudes showed clearly the crack initiation site and crack propagation area on the fracture surface. A typical example of the overall fracture surface of a sample tested at $225 \mathrm{MPa}$ is shown in Fig. 4.22(a). The crack initiation took place from the surface (Fig. 4.22(b)). The governing mechanism of fatigue crack initiation and propagation has been described in section 4.1.4.3 [61,64]. 

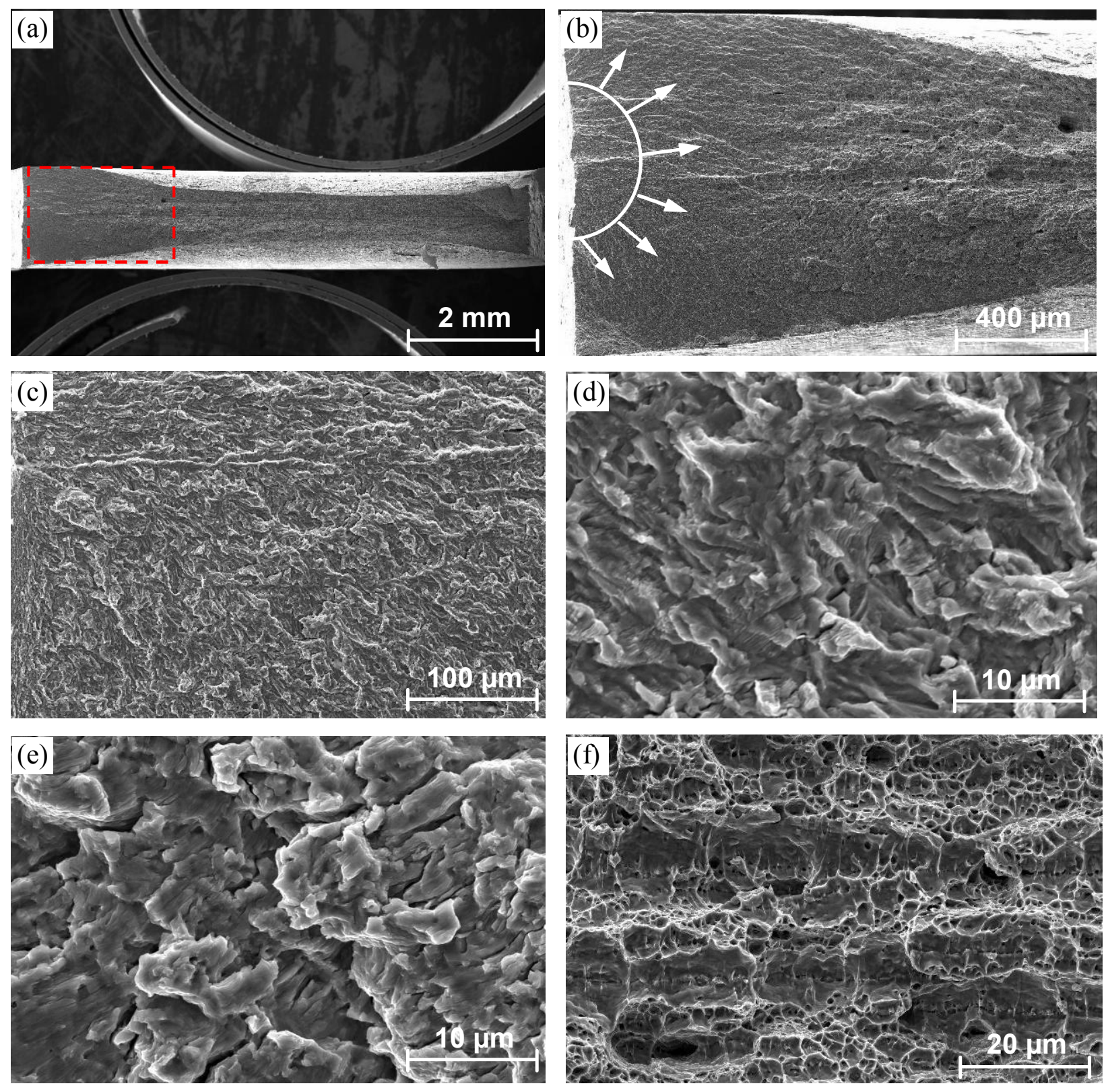

Figure 4.22 Typical fatigue fracture surface of the dissimilar welded joint tested at a stress amplitude of $225 \mathrm{MPa}$, (a) overall view of the fracture surface at a low magnification, (b) magnified view of the dashed box in (a) showing the crack initiation site, (c) crack propagation near the crack initiation site at an intermediate magnification, (d) crack propagation near the crack initiation site at a higher magnification, (e) crack propagation with secondary cracks at a higher magnification, (f) center of the fracture surface showing the final rapid crack propagation. 
A magnified view of the crack initiation site is shown in Fig. 4.22(c), and the early stage of crack propagation near the crack initiation site is in Fig. 4.22(d), where fatigue striations could be seen but their spacing was very small, reflecting an initially slow rate of crack propagation. With increasing distance from the crack initiation site, the spacing of fatigue striations became gradually larger representing an increasingly faster propagation, as shown in (Fig. 4.22(e)). The fatigue striations occurred usually perpendicular to the propagation direction. The presence of secondary cracks was also evident in the faster crack propagation area, which appeared to increase with increasing distance from the initiation site as well. The formation of fatigue striations was basically considered to be due to a repeated plastic blunting-sharpening process caused by either dislocation slip [79] or twinning [82] in the plastic zone ahead of the fatigue crack tip. The final rapid crack propagation at the center of the fracture surface was mainly characterized by the cup-like dimples, as shown in Fig. 4.22(f), which was indeed the same as the monotonic tensile fracture surface characteristics (Fig. 4.19(a)). 


\subsection{Effect of heat treatment on the laser welded DP980 joints}

The extent or severity of the softening was found to be associated with the volume fraction of pre-existing original martensite in the DP steels $[4,83]$ which usually increases with increasing strength grades of DP steels. For instance, the degree of softening was observed to be much more severe in the DP980 welded joints than in the DP600 welded joints due to the higher amount of martensite pre-existing in the DP980 base metal [83]. The presence of severe soft zone resulted in a significant decrease in the tensile strength and fatigue limit compared with the corresponding base metal [83]. A possible solution to this problem would be the application of post-weld heat treatment (PWHT) to the welded DP980 joints to eliminate the soft zone and improve the mechanical properties. The following sections will discuss the results of the effect of PWHT on the microstructure and mechanical properties of laser welded DP980 joints.

\subsubsection{Effect of heat treatment on the microhardness and microstructure}

Fig. 4.23 shows the micro-indentation hardness profile across the laser welded DP980 joints and also the effect of heat treatment on the hardness profile of these joints. It is seen that in the as-welded (i.e., non-heat-treated) DP980 joint significantly higher hardness values was obtained in the FZ corresponding to the mostly martensitic structure (Fig. 4.1(e)). However, in the HAZ the hardness became considerably lower than that in the BM, with the lowest value appeared near the FZ. The presence of such a severe soft zone in the DP980 welded joints was attributed to the occurrence of tempering and vanishing of the pre-existing martensite in this area (Fig. 4.1(f)). Similar observations have also been reported in [4,13,14,61,83]. 
The hardness profile of the welds changed considerably after heat treatment as seen from Fig. 4.23. In particular, the hardness values became basically constant throughout different zones of the laser welded joints. The hardness increased clearly with increasing heat treatment temperature, and the loss of hardness in the soft zone caused by the welding has been fully recovered to the base metal hardness level of about HV310 in the temperature range between $750^{\circ} \mathrm{C}$ and $780^{\circ} \mathrm{C}$. Therefore the goal of getting rid of the soft zone via the present simple postweld heat treatment has been achieved.

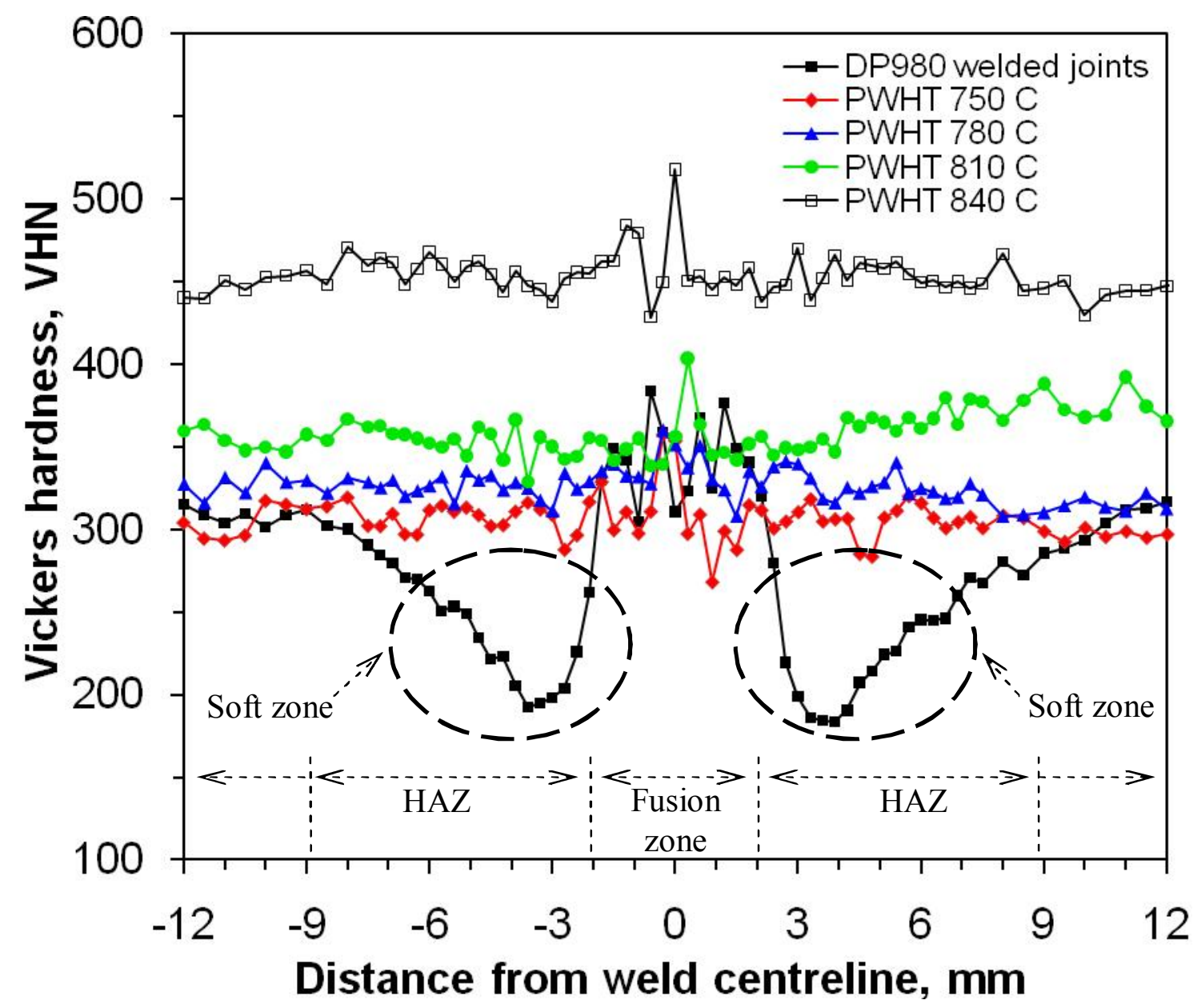

Figure 4.23 Effect of heat treatment on the microhardness profile of the laser welded DP980 steel joints. 
The change in the hardness shown in Fig.4.23 was directly associated with the evolution in the microstructure after heat treatment. Microstructural examinations using SEM indicated that the microstructure across the different zones of the laser welded joints after PWHT was basically homogeneous and consistent, thus giving rise to the constant hardness values illustrated in Fig.4.23. Some typical SEM micrographs showing the microstructures of the laser welded DP980 steel joints after PWHT at different temperatures following the procedure given in Fig. 3.8 are shown in Fig. 4.24.
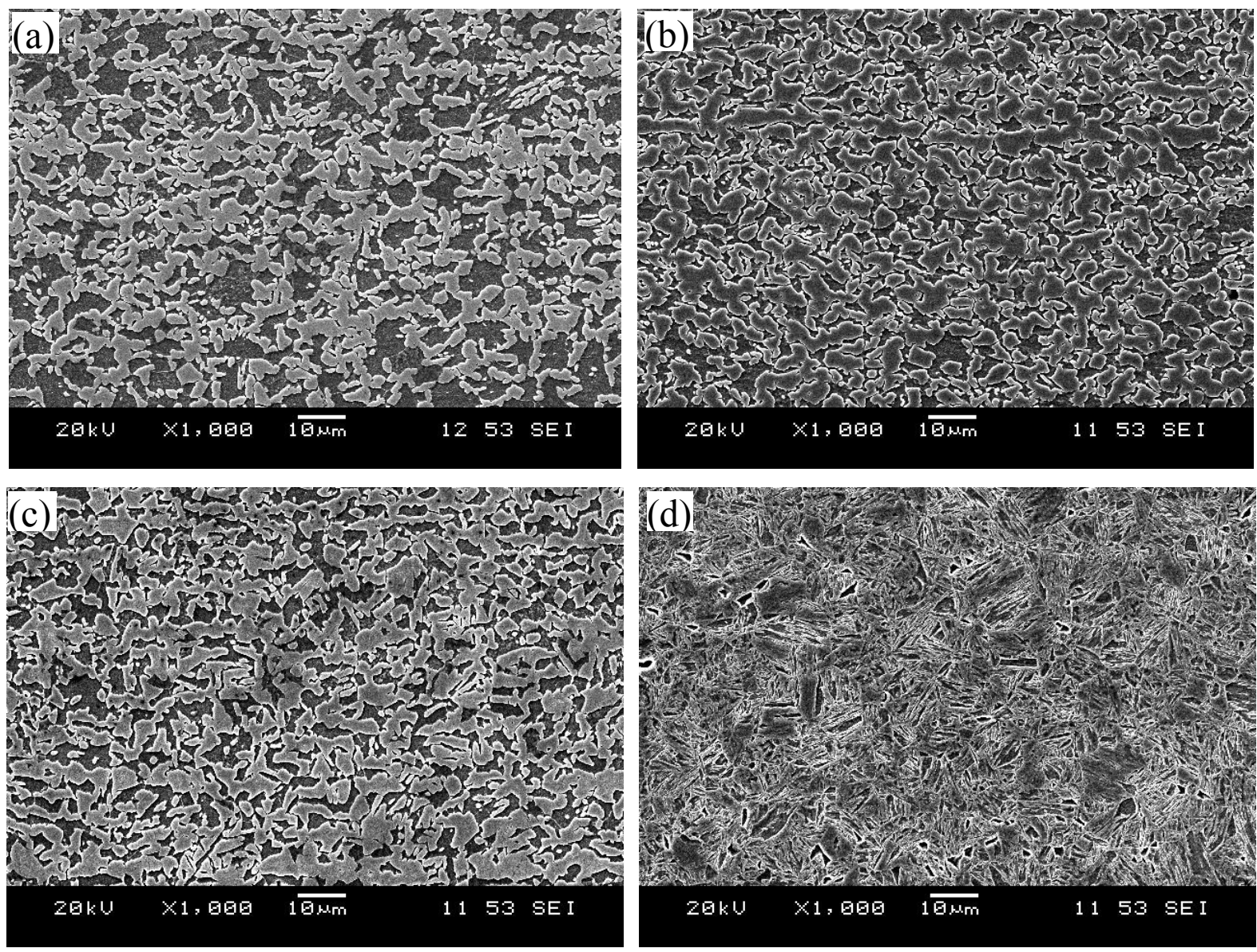

Figure 4.24 Typical microstructures of the laser welded DP980 steel joints after post-weld heat treatment at (a) $750^{\circ} \mathrm{C}$, (b) $780^{\circ} \mathrm{C}$, (c) $810^{\circ} \mathrm{C}$ and (d) $840^{\circ} \mathrm{C}$. 
It should be noted that all the micrographs shown in Fig. 4.24 were taken at a distance of about $3 \mathrm{~mm}$ from the weld centerline, i.e., in the original hardness valley area in Fig.4.23. It is clear that the distribution of martensite was uniform and the amount of martensite increased with increasing heat treatment temperature. Quantitative image analysis indicated that the volume fraction of martensite was about 0.52 for the $\mathrm{BM}$, and increased to $0.60,0.69,0.76$, and 0.86 after PWHT at $750^{\circ} \mathrm{C}, 780^{\circ} \mathrm{C}, 810^{\circ} \mathrm{C}$ and $840^{\circ} \mathrm{C}$, respectively. This was due to the fact that more austenite was formed at higher temperatures, which subsequently transformed into martensite upon quenching into water. The increased hardness with increasing heat treatment temperature shown in Fig. 4.23 was just a consequence of the increased volume fraction of martensite present in the laser welded DP980 steel joints after PWHT.

\subsubsection{Effect of heat treatment on the tensile properties}

Based on the microstructural change (Fig. 4.24) and hardness profile (Fig. 4.23) two PWHT conditions $\left(750^{\circ} \mathrm{C}\right.$ and $\left.810^{\circ} \mathrm{C}\right)$ were selected to conduct tensile and fatigue tests. Fig. 4.25 shows the engineering stress-strain curves obtained from the DP980 base metal, DP980 welded joints, $\mathrm{PWHT} 750^{\circ} \mathrm{C}$ joints and PWHT $810^{\circ} \mathrm{C}$ joints. In all the cases the test materials showed a smooth and continuous stress-strain curve without the presence of yield-point phenomenon. Careful observations during the tensile tests of as-welded joints showed that the onset of yielding occurred in the soft zone and then the majority of the plastic deformation accumulated in that zone until final failure. However, the tensile failure locations of PWHT joints were observed to be indefinite, i.e., no longer fixed at the original soft zone, due to the occurrence of homogeneous ferrite-martensite dual-phase microstructure and nearly horizontal microhardenss distribution across the weld after PWHT (Figs 4.23 and 4.24). 


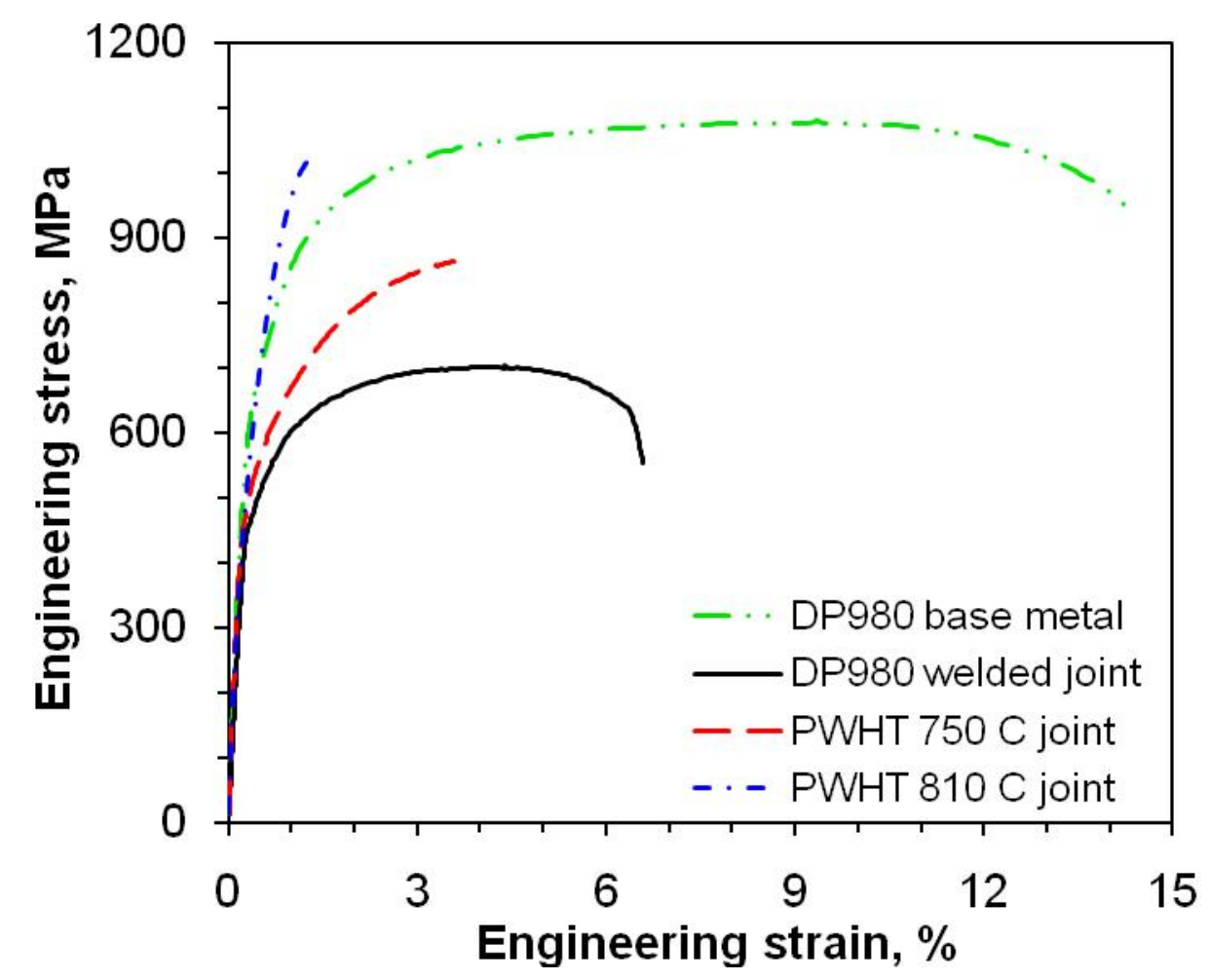

Figure 4.25 Typical stress-strain curves of the DP980 base metal, welded joints without and with PWHT obtained at a strain rate of $1 \times 10^{-4} \mathrm{~s}^{-1}$.

The evaluated tensile properties of the test materials are tabulated in Table 4.4. Welding led to a significant decrease in both strength and ductility of the DP980 steel mainly due to the softening in the $\mathrm{HAZ}$ of the welded joints. After PWHT at $750^{\circ} \mathrm{C}$ the strength increased. The $810^{\circ} \mathrm{C}$ PWHT resulted in almost recovery of the strength in comparison with the base metal. However, the ductility became lower. One of the potential reasons for this was the increasing volume fraction of martensite with increasing PWHT temperature, as mentioned earlier and seen in Fig. 4.24. Another significant reason might be hydrogen induced embrittlement caused by dissociated $\mathrm{NH}_{3}$ and natural gas $\left(\mathrm{CH}_{4}\right)$ supplied during the heat treatment process. At high temperature the elevated solubility of hydrogen atom disassociated from ammonia allowed hydrogen to diffuse 
into the metal. When these hydrogen atoms re-combined in minuscule voids of the metal matrix to form hydrogen molecules, they created pressure from inside the cavity they were in. This pressure might increase to levels where the PWHT joints had reduced ductility up to the point where it cracked open. It has been also reported that the atomic hydrogen formed in the dissociation of ammonia penetrates into the steels and embrittles it [84, 85]. Usually steels grade having higher strength and lower alloying addition are susceptible to this kind of hydrogen embrittlement at higher temperature [86].

After yielding the stress-strain relationship in the uniform deformation stage may be expressed by Hollomon equation [48]. The evaluated $n$ values following Hollomon equation are shown in Table 4.4 for the tested materials. It is seen that PWHT $810^{\circ} \mathrm{C}$ joints showed the highest value of strain hardening exponent due to the higher volume fraction of martensite in comparison with the PWHT $750^{\circ} \mathrm{C}$ joints and base metal.

Table 4.4 Tensile properties of the DP980 base metal, welded joints and PWHT joints.

\begin{tabular}{lcccc}
\hline Materials & $\begin{array}{c}\text { Yield strength } \\
(\mathrm{MPa})\end{array}$ & $\begin{array}{c}\text { Ultimate tensile } \\
\text { strength }(\mathrm{MPa})\end{array}$ & $\begin{array}{c}\text { Percent } \\
\text { elongation (\%) }\end{array}$ & $\begin{array}{c}\text { Work hardening } \\
\text { exponent (n) }\end{array}$ \\
\hline DP980 base metal & 717 & 1090 & 14 & 0.163 \\
DP980 welded joints & 510 & 714 & 6.8 & 0.167 \\
PWHT 750 & 528 & 859 & 5.6 & 0.24 \\
PWHT $810^{\circ} \mathrm{C}$ & 700 & 982 & 1.8 & 0.42 \\
\hline
\end{tabular}

Fig. 4.26 presents a Kocks-Mecking type plot [65] of work hardening rate vs. net flow stress $\left(\sigma-\sigma_{y}\right)$ at a strain rate of $1 \times 10^{-4} \mathrm{~s}^{-1}$. While the DP980 welded joints, PWHT $750^{\circ} \mathrm{C}$ joints and PWHT $810^{\circ} \mathrm{C}$ joints showed basically stage III work hardening behavior as indicated by a linear 
decrease of work hardening rate with increasing net flow stress (Fig. 4.26), the DP980 base metal showed multi-stage work hardening behavior. The DP980 base metal showed a clear stage II work hardening by maintaining almost constant work hardening rate up to a net flow stress of about $120 \mathrm{MPa}$ followed by stage III and then stage IV hardening when the net flow stress exceeded $\sim 290 \mathrm{MPa}$ although the change of the value of work hardening rate was small in stage IV.

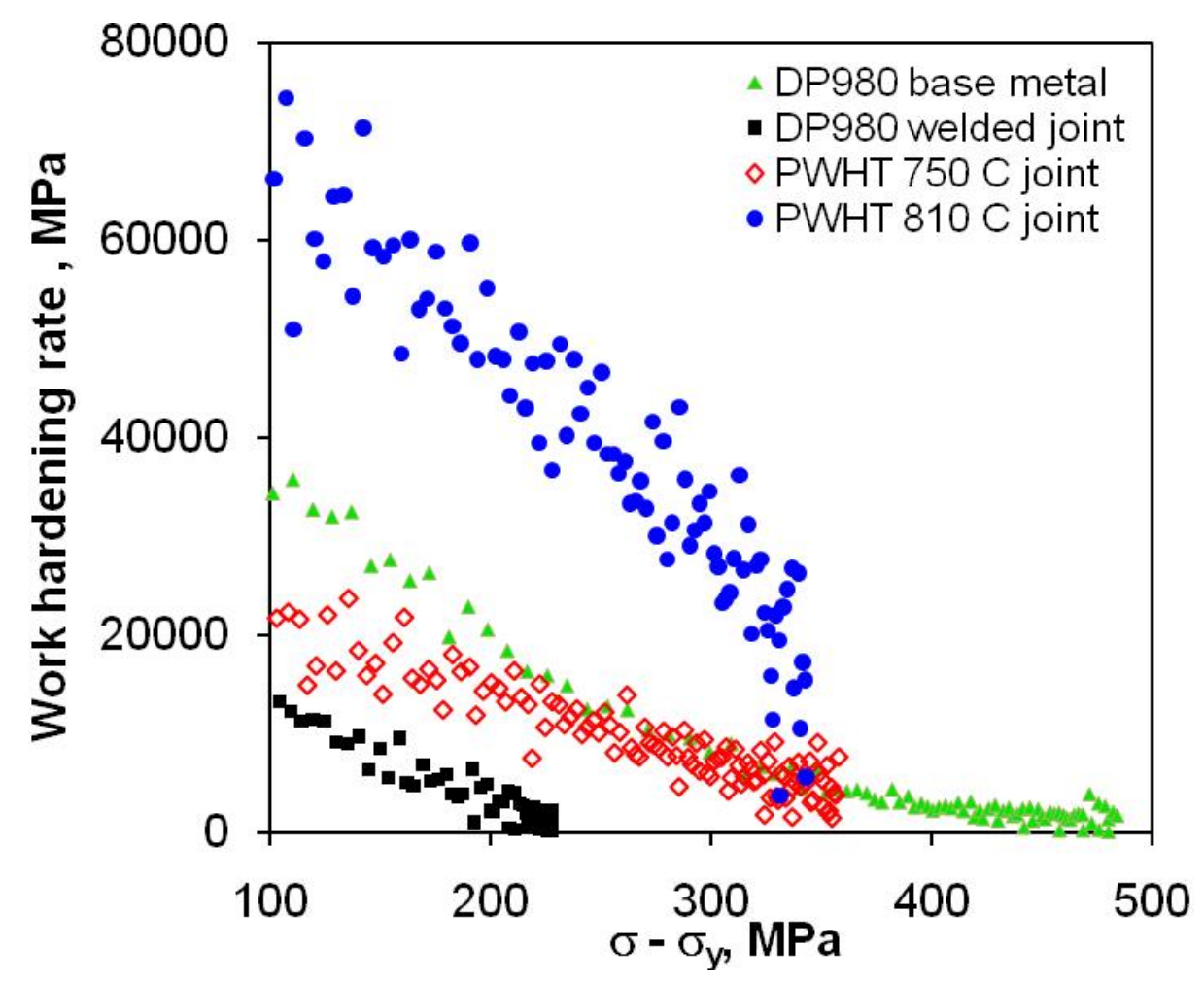

Figure 4.26 Work hardening rate vs. net flow stress for the DP980 base metal, welded joints without and with PWHT tested at a strain rate of $1 \times 10^{-4} \mathrm{~s}^{-1}$.

These three stages of work hardening behavior have been already elaborated in literature $[21,37,53,66]$ and discussed in earlier sections. While only stage III work hardening were present in all the cases of welded joints, after PWHT the work hardening rate became clearly higher. In 
particular, the PWHT $810^{\circ} \mathrm{C}$ joints exhibited about twice the values of work hardening rate of PWHT $750^{\circ} \mathrm{C}$ joints due to the strong resistance of more martensite to the motion of dislocations during plastic deformation.

\subsubsection{Effect of heat treatment on the fatigue properties}

The S-N curves obtained from the load control fatigue tests are shown in Fig. 4.27. Compared with the base metal, the DP980 welded joints showed considerably lower fatigue life at all stress amplitudes due to the occurrence of the severe soft zone with a substantial reduction in hardness (Fig. 4.23). Due to this acute softening in the HAZ the DP980 welded joints showed a considerably ( $\sim 100 \mathrm{MPa})$ lower fatigue limit than the DP980 base metal. On the other hand PWHT $810^{\circ} \mathrm{C}$ joints showed an obvious recovery of the fatigue limit from the DP980 welded joints although the fatigue strength at the higher stress amplitudes was still lower than that of the base metal. However, the PWHT $750^{\circ} \mathrm{C}$ joints showed no improvement in the fatigue limit in comparison with the welded DP980 joints. The higher martensitic volume fraction in the PWHT $810^{\circ} \mathrm{C}$ joints gave an additional strengthening effect and resulted in a fatigue limit of $\sim 50 \mathrm{MPa}$ higher than that of both the DP980 welded joints and PWHT $750^{\circ} \mathrm{C}$ joints.

The obtained fatigue limit and fatigue ratio are tabulated in Table 4.5. The fatigue limit of the DP980 welded joints was $40 \%$ lower than that of the base metal whereas the fatigue limit of the PWHT $810^{\circ} \mathrm{C}$ joints was $33 \%$ higher than that of the DP980 welded joints. However the PWHT $810^{\circ} \mathrm{C}$ joints showed approximately the same or slightly lower fatigue ratio of 0.20 compared to that of the welded joints which was 0.21 , due to the much higher ultimate tensile strength in the PWHT $810^{\circ} \mathrm{C}$ joints. 


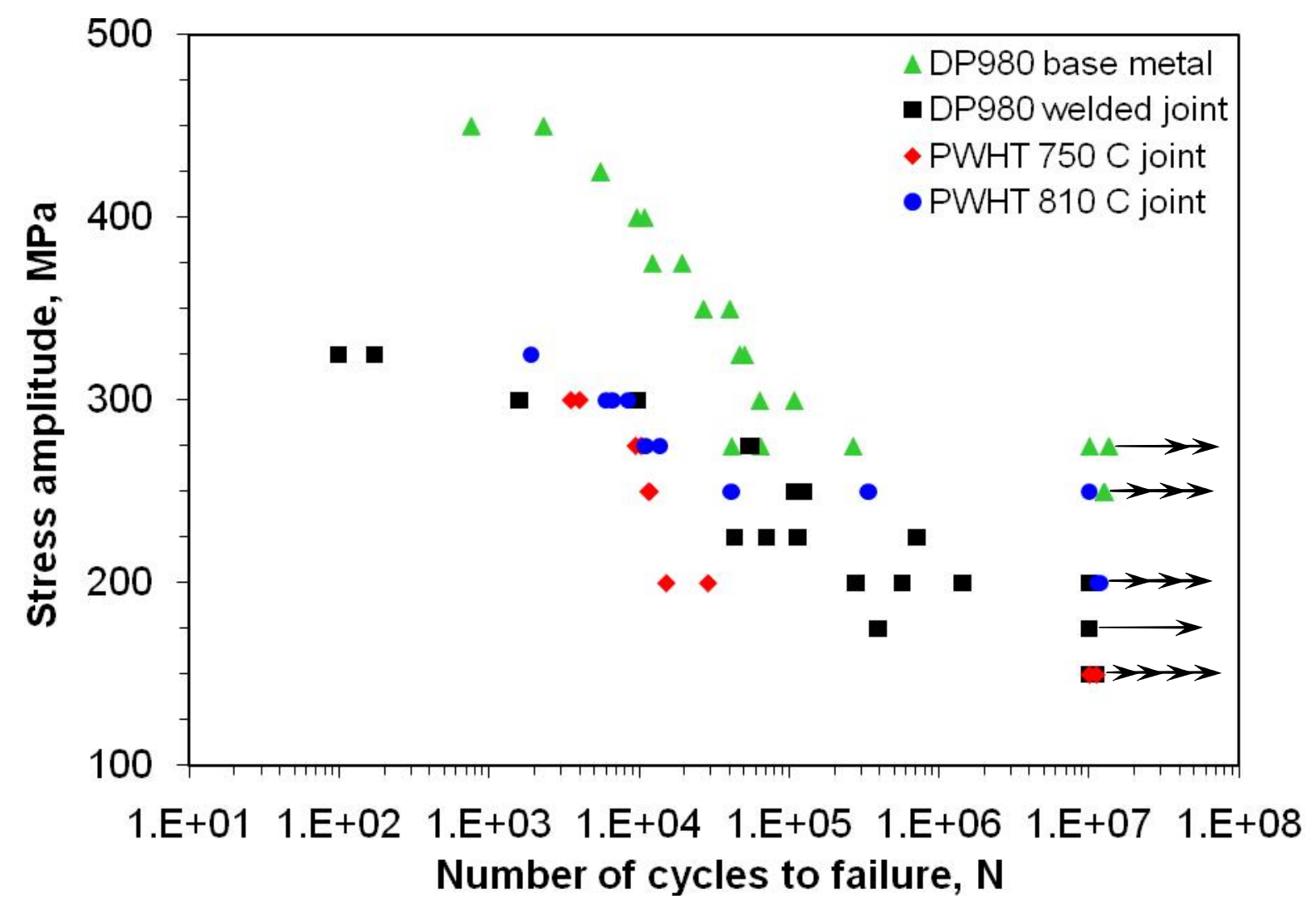

Figure 4.27 S-N curves of the DP980 base metal, welded joints without and with PWHT tested at $\mathrm{R}=0.1,50 \mathrm{~Hz}$ and room temperature where the run-out samples were indicated by arrow marks.

Table 4.5 Fatigue limit and fatigue ratio of the DP980 base metal, welded joints without and with PWHT.

\begin{tabular}{lccc}
\hline Materials & Fatigue limit (MPa) & $\begin{array}{c}\text { Ultimate tensile strength } \\
(\mathrm{MPa})\end{array}$ & Fatigue ratio \\
\hline DP980 base metal & 250 & 1090 & 0.23 \\
DP980 welded joints & 150 & 714 & 0.21 \\
PWHT $750^{\circ} \mathrm{C}$ & 150 & 859 & 0.17 \\
PWHT $810^{\circ} \mathrm{C}$ & 200 & 982 & 0.20 \\
\hline
\end{tabular}




\subsubsection{Fractographic analysis}

The tensile fracture surfaces showed mostly equiaxed dimples (Fig. 4.28(a)) at the center indicating typical ductile fracture in the DP steels, irrespective of the welding. The fracture surface near the specimen surface showed a combination of both equiaxed and elongated dimples near the edge (Fig. 4.28(b)), indicating the occurrence of shearing motion. However, the PWHT $750^{\circ} \mathrm{C}$ joints showed mostly cleavage type of characteristics in addition to some dimples on the tensile fracture surface due to the presence of martensite formed during the fast quenching (Fig. 3.8) ) and possible hydrogen induced embrittlement [87].

SEM observations revealed that the PWHT $810^{\circ} \mathrm{C}$ joints had similar but more cleavage fracture characteristics due to the presence of higher amount of martensite. Similar results were reported in [88] where the fracture mode under tensile load became more brittle with increasing volume fraction of martensite and martensitic particle size in a surface-carburized AISI 8620 steel with dual phase core microstructure and in [87] where brittle fracture surface dominated by cleavage characteristics was identified in steel pipes in ammonia synthesis plant caused by hydrogen induced cracking.. Almost no difference between the center and edge of the tensile fracture surface could be identified in the PWHT joints, as seen from Fig. 4.28(c) and 4.28(d).

Fatigue crack was observed to initiate from the specimen surface since the surface was usually less constrained than the interior grains [78]. The back and forth fine slip movement during cyclic loading built up notches or ridges at the surface (i.e., extrusions and intrusions) [64] having notch root of atomic dimension could act as a stress riser and might act as the nucleation site of the fatigue crack. 

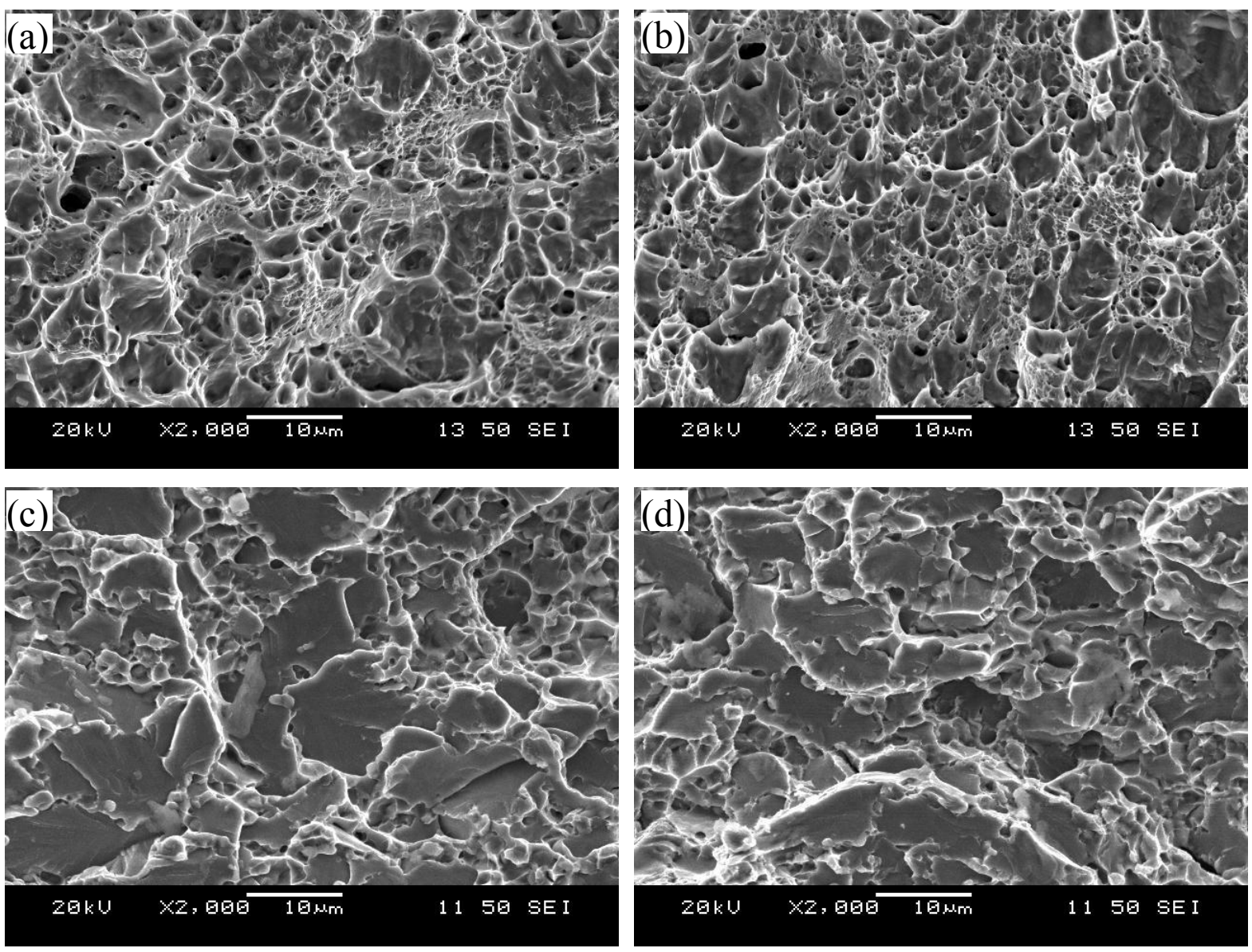

Figure 4.28 Typical SEM micrographs of the tensile fracture surface tested at a strain rate of

$1 \times 10^{-4} \mathrm{~s}^{-1}$, (a) center of DP980 base metal (b) edge of DP980 base metal, (c) center of PWHT $750^{\circ} \mathrm{C}$ joints and $(\mathrm{d})$ edge of PWHT $750^{\circ} \mathrm{C}$ joints.

The fatigue crack could also result from the surface roughness. A typical example showing the overall view of the fracture surface of the PWHT $810^{\circ} \mathrm{C}$ joint tested at a stress amplitude of $250 \mathrm{MPa}$ is shown in Fig. 4.29(a). The crack initiation site and the nearby slower crack growth area could be seen in Fig. 4.29(b). The faster fatigue crack growth zone at a higher magnification was seen to be mainly characterized by fatigue striations which were usually perpendicular to the propagation direction, as seen from Fig. 4.29(c). 

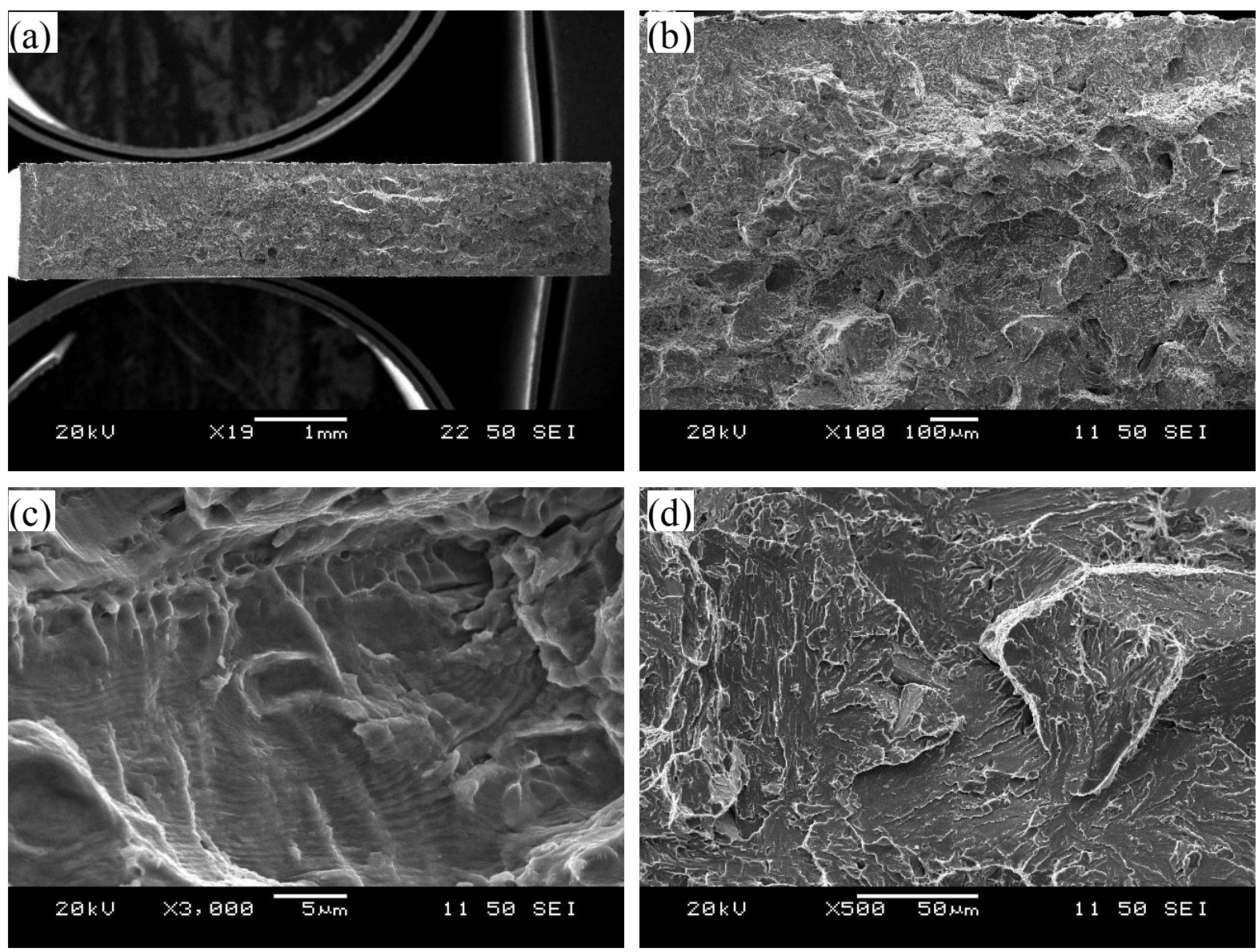

Figure 4.29 Typical fatigue fracture surface of the PWHT $810^{\circ} \mathrm{C}$ joints tested at a stress amplitude of $250 \mathrm{MPa}$, (a) overall view of the fracture surface at a low magnification, (b) magnified view of the crack initiation site, (c) crack propagation zone with fatigue striations and secondary cracks at a higher magnification and (d) center of the fracture surface showing the final rapid crack propagation.

The striation spacing was smaller near the crack initiation site and became larger with increasing distance from the crack initiation site since it was associated with fatigue crack propagation rate. The formation of fatigue striations, basically in the relatively soft ferrite portion of the DP base metal and welded joints without or with PWHT, was generally considered to be 
attributed to a repeated plastic blunting-sharpening process associated with either the dislocation slip in fcc and bcc metals [79] or twinning observed recently in hcp metals, e.g., Mg alloys [8992]. The final rapid crack propagation at the center of the fracture surface was mainly characterized by the cleavage fracture being typical of the brittle fracture mode (Fig. 4.29(d)). 


\section{Chapter 5}

\section{Conclusions and Future Work}

\subsection{Conclusions and summaries}

Based on the discussion on the laser welded similar and dissimilar joints of DP600 and DP980 steels, as well as post-weld heat treatment (PWHT), the following conclusions could be drawn:

1. The laser welding of DP steels resulted in a large amount of martensitic structure in the FZ due to the rapid cooling during welding, leading to a considerable increase in the hardness. However, a soft zone in the HAZ was observed due to the partial vanishing and tempering of the pre-existing martensite in the DP steels. The extent of softening and the size of the soft zone were larger in the DP980 welded joints than in the DP600 welded joints. Due to the difference in the degree of softening, the dissimilar DP600/DP980 welded joints showed a characteristic unsymmetrical hardness profile across the dissimilar welded joint.

2. While the presence of the HAZ softening reduced the ductility to a certain extent, the ultimate tensile strength remained nearly unchanged after laser welding in the case of DP600 welded joints. However, the yield strength of the DP600 welded joints was observed to increase after laser welding due to the presence of yield point phenomena.

3. DP980 welded joints showed lower yield strength and ultimate tensile strength compared to its base metal due to the significant reduction in the hardness in the HAZ. The ductility reduced after welding in both DP steels. 
4. The YS of the dissimilar welded joints were higher than those of DP600 base metal but lower than those of DP980 base metal. The UTS of the dissimilar welded joints was essentially the same as that of the DP600 base metal, while its ductility was equivalent to that of the DP980 base metal.

5. The strain rate dependence of the tensile properties was observed to be weak, since the yield strength and ultimate tensile strength only slightly increased with increasing strain rate from $1 \times 10^{-5} \mathrm{~s}^{-1}$ to $1 \times 10^{-2} \mathrm{~s}^{-1}$ in both base metals and their respective welded joints.

6. The base metals of DP steels exhibited multi-stage work hardening, whereas their respective similar and dissimilar welded joints showed only a single-stage (or stage III) work hardening where the work hardening rate decreased linearly with increasing net flow stress.

7. The work hardening exponents evaluated for both the base metals and the welded joints increased slightly with increasing strain rate, indicating weak strain rate dependence as well.

8. Both the similar and dissimilar welded joints tested at different strain rates failed exclusively in the soft zone under monotonic loading and the fracture surface showed ductile fracture characteristics containing mostly dimpled impressions.

9. As a result of the presence of a severe soft zone, the DP980 welded joints showed a significant decrease in the fatigue limit compared with the corresponding base metal. On the other hand, the presence of a mild soft zone in the DP600 welded joints was observed to have little or only a minor effect on the fatigue limit and fatigue life at higher stress amplitudes within the experimental scatter. However, even though the negative effect of the severe soft zone on the fatigue resistance of the DP980 welded joints was large, the fatigue 
life of the DP980 welded joints was still equivalent to or even longer than that of both the DP600 welded joints and DP600 base metal at higher stress amplitudes

10. The dissimilar welded joints exhibited a lower fatigue limit than the base metals but at higher stress amplitudes, they had almost the same fatigue life as DP600 base metal despite the presence of the soft zone.

11. The DP980 welded joints failed exclusively in the soft zone, irrespective of the applied stress amplitudes. The DP600 welded joints failed in the soft zone at the stress amplitudes above $250 \mathrm{MPa}$ but failed in the base metal area at the stress amplitudes below $250 \mathrm{MPa}$. This distinct failure location appeared to be associated with deformation induced martensitic transformation. Like DP600 welded joints, the fatigue fracture location of the dissimilar DP steel joints was observed to be associated with the stress amplitude applied. While the fatigue failure occurred mainly in the soft zone at the higher stress amplitudes, nearly no failure appeared in the soft zone at the lower stress amplitudes.

12. In all cases, the fatigue fracture was observed to initiate from the specimen surface and the crack propagation was characterized by typical fatigue striation together with secondary cracks.

13. The post-weld heat treatment (PWHT) was observed to be able to eliminate the soft zone, giving rise to homogeneously distributed ferrite-martensite dual-phase microstructure and nearly constant hardness profile across the weld.

14. With increasing PWHT temperature the hardness, yield strength, ultimate tensile strength, and fatigue limit all increased due to the formation of more martensite. However, the 
ductility decreased, resulting in more brittle cleavage fracture due to both formation of more martensites and possible hydrogen induced embrittlement occurred during heat treatment..

15. While the PWHT sample showed only stage III strain hardening behavior as well, the failure location after PWHT was observed to no longer concentrate at the location of the previous soft zone under both tensile and fatigue loading, in spite of a brittle fracture mode.

\subsection{Scope of future work}

Welding and joining is one of the most widely used secondary manufacturing operations of materials. The research in this field has been carried out significantly over the past decades. The material scenario of today's world is also different from what it was 10 or 20 years ago and in this changed material scenario, DP steels have been considered as one of the significant additions due to their unique mechanical properties. A lot of work has been conducted on the weldability of DP steels in terms of different welding process and varying welding parameters. This thesis work is also another addition to that systemic research which has contributed significantly to modern technology by analyzing the usability of advanced structural materials in the transportation industries. Based on this thesis work and the published literature pertaining to the related kind of work, the following recommendations are proposed as future work,

1. This work dealt with only one type of optimized laser welding parameters. It should be interesting to examine the detailed effect of different welding parameters on the mechanical properties of laser welded DP steel joints. 
2. The steel sheets used in this study had a thickness of $1.2 \mathrm{~mm}$. Studies should be conducted to investigate the laser weldability of DP steels having different thicknesses.

3. A detailed study related to the microstructural evolution in the HAZ with different welding parameters and varying amounts of heat input would further facilitate the understanding of the soft zone formation.

4. The fastest strain rate used in the tensile tests in the present study was $0.01 \mathrm{~s}^{-1}$. Detailed studies on the dynamic tensile properties of laser welded DP steel joints under faster strain rates would be of great interest.

5. Only load-controlled fatigue tests were performed in this study. Low cycle fatigue (LCF) tests of these joints would be of significance for the applications of the welded DP steel joints in the automotive industry.

6. The fractography in this study showed the presence of deformation bands on the fatigue fracture surface of DP600 welded joints and their respective base metal at lower stress amplitudes. Further studies related to texture can be another interesting aspect of future work.

7. The current study clearly demonstrated that the applied PWHT could be used to eradicate the severe soft zone and effectively enhance the yield strength, ultimate tensile strength and fatigue limit of the DP980 welded joints. However, the ductility did not improve or became even lower leading to more obvious brittle cleavage fracture as observed in the fractographic analysis of fracture surface. Further studies are thus needed to optimize the PWHT process, e.g., via identifying an optimal volume fraction of martensite and/or conducting proper tempering treatment, etc. 
8. It should be pointed out that the severe soft zone was mainly present in the high strength DP980 steel after welding. This might occur in other high strength steels as well; then such studies on other welded joints of high strength steels would be needed to ensure the structural integrity and reliability. On the other hand, for the lower strength DP600 steel, while the soft zone was also observed after laser welding, its softening degree was minor or negligible without seriously affecting the mechanical properties. In such cases, the PWHT might not be necessary. 


\section{References}

1. Advance High Strength Steel (AHSS) Application Guidelines. International Iron and Steel Institute, Date retrieved: March 2010, (www.worldautosteel.com).

2. Automotive environmental case study, World Auto Steel, Date retrieved: June 2010, ( http://www.corusgroup.com/file_source/StaticFiles/Business_Units/CSPUK/Worldsteel\%20A utomotive $\% 20$ case $\% 20$ study.pdf).

3. W. Bleck, Cold-rolled, high-strength sheet steels for auto applications, JOM, 1996, 48, 26-30.

4. M. Xia, E. Biro, Z. Tian, Y. N. Zhou, Effects of heat input and martensite on HAZ softening in laser welding of dual phase steels, ISIJ Int, 2008, 48, 809-814.

5. S. R. Mediratta, V. Ramaswamy, V. Singh, P. Rama Rao, Microstructure-Mechanical property correlations in dual phase steels, Transactions of the Indian Institute of Metals, 1985, 38, 350372.

6. D. L. Chen, Z. G. Wang, X. X. Jiang, S. H. Al, C. H. Shih, Dependence of near-threshold fatigue crack growth on microstructure and environment in dual-phase steels, Material Science \& Engineering A, 1989, 108, 141-151.

7. Z. G. Wang, D. L. Chen, X. X. Jiang, S. H. Ai, C. H. Shih, Relationship between fractal dimension and fatigue threshold value in dual-phase steels, Scripta metallurgica, 1988, 22, $827-832$.

8. M. Sarwar, R. Priestner, E. Ahmad, Influence of martensite volume fraction on fatigue limit of a dual-phase steel, Journal of Materials Engineering and Performance, 2002, 211, 274-277. 
9. H. B. Carry, Modern Welding Technology, $5^{\text {th }}$ Edition, 2005 (Pearson Education, Inc., Upper Saddle River, New Jersey, U.S.A.).

10. J. K. Larsson, Overview of joining technologies in the automotive industry, Weld Research Abroad, 2003, 49, 29-45.

11. Kang Chung-Yun, Han Tae-Kyo, Lee Bong-Keun, Kim Jeong-Kil, Characteristics of Nd:YAG laser welded $600 \mathrm{MPa}$ grade TRIP and DP steels, Material Science Forum, 2007, 539-543, 3967-72.

12. N. Sreenivasan, M. Kuntz, Y. Zhou, Influence of laser welding on the formability of AHSS steels, proceedings of Materials Science and Technology Conference and Exhibition, MS and T'07 - "Exploring Structure, Processing, and Applications Across Multiple Materials Systems", 2007, (Curran Associates Inc, Detroit, MI, United states).

13. M. Xia, N. Sreenivasan, S. Lawson, Y. Zhou, Z. Tian, A comparative study of formability of diode laser welds in DP980 and HSLA steels, Journal of Engineering Materials \& Technology- ASME Transaction, 2007, 129, 446-452.

14. N. Sreenivasan, M. Xia, S. Lawson, Y. Zhou, Effect of laser welding on formability of DP980 steel, Journal of Engineering Materials \& Technology- ASME Transaction, 2008, 130, 0410041-0410049.

15. M. S. Xia, M. L. Kuntz, Z. L. Tian, Y. Zhou, Failure study on laser welds of dual phase steel in formability testing, Science and Technology of Welding and Joining, 2008, 13, 378-387.

16. N. D. Beynon, S. Oliver, T. B. Jones, G. Fourlaris, Tensile and work hardening properties of low carbon dual phase strip steels at high strain rates, Materials Science and Technology, 2005, 21, 771-778. 
17. M. Sarwar, R. Priestner, Influence of ferrite-martensite microstructural morphology on tensile properties of dual-phase steel, Journal of Material Science, 1996, 31, 2091-2095.

18. M. Sarwar, E. Ahmad, N. Hussain, B. Ahmad, T. Manzoor, Crack path morphology in dualphase steel, Journal of Materials Engineering and Performance, 2006, 15, 352-354 (2006).

19. M.S. Khan, S.D. Bhole, D.L. Chen, G. Boudreau, E. Biro, J. Van Deventer, Welding behavior, microstructure and mechanical properties of dissimilar resistance spot welds between galvannealed HSLA350 and DP600 steels, Science and Technology of Welding and Joining, 2009,14, 616-625.

20. C. Ma, S.D. Bhole, D.L. Chen, A. Lee, E. Biro, G. Boudreau, Expulsion monitoring in the spot welded auto steels, Science and Technology of Welding and Joining, 2006, 11, 480-487.

21. T. S. Byun, I. S. Kim, Tensile properties and inhomogeneous deformation of ferritemartensite dual-phase steels, Journal of Material Science, 1993, 28, 2923-2932.

22. R. G. Davies, Influence of silicon and phosphorous on the mechanical properties of both ferrite and dual-phase steels, Metallurgical Transactions A, 1979, 10, 113-118.

23. W. W. Duley, Laser Welding, $1^{\text {st }}$ Edition, 1999, (John Wiley \& Sons, Inc., New York, USA).

24. N. Ahmed, New Developments in Advanced Welding, $1^{\text {st }}$ Edition, 2005, (Woodhead Publishing Ltd., Abington, Cambridge, England).

25. R. M. Miranda, L. Quintino, A. Costa, J. C. P. Pina, T. Rosa, P. Catarino, J. P. Rodrigues, Analysis of different laser welding processes for joining hardmetals to steel, Welding in the World, 2008, 52, 42-51. 
26. C. Ma, D. L. Chen, S. D. Bhole, G. Boudreau, A. Lee, E. Biro, Microstructure and fracture characteristics of spot-welded DP600 steel, Materials Science and Engineering A, 2008, 485, 334-346.

27. F. Rossillon, A. Galtier, J. L. Robert, M. Duchet, A. Lens, H. Oikawa, Effect of welding cycle on the fatigue behaviour of resistance spot welded dual phase steels, Welding in the World, 2008, 52, 30-41.

28. P. K. Ghosh, P. C. Gupta, R. Avtar, B. K. Jha, Resistance spot weldability of comparatively thick C-Mn-Cr-Mo dual phase steel sheet, ISIJ Int, 1990, 30, 233-240.

29. S. Daneshpour, S. Riekehr, M. Koçak, C. h. J. Gerritsen, Mechanical and fatigue behaviour of laser and resistance spot welds in advanced high strength steels, Science and Technology of Welding and Joining, 2009, 14, 20-25.

30. R. Koganti, S. Angotti, A. Joaquin, C. Jiang, C. Karas, Gas Metal Arc Welding (GMAW) process optimization for uncoated dual phase 600 material combination with aluminized coated and uncoated boron steels for automotive body structural applications, Proceedings of ASME International Mechanical Engineering Congress and Exposition, IMECE 2007, 2008(American Society of Mechanical Engineers, Seattle, WA, United states).

31. M. P. Miles, J. Pew, T. W. Nelson, M. Li, Comparison of formability of friction stir welded and laser welded dual phase 590 steel sheets, Science and Technology of Welding and Joining, 2006, 11, 384-388.

32. R. S. Sharma, P. Molian, Yb:YAG laser welding of TRIP780 steel with dual phase and mild steels for use in tailor welded blanks, Journal of Material \& Design, 2009, 30, 4146-55. 
33. S. K. Panda, N. Sreenivasan, M. L. Kuntz, Y. Zhou, Numerical simulations and experimental results of tensile test behavior of laser butt welded DP9B0 steels, Journal of Engineering Materials \& Technology- ASME Transaction, 2008, 130, 0410031-0410039.

34. M. Uchihara, K. Fukui, Tailored blanks of high strength steels - Comparison of welding processes, Welding in the World, 2002, 46, 41-48.

35. H. Huh, S. Kim, J. Song, J. Lim, Dynamic tensile characteristics of TRIP-type and DP-type steel sheets for an auto-body, International Journal of Mechanical Science, 2008, 50, 918931.

36. N. Peixinho, N. Jones, A. Pinho, Application of dual-phase and TRIP steels on the improvement of crashworthy structures, Material Science Forum, 2005, 502, 181-6.

37. A. Bag, K. K. Ray, E. S. Dwarakadasa, Influence of martensite content and morphology on tensile and impact properties of high-martensite dual-phase steels, Metallurgical and Materials Transactions A , 1999, 30, 1193-1202.

38. E. Ahmad, T. Manzoor, K. L. Ali, J. I. Akhter, Effect of microvoid formation on the tensile properties of dual-phase steel, Journal of Materials Engineering and Performance, 2000, 9, 306-310.

39. H. Chen, G. Cheng, Effect of martensite strength on the tensile strength of dual phase steels, Journal of Material Science, 1989, 24, 1991-1994.

40. D. Das, P. P. Chattopadhyay, Influence of martensite morphology on the work-hardening behavior of high strength ferrite-martensite dual-phase steel, Journal of Material Science, 2009, 44, 2957-2965. 
41. M. Erdogan, S. Tekeli, The effect of martensite particle size on tensile fracture of surfacecarburised AISI 8620 steel with dual phase core microstructure, Journal of Materials and Design, 2002, 23, 597-604.

42. S. K. Panda, M. L. Kuntz, Y. Zhou, Finite element analysis of effects of soft zones on formability of laser welded advanced high strength steels, Science and Technology of Welding and Joining, 2009, 14, 52-61.

43. M. J. Hadianfard, Low cycle fatigue behavior and failure mechanism of a dual-phase steel, Materials Science and Engineering A, 2009, 499, 493-499.

44. A. Galtier, M. Duchet, Fatigue behaviour of high strength steel thin sheet assemblies, Welding in the World, 2007, 51, 19-27.

45. M. R. Akbarpour, A. Ekrami, Effect of temperature on flow and work hardening behavior of high bainite dual phase (HBDP) steels, Materials Science and Engineering A, 2008, 475, 293298.

46. F. H. Samuel, Effect of strain rate and microstructure on the work hardening of a Cr-Mo-Si steel, Materials science and engineering, 1987, 92, 15-18.

47. M. S. Nagorka, G. Krauss, D. K. Matlock, Effect of microstructure and strain rate on the stage III strain hardening and ductility of dual-phase steels, Materials science and engineering, 1987, 94, 183-193.

48. J. H. Hollomon, Tensile deformation, American Institute of Mining and Metallurgical Engineers -- Transactions -- Iron and Steel Division, 1945, 162, 268-289. 
49. C. Crussard, Relationship between exact form of tensile curves of metals and accompanying changes in their structure (Rapport entre la forme exacte des courbes de traction des metaux et les modifications concomitantes de leur structure), Revue de Metallurgie, 1953, 50, 697-710.

50. B. Jaoul, Etude de plasticite et application aux meatux, J. Mech. Phy. Solid., 1957, 5, 95114,

51. P. Ludwik, Elemente der technologischen mechanic (Elements of Technical Mechanics), Springler, Berlin, 1909.

52. H. W. Swift, Plastic instability under plane stress, Journal of Mechanics and Physics of Solids, 1952, 1, 1-18.

53. S.N. Monteiro, R. Reed-Hill, On the double - $\mathrm{n}$ behaviour of iron, Metallurgical and Materials Transactions B, 1971, 2, 2947-2948.

54. L.F. Ramos, D.K. Matlock, G. Krauss, On the deformation behavior of dual-phase steels, Metallurgical and Materials Transactions A, 1979, 10, 259-261.

55. F. H. Samuel, Tensile stress-strain analysis of dual-phase structures in an Mn-Cr-Si steel, Materials science and engineering, 1987, 92, 11-14.

56. B. K. Jha, R. Avtar, V. Sagar Dwivedi, V. Ramaswamy, Applicability of midified CrussardJaoul analysis on the deformation behaviour of dual-phase steels, Journal of Material Science Letter, 1987, 6, 891-893.

57. J. K. Larsson, Overview of joining technologies in the automotive industry, Proceedings of 2002 International Conference: Advanced Processes and Technologies In Welding And Allied Processes, 2002 (Institut International de la Soudure, Copenhagen, Denmark). 
58. H. Haferkamp, O. Meier, K. Harley, Laser beam welding of new high strength steels for auto body construction, Key Engineering Materials, 2007, 344, 723-730.

59. O. Meier, H. Haferkamp, A. Ostendorf, A. Bormann, Induction assisted laser beam welding of high strength steel sheets, Proceedings of 24th International Congress on Applications of Lasers and Electro-Optics, ICALEO 2005, 2005 (Laser Institute of America, Orlando, FL 32826, United States, Miami, FL, United States).

60. Product information of JEOL JSM-6380LV SEM, http://www. Jeolusa.com/sem/sem.html, (Date retrieved: July, 2009).

61. N. Farabi, D. L. Chen, J. Li, Y. Zhou, S. J. Dong, Microstructure and mechanical properties of laser welded DP600 steel joints, Materials Science and Engineering A, 2010, 527, 12151222.

62. P. Movahed, S. Kolahgar, S. P. H. Marashi, M. Pouranvari, N. Parvin, The effect of intercritical heat treatment temperature on the tensile properties and work hardening behavior of ferrite-martensite dual phase steel sheets, Materials Science and Engineering A, 2009, 518, $1-6$.

63. W. D. Callister Jr., Material Science and Engineering-An Introduction, $7^{\text {th }}$ Edition, 2007, (John Wiley \& Sons, Inc., New York, USA).

64. G. E. Dieter, Mechanical Metallurgy, SI Metric Edition, 1988, (Mcgraw-Hill Book Co., UK).

65. U. F. Kocks, H. Mecking, Physics and phenomenology of strain hardening: The FCC case, Progress in Materials Science, 2003, 48, 171-273

66. J. Cuddy, M. Nabil Bassim, Study of dislocation cell structures from uniaxial deformation of AISI 4340 steel, Materials Science and Engineering A, 1989, 113, 421-429. 
67. N. Afrin, D. L. Chen, X. Cao, M. Jahazi, Strain hardening behavior of a friction stir welded magnesium alloy, Scripta metallurgica, 2007, 57, 1004-1007 (2007).

68. W. S. Lee, C. F. Lin, B. T. Chen, Tensile properties and microstructural aspects of 304L stainless steel weldments as a function of strain rate and temperature, Proc. Inst. Mech. Eng. Part C, 2005, 219, 439-451.

69. S. Kim, Y. R. Im, S. Lee, H. C. Lee, J. O. Yong, H. H. Jun, Effects of alloying elements on mechanical and fracture properties of base metals and simulated heat-affected zones of SA 508 steels, Metallurgical and Materials Transactions A, 2001, 32, 903-911.

70. T. H. Myeong, Y. Yamabayashi, M. Shimojo, Y. Higo, New life extension method for high cycle fatigue using micro-martensitic transformation in an austenitic stainless steel, International Journal of Fatigue, 1997, 19, S69-S73.

71. U. Krupp, H. J. Christ, P. Lezuo, H. J. Maier, R. G. Teteruk, Influence of carbon concentration on martensitic transformation in metastable austenitic steels under cyclic loading conditions, Materials Science and Engineering A, 2001, 319-321, 527-530.

72. U. Krupp, C. West, H. J. Christ, Deformation-induced martensite formation during cyclic deformation of metastable austenitic steel: Influence of temperature and carbon content, Materials Science and Engineering A, 2008, 481-482, 713-717.

73. X. Cheng, R. Petrov, L. Zhao, M. Janssen, Fatigue crack growth in TRIP steel under positive R-ratios, Engineering Fracture Mechanics, 2008, 75, 739-49.

74. T. B. Hilditch, I. B. Timokhina, L. T. Robertson, E. V. Pereloma, P. D. Hodgson, Cyclic deformation of advanced high-strength steels: Mechanical behavior and microstructural analysis, Metallurgical and Materials Transactions A, 2009, 40, 342-353. 
75. K. Sugimoto, M. Kobayashi, S. Yasuki, Cyclic deformation behavior of a transformationinduced plasticity-aided dual-phase steel, Metallurgical and Materials Transactions A, 1997, 28, $2637-2644$.

76. P. Lukas, L. Kunz, Specific features of high-cycle and ultra-high-cycle fatigue, Fatigue and Fracture of Engineering Materials and Structures, 2002, 25, 747-753.

77. M. Sauzay, P. Gilormini, Surface and cyclic microplasticity, Fatigue and Fracture of Engineering Materials and Structures, 2000, 23, 573-579.

78. K. S. Chan, Pan Yi-Ming, D. Davidson, R. C. McClung, Fatigue crack growth mechanisms in HSLA-80 steels, Materials Science and Engineering A, 1997, 222, 1-8.

79. C. Laird, The influence of metallurgical structure on the mechanism of fatigue crack propagation, ASTM Spec. Tech. Publ., 1967, 415, 131-168.

80. B. J. Duggan, Y. Y. Tse, H. Ning, M. Z. Quadir, Mechanisms of recrystallization in cold and warm rolled low carbon steel and IF steel, Proceedings of the 13th International Conference on Textures of Materials, 2002, 408-412, (Trans Tech Publications Ltd, Seoul, Korea Republic).

81. B. J. Duggan, C. S. Lee, R. E. Smallman, New theory of the FCC rolling texture transition, Material Science Forum, 1994, 157-6, 1759-1764.

82. S. Begum, D. L. Chen, S. Xu, A. A. Luo, Strain-controlled low-cycle fatigue properties of a newly developed extruded magnesium alloy, Metallurgical and Materials Transactions A, 2008, 39, 3014-3026. 
83. N. Farabi, D. L. Chen, Y. Zhou, Fatigue properties of laser welded dual-phase steel joints. Procedia Engineering, 2010, 2, 835-843, (Proceedings of the 10th International Fatigue Congress, Czech Republic, 2010).

84. F. S. Seredyuk, Y. L. Bezzubov, V. G. Moroz, L. P. Ivako, The embrittlement of steels under the action of nitrogen-hydrogen-ammonia atmospheres, Chemical and Petrolium Eng ineering, 1977, 13, 139-41.

85. E. P. Mogilevskii, Embrittlement of steel during nitriding, Material Science and Heat Treatment, 1960, 2, 355-57.

86. R. P. Jewett, R. J. Walter,W. T. Chandler,R. P. Frohmberg, Hydrogen environment embrittlement of metals, Nasa Technical Report, 1973, NASA-CR-2163.

87. H. Cui, W. Wang, A. Li, M. Li, S. Xu, H. Liu, Failure analysis of the brittle fracture of a thick-walled 20 steel pipe in an ammonia synthesis unit, Engineering Failure Analysis, 2010, $17,1359-1376$.

88. M. Erdogan, S. Tekeli, The effect of martensite particle size on tensile fracture of surfacecarburised AISI 8620 steel with dual phase core microstructure, Journal of Materials and Design, 2002, 23, 597-604.

89. S. Begum, D. L. Chen, S. Xu, A. A. Luo, Effect of strain ratio and strain rate on low cycle fatigue behavior of AZ31 wrought magnesium alloy, Materials Science and Engineering A, 2009, 517, 334-343.

90. S. Begum, D. L. Chen, S. Xu, A. A. Luo, Strain-controlled low-cycle fatigue properties of a newly developed extruded magnesium alloy, Metallurgical and Materials Transactions A, $2009, \mathbf{4 0}, 255-255$. 
91. S. Begum, D. L. Chen, S. Xu, A. A. Luo, Low cycle fatigue properties of an extruded AZ31 magnesium alloy, International Journal of Fatigue, 2009, 31, 726-735.

92. X. Z. Lin, D. L. Chen, Strain hardening and strain-rate sensitivity of an extruded magnesium alloy, Journal of Materials Engineering and Performance, 2008, 17, 894-901. 


\section{Naheen Farabi}

112-230 Oak Street, Toronto, Ontario M5A 2E2, Canada

Tel: 16477011900 Email: nfarabio@gmail.com

\section{Education}

Masters of Applied Science (MASc.) in Mechanical Engineering

Ryerson University, Toronto, Ontario, Canada [September, 2008 - August, 2010]

Concentration: Material Science and Engineering

GPA: $\mathbf{4 . 0 0}$ out of 4.33

Thesis: "Mechanical properties of laser welded dual-phase steel joints."

Bachelor of Science in Engineering (B.Sc. Engg.) in Mechanical Engineering

Islamic University of Tech. (IUT), Dhaka, Bangladesh [January, 2004 - October, 2007]

Concentration: Production \& Manufacturing

GPA: $\mathbf{4 . 7 2}$ out of 5.00

Thesis: "Supply Chain Management (SCM) of a textile industry."

\section{Publications during My MASc Studies}

\section{Journal Paper (published):}

- Microstructure and mechanical properties of laser welded DP600 steel joints, by N. Farabi, D. L. Chen, J. Li, Y. Zhou \& S. J. Dong, Materials Science and Engineering A, 527, 12151222, 2010.

\section{Journal Papers in Progress (under review):}

- Microstructure and mechanical properties of laser welded dissimilar DP600/DP980 dualphase steel joints, by N. Farabi, D.L. Chen \& Y. Zhou, Journal of Alloys and Compounds (Submitted).

- Tensile properties and work hardening behavior of laser welded dual-phase steel joints, by N. Farabi, D.L. Chen \& Y. Zhou, Journal of Material Engineering and Performance (Submitted).

- Effect of post-weld heat treatment on the microstructure and mechanical property of laser welded DP980 steel joints, by N. Farabi, D.L. Chen \& Y. Zhou (Under the internal review).

\section{Conference Paper:}

- Fatigue properties of laser welded dual-phase steel joints, by N. Farabi, D. Chen and Y. Zhou, Procedia Engineering, 2, 835-843, 2010 (Proceedings of the 10th International Fatigue Congress, Prague, Czech Republic, June 6-11, 2010).

\section{Conference Presentation:}

- Mechanical behavior of laser butt welded DP600 steel joints, by N. Farabi, D.L. Chen and Y. Zhou, The 21st Canadian Material Science conference (CMSC), Kingston, Ontario, June 911, 2009 (Oral presentation given by N. Farabi).

- Effect of laser welding on fatigue properties in dual-phase steels, by N. Farabi, D.L. Chen, J. Li, Y. Zhou, The 21st Canadian Material Science conference (CMSC), Waterloo, Ontario, June 9-11, 2010 (Oral presentation given by N. Farabi). 